\title{
ILIA UND ANIO BEI OVID, AMORES 3.6: EINE AMPHIBOLISCHE VERMÄHLUNG
}

\author{
Christian Zgoll
}

\begin{abstract}
In Amores 3.6 greift Ovid den römischen Gründungsmythos auf, die Vermählung der von Mars unfreiwillig geschwängerten und später verstoßenen Vestalin Ilia mit dem Flußgott Anio. Eine Rekonstruktion von Ovids „Arbeit am Mythos“ zeigt, wie der Dichter durch erzählerische Abwandlung, durch Psychologisierung, Erotisierung und Ironisierung dieser „Vermählung“ durchaus amphibolische Züge verleiht. Der Blick auf die antike Bildersprache metapoetischer Reflexion und auf entsprechende Intertexte eröffnet ein tieferes Verständnis für den merkwürdigen Umstand, daß Ovid ein so breit ausgeführtes und ernstes mythisches exemplum zum Kernstück einer Liebeselegie macht, indem er eine weitere, hinter der narrativen Oberfläche liegende Aussageintention erkennen läßt: Die Flüsse im „Flüssekatalog“ verweisen durchweg auf große epische Stoffe und Werke, der Anio selbst auf die Annalen des Ennius; Ilia aber trägt Züge der personifizierten Elegie. Die Vermählung von Ilia und Anio ist daher auch insofern „amphibolisch“, als sie nicht nur auf der Erzählebene die Verbindung zweier mythischer Personen etwas schillernd darstellt, sondern sich zugleich als poetologische Chiffre für das Zusammenfließen zweier verschiedener poetischer Stile, des elegischen und des epischen Dichtens, erweist. Der namenlose, von mehreren Zuflüssen gespeiste „Sturzbach“ der Rahmenhandlung aber entpuppt sich als vorausgreifendes Bild für die neuartige Vermischung verschiedenster Gattungen in Ovids Metamorphosen.
\end{abstract}

\section{Inhaltsübersicht}

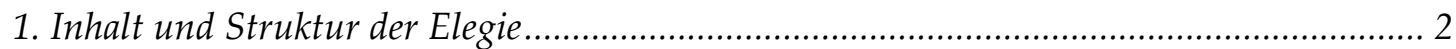

2. Merkwürdigkeit der Ausgangssituation ........................................................................ 3

3. Der Flußkatalog als Schlüssel für die Interpretation ....................................................... 5

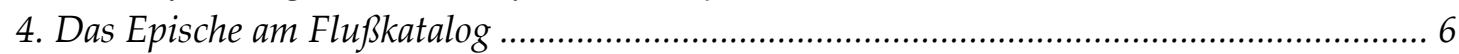

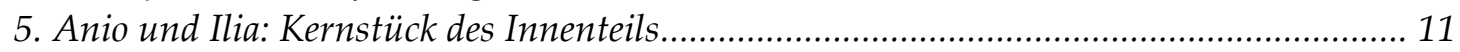

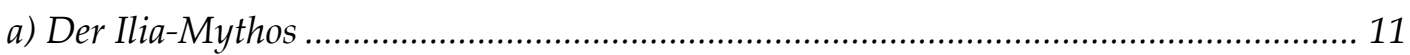

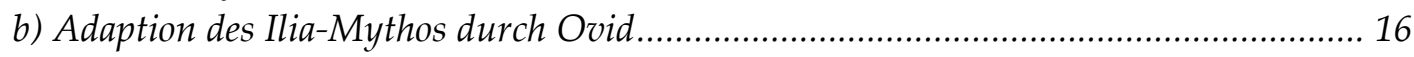

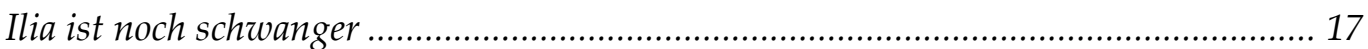

Romulus und Remus sind bereits geboren .............................................................. 19

c) Ovid'sche Polysemie und Psychologie: Über lüsterne Flüsse ....................................... 20

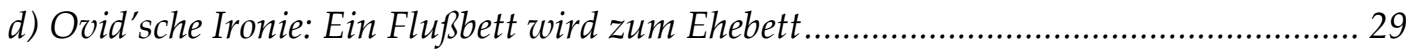

e) Amores 3.6.45-82: Übersetzung mit Anmerkungen ................................................. 33

6. Flußmetaphorik und poetologische Aussageebene in der Elegie....................................... 35

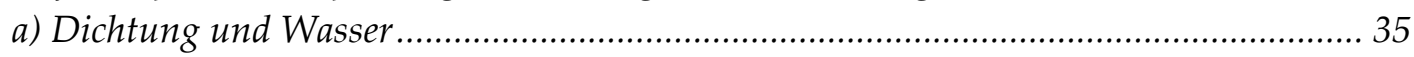

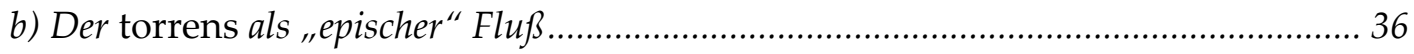

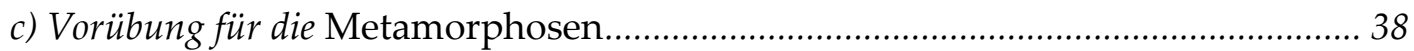

d) Das Amphibolische an der Vermählung von Anio und Ilia ......................................... 40

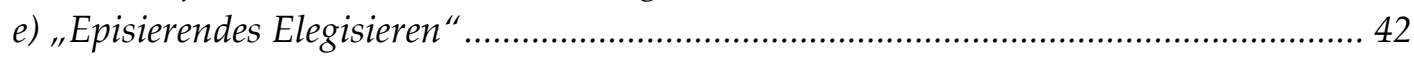

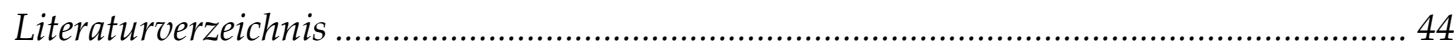

Anhang: Textkritische Bemerkung zu Vers 3.6.31 ….......................................................... 48 


\section{Inhalt und Struktur der Elegie ${ }^{1}$}

Ähnlich wie bei Properz 3.16 geht es in Ovids sechstem Gedicht des dritten AmoresBuches um eine Reise des Liebenden zu seiner Geliebten. Ovid mag das Gedicht von Properz vor Augen gehabt haben; wie in Amores 3.6 kommt auch bei Properz 3.16 der Fluß Anio vor². Während Properz jedoch den mitternächtlichen Brief seiner Geliebten mit der Aufforderung, zu ihr nach Tibur zu reisen, lediglich als Anlaß nimmt, über die Hemmnisse und Gefahren bis hin zum möglichen Tod nachzudenken und zu dem Schluß kommt, er wolle dies alles für die Geliebte in Kauf nehmen, befindet sich der amator bei Ovid tatsächlich auf dem Weg3. Doch bald stößt er auf ein konkretes Hindernis ${ }^{4}$.

Das Hindernis, das dem Liebenden das Weiterkommen verwehrt, ist ein durch die Schneeschmelze stark angeschwollener, reißender Gebirgsbach, ohne Brücke oder Fähre $^{5}$. Die ganze Situation ist mit derjenigen in einem Paraklausithyron-Gedicht vergleichbar;; man könnte Amores 3.6 mit einer analogen Bildung als ein „Paraklausicheimarron" bezeichnen7. Der Liebende redet nun den Bach an, wobei er ihn schmeichelnd und übertreibend als "Strom“ (amnis) ${ }^{8}$ bezeichnet, und versucht ihn dazu zu bringen, seine Fluten „für einen Augenblick anzuhalten" ". Er, der Gebirgsbach, dürfe es sich nicht zuschulden kommen lassen, einen Liebenden aufgehalten zu haben; im Gegenteil, er müsse diesem auf jeden Fall behilflich sein, da doch die Flüsse selbst die Macht

\footnotetext{
${ }^{1}$ Mein Dank gilt Jan Felix Gärtner, Marcus Deufert und Niklas Holzberg für Hinweise und Anregungen und der Gutachterin bzw. dem Gutachter, die/der anonym und innerhalb kürzester Zeit für die Aufnahme dieses Beitrages in die Zeitschrift Studia Humaniora Tartuensia plädiert und gleichermaßen konstruktive wie wertvolle Ergänzungen eingebracht hat.

${ }^{2}$ Vgl. Ov. am. 3.6.51 und Prop. 3.16.4. Wegen der unsicheren Datierung muß offenbleiben, ob das Epigramm des Antiphilos von Byzanz (Anth. Gr. 9.277) eine mögliche Vorlage für das Gedicht Ovids darstellt, vgl. Sabot 1976: 484, der in Anm. 396 das Epigramm im Original zitiert. Im Unterschied zu Antiphilos schwillt bei Ovid der Fluß während des Gedichts weiter an, worauf Albert 1988: 228, Anm. 691 hingewiesen hat.

${ }^{3}$ Im Ablauf des „Liebesromans“ (zur Deutung der Amores als fortlaufender „Roman“ vgl. Holzberg 1998: 55 ff; Gegenposition bei Luck 1961: 195; kritisch Schmitzer 2001: 40; Zusammenfassung verschiedener Forschungsergebnisse bei Bretzigheimer 2001: 107, Anm. 59) könnte 3.6 insofern eine „Fortsetzung“ der vorigen Gedichte darstellen, als 3.4 problematisiert hatte, daß die puella durch ihren vir zu streng bewacht wird. Offenbar will sie aber mit dem Sprecher zusammentreffen und hat sich vielleicht aus diesem Grunde der strengen Bewachung durch eine Fahrt aufs Land entzogen und dort einen Treffpunkt mit dem Sprecher vereinbart. Das wäre nichts völlig Abgelegenes, sondern hätte neben Properz 3.16 noch ein weiteres Vorbild in Catulls Gedicht 68, wo deutlich wird, daß der Adressat der Elegie Catull zu einem Treffen mit Lesbia an einem einsamen Ort auf dem Lande verholfen hat.

${ }^{4}$ Ein Beispiel für die bei Ovid durchgängig zu beobachtende Tendenz, realitätsbezogener zu schreiben als seine Vorgänger Tibull und Properz, wodurch unter anderem die Identifikationsmöglichkeit für den Leser gesteigert wird. Vgl. dazu Gauly 1990: 119; Holzberg 1998: 77.

${ }^{5}$ Vgl. am. 3.6.1-8. Eine ähnliche Situation mit wörtlichen Anklängen findet sich met. 8.547, wo der angeschwollene Achelous den von der Kalydonischen Eberjagd kommenden Theseus an seiner Weiterreise nach Athen hindert. Weinlich 1999: 214 und De Caro 2003: 173 ziehen zudem Parallelen zwischen am. 3.6 und am. 1.13 .

${ }^{6}$ Vgl. Scivoletto 1976: 24; Davis 1981: 2489; Bretzigheimer 2001: 147. Vgl. zur ganzen Elegie das Paraklausithyron am. 1.6. Zum Paraklausithyron-Motiv in der römischen Liebeselegie s. Copley 1956, der es für eines der zentralen Motive überhaupt hält (ebd. 70).

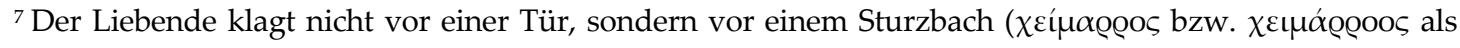
griechische Entsprechung zu torrens).

${ }^{8}$ Ov. am. 3.6.1.19.

${ }_{9}$ Ov. am. 3.6.2: siste parumper aquas; vgl. auch Vers 20 (labere fine tuo).
} 
Amors am eigenen Leib erfahren hätten ${ }^{10}$. Darauf folgt eine Aufzählung von neun Liebesgeschichten, in denen Flüsse die Hauptakteure sind ${ }^{11}$, wobei die ersten acht Beispiele aus dem griechischen Osten jeweils in ein bis zwei Distichen kurz angesprochen werden $^{12}$, während die italische Geschichte von Ilia und Anio für den Leser überraschenderweise über 38 Verse breit ausgeführt wird ${ }^{13}$. Doch alles Reden ist umsonst; der Sturzbach ist ganz im Gegenteil noch mehr an- als abgeschwollen ${ }^{14}$, und der von der ersten bis zur letzten Zeile währende, lange Monolog des Bittstellers verhallt scheinbar ungehört, jedenfalls aber unbeantwortet. Die Stimmung des Reisenden schlägt um, und er beginnt, sich über den sinnlosen Zeitverlust zu ärgern und den Sturzbach zu beschimpfen bis hin zur Verfluchung, mit der die Elegie dann auch endet.

\section{Merkwürdigkeit der Ausgangssituation}

Insgesamt ist die Rahmenhandlung der Elegie äußerst skurril, was man sich deutlich vor Augen führen sollte ${ }^{15}$. Welcher Liebhaber, der es eilig hat, wird an einem angeschwollenen Fluß stehenbleiben und lange Geschichten erzählen, mit der Hoffnung darauf, daß der Fluß ihn "hört" und sich besinnt und abschwillt ${ }^{16}$ - und das vor allem dann, wenn man wenige Zeilen zuvor die Mythen (oder doch zumindest die in Mythen vorkommenden Fluggeräte) als veterum mendacia vatum bezeichnet hat ${ }^{17}$ ? Eine solche Vermischung mythischer Denkweise mit der elegischen Alltagswelt wirkt in hohem Maße lächerlich. Viel weniger abstrus ist noch die typische elegische ParaklausithyronSzenerie, denn da besteht wenigstens eine einigermaßen realistische Chance, daß die puella oder der Türhüter den Bittsteller erhören und die Türe öffnen. Ein sprechender, gar eine Bitte gewährender Flußgott hingegen gehört eindeutig in den Bereich des Mythos und des Epos, nicht in die (Alltags-)Welt der elegischen Liebe, und selbst im Bereich des Epos ist die Bitte an einen Fluß, mit dem Fließen aufzuhören, zumindest ungewöhnlich ${ }^{18}$.

\footnotetext{
${ }^{10}$ Vgl. Ov. am. 3.6.21-24.

${ }^{11}$ Stroh 1971: 93, Anm. 129 vermutet, daß Ovid seine Beispiele aus einem erschlossenen Gedicht „Verliebte Flüsse" des Kallimachos schöpfen könnte; vgl. dazu auch Courtney 1988: 22 f.

${ }^{12}$ Ov. am. 3.6.25-44.

${ }^{13}$ Ov. am. 3.6.45-82. Nach Heinze 1919: 98 hat sich Ovid in seinen elegischen Erzählungen die Freiheit, die Kallimachos in bezug auf die Symmetrie walten ließ, weitgehend zunutze gemacht. Donini 1969: 211 schreibt diesem Abschnitt eine Schlüsselstellung zu: „Cuius catalogi venuste narrata de Ilia atque Aniene fabula finis et fastigium est, sed etiam totius carminis optima pars et quasi nodus exstat", während Frécaut 1972: 145, Anm. 38 dem Ilia-Abschnitt lediglich die Funktion zuschreibt, die Banalität der vorangehenden Aufzählung kurzer Beispiele zu kompensieren.

${ }^{14}$ Vgl. Ov. am. 3.6.85 (increvit).

${ }^{15}$ Und geht auch auf Ovids eigene Idee zurück, vgl. Marg \& Harder 1962: 220, die als Vorbild für den Rahmen allenfalls Anth. Gr. 9.277 in Erwägung ziehen (dagegen ablehnend mit Literaturhinweisen Lenz 1966: 221). Zum Halten einer langen Suasorie als „comic technique“ in den Amores s. Davis 1981: 2480.

${ }^{16}$ Zur Komik hier auch Olstein 1973: 211.

${ }^{17}$ Ov. am. 3.6.17; vgl. zu dieser Stelle auch Davis 1980: $413 \mathrm{f}$.

${ }^{18}$ Beispiele für Flüsse, die ihren Lauf hemmen: Hom. Od. 5.445-453; Kall. h. 4.109 ff; das prominenteste und für römische Ohren aktuellste Vorbild ist Vergil, Aen. 8.31 ff (v.a. die Verse 86-89), wo der Tiber dem Aeneas erscheint, ihn ermutigt und für ihn zum Stillstand kommt wie ein friedlicher See (v.a. v 87: substitit unda).
} 
Angesichts dieser sonderbaren Rahmenhandlung stellt sich die Frage ${ }^{19}$ : Was hat Ovid eigentlich mit dieser Elegie bezweckt? Ein Witz um seiner selbst willen? Oder reine Fabulierlust? Dagegen spricht die Länge und die sorgfältige Ausarbeitung der Elegie. Soll die Elegie eine Parodie auf das Paraklausithyron-Motiv darstellen ${ }^{20}$, speziell auf die Gattung der Suasorie? Das ist nicht prinzipiell auszuschließen, aber mehrere Gründe sprechen dagegen. Für eine Suasorien-Parodie hätte Ovid die Szenerie nicht wechseln müssen; sie hätte sich ohne Schwierigkeit mit dem traditionellen ParaklausithyronTypus verbinden lassen. Im Fall einer Paraklausithyron-Parodie hätte sich überdies das Witzige der Elegie spätestens nach ein paar Dutzend Versen erschöpft; jedenfalls könnte der gesamte Mittelteil, der ganze Katalog mit den Liebesgeschichten von Flüssen problemlos fehlen und die Elegie nach dem Distichon $23 \mathrm{f}$

flumina debebant iuvenes in amore iuvare:

flumina senserunt ipsa, quid esset amor.

„Flüsse müßten junge Männer in der Liebe unterstützen,

haben Flüsse doch selbst gespürt, was Liebe ist"

direkt mit dem Distichon $83 \mathrm{f}$ fortfahren:

te quoque credibile est aliqua caluisse puella, sed nemora et silvae crimina vestra tegunt.

„Auch Du bist wahrscheinlich für irgendeine Geliebte erglüht, aber Haine und Wälder verbergen euer verbotenes Treiben."

Man kann einwenden, daß die Aufzählung der vielen Flüsse und ihrer Liebesgeschichten das Komische und Erfolglose des ganzen Monologes noch steigern. Selbst wenn man dies zugesteht, so sprengt doch ohne Frage die lange Erzählung von Anio und Ilia dann völlig den zu erwartenden Rahmen. Gerade diese in den Flüssekatalog eingebettete Erzählung macht aber unabweisbar einen inhaltlichen Kern der Elegie aus ${ }^{21}$. Über 100 Verse, ein elaborierter Flüssekatalog, eine breit ausgemalte und fein stilisierte mythische Erzählung, insgesamt die mit Abstand längste Elegie von Buch 3, die zweitlängste in den Amores überhaupt nur für einen Witz, nur für eine übertrieben lang ausgeführte Parodie auf die Paraklausithyron-Topik?

\footnotetext{
${ }^{19}$ Diese weiterführende Frage wird oft nicht mehr gestellt. Vgl. etwa Marg \& Harder 1962: 220: „Der Stilwechsel zwischen der trockenen gelehrten Aufzählung, der pathetischen und dramatischen Ilia-Szene und dem leicht komischen Rahmen beabsichtigt“ (aber wozu?). Lenz 1966: 222: „Der Liebende, der es zuerst so eilig hatte, hat viel Zeit. In Wirklichkeit ist der Dichter an der Situation des Eingangs wenig interessiert." Die Antwort von Lenz auf die Frage nach dem eigentlichen Zweck der Elegie (,ihn reizte die Aufgabe, die Seelenqual des Mädchens darzustellen“) bleibt unbefriedigend und bezieht sich außerdem nicht auf die gesamte Elegie, sondern nur auf den Mythos von Ilia und Anio.

${ }^{20}$ Vgl. Courtney 1988: 23: Ovid mokiere sich über Gattung der Elegie, indem er den Liebenden darstelle als ", frustrated and ineffectual figure“.

${ }^{21}$ Vgl. Donini 1969: 211, welcher der Erzählung von Ilia und Anio eine Schlüsselstellung innerhalb von Amores 3.6 zuerkennt.
} 


\section{Der Flußkatalog als Schlüssel für die Interpretation}

Der Flußkatalog ist ganz offensichtlich ein zentraler Bestandteil der Elegie 3.6; gleichzeitig stellt er eine Art „Fremdkörper" dar ${ }^{22}$. Dies ist ein Anzeichen dafür, daß man gerade in ihm den Schlüssel für die Frage nach einer tieferen Aussageabsicht der ganzen Elegie zu suchen hat.

Man hat längst bemerkt, daß in Amores 3.6 epische Elemente in die elegische Art des Dichtens eindringen. Es ist eine Elegie mit - natürlich übertrieben ausgedrückt fast „epischen“ Ausmaßen, mit einem eigentlich für das Epos charakteristischen Katalog und mit einem ausgemalten, mythisch-epischen exemplum ${ }^{23}$. Speziell der Ilia-Mythos wurde als Fremdkörper epischer Herkunft empfunden, nicht zuletzt weil Ennius, der Begründer des römischen hexametrischen Epos, das Schicksal der Ilia in seinen Annalen behandelt hatte ${ }^{24}$. Die Frage nach der Funktion dieser epischen Elemente scheint schon deshalb der richtige Weg für die Deutung zu sein, weil man mit dem Hinweis auf diese „Episierung“ den Wechsel der Szenerie von der verschlossenen Tür zum wegversperrenden Fluß, vom Paraklausithyron zum „Paraklausicheimarron“ begründen kann. Denn mit Flüssen lassen sich mythisch-epische Geschichten verbinden, mit Türen nicht ${ }^{25}$. Einen Fluß kann man mit dem Hinweis auf verliebte Flüsse zu überzeugen versuchen und ihm Geschichten von verliebten Flüssen erzählen; deutlich weniger ergiebig wäre da die Suche nach exempla für verliebte Türen.

Wenn aber Ovid vor allem diese mythisch-epischen exempla wichtig waren, wenn im Einbringen von epischen Elementen ein Kernanliegen der Elegie liegt, dann geht es in 3.6 nicht lediglich um eine weitere Präsentation elegischer Nöte, um eine Variation zum Thema „erfolgloser Liebhaber". Der Flußkatalog in Amores 3.6 hat freilich die primäre Funktion, den Gebirgsbach durch den Appell an eine gemeinsame Erfahrung zur Solidarität mit dem amator zu bewegen. Durch die zum Teil sehr gesuchten mythologischen Beispiele des Kataloges erweist sich Ovid außerdem als poeta doctus im Sinne des Kallimachos ${ }^{26}$. Als Abschweifung aus dem Munde eines Mannes, den es zur Geliebten drängt, leicht fehl am Platz, steht der Flußkatalog aber darüber hinaus im

\footnotetext{
${ }^{22}$ Was (zusammen mit anderen Argumenten) auch dazu geführt hat, Teile des Flüssekataloges und die gesamte Erzählung von Anio und Ilia als eine spätere Interpolation anzusehen (s. Zwierlein 1999: 422, Anm. 4).

${ }^{23}$ Vgl. Holzberg 1998: 72: Flüssekatalog und Mythos hätten gut in die Metamorphosen oder in die Fasti gepaßt. So schon Lörcher 1975: 79: „Dieser Mittelteil rückt das Gedicht stark in die Nähe des Epos; die Liste der verliebten Flußgötter erinnert sofort an den Schiffskatalog Homers oder den Nereidenkatalog aus der Theogonie Hesiods; die Sage von der geschändeten Vestalin und dem verliebten Gott würde gut in ein Epos passen.“ Bretzigheimer 2001: 147: „Daß der amator außer Gefecht gesetzt ist, nutzt der poeta gleichsam, um sich den Gattungsgrenzen zu entwinden.“ De Caro 2003: 174 macht die treffende Beobachtung, daß analog zum Naturbild auch diese Aufzählung sich „sturzbachartig“ auf den Angeredeten ergießt: „Il catalogo ... si snoda inizialmente come un cumulo 'torrenziale' di allusioni, che dovrebbero confondere e travolgere il destinatario." Will man in katalogartigen Aufzählungen ein genuin episches Element erblicken, so wäre dieses bereits in der hellenistischen Dichtung in der Gattung der Elegie auszumachen; dem anonymen Gutachten verdanke ich den Hinweis auf die Katalogelegie des Phanokles über homoerotische amores, in die eine ausführliche Orpheus-Erzählung eingebettet war. Vgl. dazu jüngst Gärtner 2008; zu den mythologischen Exempelkatalogen in den Amores übergreifend Gärtner 2005.

${ }^{24}$ Vgl. Sabot 1976: 485; Barchiesi 1989: 63; Connors 1994: 102.

${ }^{25}$ Zwar hat Catull (67) immerhin eine Türe personifiziert und zur Sprecherin in Liebesangelegenheiten gemacht, aber dabei handelt es sich nicht um ein mythologisches exemplum.

${ }^{26}$ Vgl. Sabot 1976: 485. De Caro 2003: 174, geht vielleicht etwas zu weit, wenn er in dem Flüssekatalog sogar eine Parodie auf alexandrinische mythologische Gelehrsamkeit erblicken will.
} 
Kontext mehrerer sich gerade im dritten Buche der Amores häufender Stellen, die „inhaltlich und darstellungstechnisch den Rahmen des Gattungstyps Amores-Dichtung sprengen “27. Hier spricht nicht mehr so sehr der amator als vielmehr der poeta ${ }^{28}$.

Neben seiner gedichtimmanenten Funktion erfüllt der Flüssekatalog somit allem Anschein nach noch eine über das Gedicht hinausreichende poetologische Funktion, die das Können und die Absichten des Dichters in Bezug auf Art und Weise seines Dichtens zutage treten läßt. Genauer läßt sich schon jetzt sagen, daß es auf der poetologischen Aussageebene speziell um das Verhältnis zweier verschiedener Gattungen geht, um Elegie und Epos. Daß Ovid in den Amores die Gattungsproblematik besonders beschäftigt, fällt nicht vom Himmel; in der „Programmelegie“ 3.1 war das Verhältnis zwischen den Gattungen Elegie und Tragödie das zentrale und bucheröffnende Thema.

Rahmen und Innenteil der Elegie 3.6 haben zentral etwas mit Flüssen zu tun; man kann davon ausgehen, daß dies kein Zufall ist. Eine poetologische Aussageabsicht ist deshalb in beiden Teilen zu suchen; außerdem stellt sich die Frage nach dem Verhältnis der beiden Teile zueinander.

\section{Das Epische am Flußkatalog}

Erscheint der an den Gebirgsbach gerichtete Monolog des Liebenden durch die Vergleichbarkeit der Situation mit der eines amator, der vor der verschlossenen Tür der Geliebten klagt, in die Tradition der elegischen Liebesdichtung noch halbwegs eingebettet und gerechtfertigt, gehört die katalogartige Aufzählung der Flüsse und vollends die breit ausgemalte Geschichte der Ilia zur Gattung des Epos ${ }^{29}$; man denke dabei an den Schiffskatalog in der Ilias ${ }^{30}$ und an die Flußkataloge bei Homer ${ }^{31}$, Hesiod ${ }^{32}$ und Ovid selbst $^{33}$. Freilich wird die Eigenart dieses „Fremdkörpers“ dadurch abgemildert, daß es

\footnotetext{
${ }^{27}$ Holzberg 2001: 134, mit einer Auflistung von Beispielen; vgl. auch Schmitzer 2001: 40. De Caro 2003: 175 bleibt auf der ersten Verständnisebene, wenn er in dem Flüssekatalog lediglich eine rein rhetorische, hohle Verwendungsweise mythischer exempla erblickt; in seinen Augen geht es Ovid in am. 3.6 (und vergleichbaren Elegien) v.a. darum zu zeigen, daß die elegischen Topoi nicht wirklich funktionieren, daß sie an der Realität scheitern, vgl. ebd. 176: „Le suarorie degli Amores, cioè i brani soggetti integralmente ad un intento persuasivo, partecipiano in pieno al processo di kenosis, specialmente per via della qualità grottesca della circostanza." Eine Lanze für die Bedeutsamkeit hinter der angeblichen Ovid'schen Oberflächlichkeit und Lust an Ausführungen und Aufzählungen bricht Hinds 2006: 15-25.

${ }^{28}$ Zur Charakterisierung des Sprechers in den Amores und zur Bezeichnung des poetischen Ichs in der römischen Liebeselegie als poetalamator vgl. Holzberg 1998: 20 bzw. Holzberg 2001: $1 \mathrm{f}$ und Bretzigheimer 2001: 11, mit Anm. 1; einen Überblick über verschiedene Ansätze zur Interpretation des Ich-Sprechers in den Amores jüngst bei Katz 2009.

${ }^{29} \mathrm{Zu}$ Stilelementen aus dem Epos in der Anio-Ilia-Erzählung s. auch De Caro 2003: 175.

${ }^{30}$ Hom. Il. 2.484 ff.

${ }^{31}$ Hom. Il. 12.20-22.

${ }^{32}$ Hes. theog. 337-345.

${ }^{33}$ Ov. met. 2.241-259; 15.273-286; Pont. 4.10.45-58. Vgl. dazu insgesamt auch Bernhardt 1986: 322 ff. Die Methode, einige Beispiele kurz anzureißen (manche in Form einer praeteritio) und dann eine einzelne Geschichte herauszugreifen und länger auszuführen benutzt Ovid später auch in den Metamorphosen (vgl. Ov. met. $4.43 \mathrm{ff}$ und $4.275 \mathrm{ff}$ ). Ein mögliches Vorbild, das auch inhaltlich Parallelen aufweist, ist die Liste der Städte, Berge, Inseln und Flüsse, die vor der schwangeren Leto fliehen, im vierten Hymnus des Kallimachos (vv 70 ff); dort wird ebenfalls eine Begegnung, nämlich die mit dem Fluß Peneios, breiter ausgemalt, vgl. dazu Courtney 1988, 20 f. Eine weitere Parallele bietet der Flußkatalog in der ersten Hymne des
} 
sich um einen Katalog von Liebesgeschichten handelt, zu Liebeselegien also durchaus inhaltlich passend, und diese Geschichten sollen ja erklärtermaßen den Sturzbach dazu bringen, sich mit dem Ich-Sprecher zu solidarisieren und dessen Liebeserfüllung kein Hindernis mehr in den Weg zu stellen ${ }^{34}$.

$\mathrm{Ob}$ es in der Literatur vor Ovid schon Sammlungen zu Liebesgeschichten von Flüssen gegeben hat, ist nicht sicher auszumachen ${ }^{35}$. Wie bereits festgestellt wurde ${ }^{36}$, hat Ovid in einigen Fällen zu ziemlich abgelegenen Mythen gegriffen, manchmal sogar zu Versionen, die sonst nicht zu belegen sind, jedenfalls nicht in den uns überlieferten Texten. Das mag an der Themenwahl liegen; bekanntere mythische Liebesgeschichten von Flüssen gab es nicht in großer Zahl.

Doch diese Begründung allein greift zu kurz. Auch wenn es natürlich gut zur Rahmensituation der Elegie paßt, so war Ovid doch durchaus nicht gezwungen, sich bei den angeführten exempla auf Liebesgeschichten von Flüssen zu beschränken; um einen Flußgott zur Solidarität mit einem Liebenden zu bewegen, hätte er durchaus auch Liebesaffären von Göttern überhaupt als Beispiele anführen können. Die Beschränkung auf amores von Flußgöttern geschieht also selbstgewählt und bewußt - aber warum? Nur um als poeta doctus mit der Kenntnis abgelegener Mythenversionen zu prahlen?

Die Abgelegenheit mancher der angeführten Liebesmythen hat die Aufmerksamkeit der Forschung völlig in Anspruch genommen; darüber aber hat man übersehen, daß Ovid bei der Auswahl der männlichen Hauptakteure, der Flüsse, ganz und gar nicht auf Abgelegenes aus war, im Gegenteil: es handelt sich bei seiner Aufzählung geradezu um ein who is who der antiken Flußgottheiten. Noch wichtiger ist eine weitere Beobachtung, die eng damit zusammenhängt. Die angeführten Flüsse sind nicht nur Akteure in Liebeshändeln, sondern sie lassen sich ohne Ausnahme direkt oder indirekt mit Stoffen von großen Epen in Verbindung bringen:

Inachos: $\quad$ Sohn des Okeanos und der Thetys, zugleich sagenhafter erster König von Argos, Vater des Phoroneus, nach manchen Überlieferungen der erste Mensch, und der Io, deren Schicksal Ovid später in den Metamorphosen breit ausführen wird ${ }^{37}$. Bithynien ist außerdem eine Station auf der Argonautenfahrt und damit vielleicht eine absichtliche Reminiszenz an das Argonautenepos, gerade weil Ovid die bithynische Abstammung der Melie den fehlenden Belegen nach zu urteilen als Neuerung einführt (in Melie Bithynide pallidus).

Kallimachos (vv $17 \mathrm{ff}$ ). Freilich war diese Technik bereits lange bekannt, vgl. beispielsweise den Exkurs zum Schicksal des Tlepolemos im Schiffskatalog bei Hom. Il. 2.657-670, oder die Digression zur Styx bei Hes. theog. 383-403.

${ }^{34}$ Schön herausgearbeitet wird der Witz Ovids, der darin liegt, daß er in derselben Elegie eben noch die mendacia vatum verworfen hatte (3.6.17), dann aber in seiner Suasorie selbst wiederum zu solchen greift, bei Bretzigheimer 2001: 178.

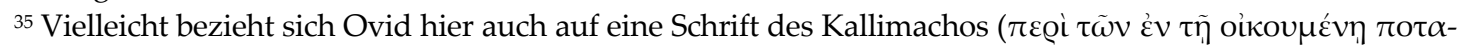
$\mu \tilde{\omega} v$, s. die Fragmente 457-458 in der Edition von Pfeiffer), aber das bleibt Spekulation.

36 Vgl. Courtney 1988: 20-22.

${ }^{37}$ Ov. met. $1.583 \mathrm{ff}$. 
Xanthos

(=Skamandros): Fluß bei Troia und von daher mit der Ilias Homers verbunden (v.a. mit dem Zweikampf Achills gegen Xanthos ${ }^{38}$ ), dem Epos par excellence, das außerdem durch nondum Troia fuit lustris obsessa duobus explizit ins Gedächtnis gerufen wird.

Alpheios: $\quad$ Hauptstrom der Peloponnes; verknüpft mit der Heraklessage, denn Herakles leitete seine Wasser um, um die Ställe des Augias zu reinigen. Von der Liebe des Alpheios zu Arethusa handelt Ovid ausführlich met. $5.577 \mathrm{ff}$.

Peneios: Der Peneios ist der Hauptfluß Thessaliens und überhaupt einer der Hauptflüsse ganz Griechenlands (Vater der Daphne; ausführlicher behandelt bei Ov. met. 1.466 ff). Kreusa ist eine thessalische Nymphe, Tochter der Ge, die dem Flußgott Peneios im Pindusgebirge den Lapithenkönig Hypseus gebar. Nach anderen Versionen ist Peneios der Großvater von Lapithes und Kentauros und gilt damit als der Stammvater der Lapithen und Kentauren (Diod. 4.69). Die Version, daß Peneios die eigentlich einem anderen versprochene Braut raubt ${ }^{39}$, findet sich nur bei Ovid. Der "Kampf um die Braut" ist ein episches Thema (zum Kampf der Lapithen gegen die Kentauren vgl. Hom. Il. 2.741 ff; Od. 21.295 ff; v.a. Ov. met. 12.210-535).

Asopos: $\quad$ Der böotische Hauptfluß, assoziiert mit der hier sicher bewußt so bezeichneten „kriegerischen Thebe“ (Martia Thebe); hier liegt die Assoziation des Flusses mit dem thebanischen Epenkreis, speziell mit dem "Zug der Sieben gegen Theben" auf der Hand. In den Metamorphosen bei Ovid spielt er nur eine Nebenrolle als Großvater des Aiakos und Vater der Aigina (6.113; 7.484.616) ${ }^{40}$.

Acheloos: Der größte Fluß Griechenlands; eng verknüpft mit der Heraklessage. Auch hier liegt die Verbindung offen zutage (cornua ... Herculis irata fracta ... manu; ausführlich bei Ov. met. $9.1 \mathrm{ff})$. Außerdem liefert Calydon (vgl. Ov. met. 9.2: Calydonius amnis) noch das Stichwort für das große epische Thema der Kalydonischen Eberjagd und den Sagenkreis um Meleagros (Ov. met. $8.273 \mathrm{ff}$ ).

Neilos: $\quad$ Überhaupt einer der größten Flüsse und insofern besonders gut geeignet als Anspielung auf die epische Dichtung ${ }^{41}$. Assoziiert ist der Nil vor allem mit dem Mythos Zeus-Io, aber auch Herakles wird mit dem Nil in Verbindung gebracht (Diod. 1.19), und im Rahmen der

\footnotetext{
${ }^{38}$ Hephaistos muß auf Geheiß Heras zugunsten von Achill rettend eingreifen; vgl. Ov. met. 2.245: arsurusque iterum Xanthus.

${ }^{39}$ Nach den Handschriften Xanthos, nach einer von den Herausgebern übernommenen Konjektur von Heinsius Xuthos. Für die vorliegende Fragestellung ist diese textkritische Problematik ohne Belang; sie wird gesondert abgehandelt (s. Anhang).

${ }^{40}$ Die Gründungssage von Theben nimmt im 3. Buch mehr Raum ein als die kurze Zusammenfassung des Bruderkrieges in den Prophezeiungen der Themis im 9. Buch (403 ff).

${ }^{41}$ Ovid selbst äußert sich ausführlich zum Nil und zu den aus seinem Schlamm sich formenden Lebewesen met. 1.422 ff; die Verhüllung seiner Quellen in $2.254 \mathrm{f}$.
} 
Enipeus: In Enipeus' Gestalt zeugt Poseidon mit Tyro Neleus und Pelias, den Vater von Achill. Der Stoff an sich ist mythisch-episch, und der Anschluß an die Ilias evoziert ebenfalls Assoziationen an das Epos (speziell Assoziationen zur Achilleus-Epik). Außerdem ist dieser Mythos eine gute Überleitung zu dem letzten Beispiel (Zeugung von bedeutenden Zwillingen; beide Male etwas weniger bekannte Flüsse ${ }^{42}$. Es ist bemerkenswert, daß Ovid hier wie im letzten Beispiel eher an Ennius als an Vergil zu denken scheint ${ }^{43}$.

Anio: Der letzte große „epische“ Fluß ist „ein Römer". Schon das ist überraschend. Man würde außerdem nach den vorangegangenen Berühmtheiten den Tiber erwarten, und der Tiber stünde dann natürlich für Vergil und die Aeneis. Der Anio ist einerseits verknüpft mit einer Liebesgeschichte, andererseits aber auch, wie der Tiber, mit dem römischen Nationalepos assoziiert, geht es doch mit Ilia um die Mutter von Romulus und Remus. Die Verbindung von Anio und Ilia beschrieb aber Ennius in seinen Annalen, so daß ein Bezug auf Ennius näher liegt als auf Vergil. Die zwei „Überraschungen“ - als letztes Beispiel nach all den „,ausländischen“ Flüssen ein aus der Reihe fallendes Beispiel aus Latium, und dann aber ausgerechnet nicht der Tiber, sondern Anio - , sind deutliche Hinweise darauf, daß es mit diesem exemplum eine besondere Bewandtnis hat

Vielleicht ist nicht mehr lückenlos nachweisbar, welche Assoziationen Ovid bei der Erstellung des Flüssekataloges im einzelnen bei seinen Lesern wecken wollte, aber eines steht fest: Er wählt für seine Liste keineswegs abgelegene, wenig bekannte Flußgötter aus, sondern durchweg bekannte und sogar berühmte, die sich leicht und vorrangig mit epischen Werken in Verbindung bringen lassen ${ }^{44}$. Ovid selbst charakterisiert den Katalog im Rückblick als eine Aufzählung von Berühmtheiten (nomina tanta), wenn er den Sprecher am Ende von Elegie 3.6 verärgert ausrufen läßt ${ }^{45}$ :

huic ego vae demens narrabam fluminum amores?

iactasse indigne nomina tanta pudet.

„Wehe! Diesem da habe ich Narr Geschichten von verliebten Flüssen erzählt?

Ich schäme mich, unangemessen so große Namen hingeworfen zu haben."

\footnotetext{
42 Andere Version vom Tyro-Enipeus-Mythos bei Ov. met. 6.116.

${ }^{43}$ Zum Tyro-Enipeus-Mythos und zur Parallelisierung von Tyro und Ilia bei Ennius s. Boyd 1997: $213 \mathrm{f}$ und Connors 1994: 101-106.

${ }^{44}$ Freilich mag der eine oder andere anklingende Stoff antiken Lesern auch in seiner Formung durch berühmte Lyriker oder Dramatiker bekannt gewesen sein; die Stoffe legen durch ihre inhaltliche Auswahl und in ihrer Gesamtheit jedoch Bezüge zu antiken Epen eindeutig näher.

${ }^{45}$ Ov. am. 3.6.101 f. Vom Sinn her könnte die von so gut wie allen späteren Handschriften bezeugte Lesart indigno („einem Unwürdigen“) den Vorzug vor indigne verdienen, doch spricht auch einiges dafür, die älter bezeugte lectio difficilior beizubehalten („,der Situation/ dem Zuhörer nicht angemessen“ i.S.v. bei einem namenlosen Sturzbach sinnlos verschwendete Zeit).
} 
Es ist also nicht so sehr die Abgelegenheit der Liebesgeschichten, durch die sich Ovid hier zu einem Callimachus Romanus stilisiert ${ }^{46}$, als vielmehr die Referentialität auf einen bunten Fächer epischer Themen, die hier poetologisch bedeutsam ist und den Dichter ansatzweise in der Gestalt eines Ennius redivivus erscheinen läßt ${ }^{47}$.

Das Ausweichen in die Welt des Mythos, die formale Form des Katalogs und die Assoziationsmöglichkeiten zu zahlreichen epischen Werken machen den Flüssekatalog zu einem Fremdkörper innerhalb der elegischen Dichtung. Andererseits gehört er durch die weitgehende Reduktion der mythischen Stoffe auf die Liebesthematik, durch die formale Gestaltung in elegischen Distichen und durch die elegische Diktion ${ }^{48}$ eindeutig in den Bereich der Elegie. Es sind diese schillernden, doppelten Bezugsmöglichkeiten, die als Hauptcharakteristikum des Flüssekataloges festzuhalten sind.

Diese Amphibolie wird von Ovid selbst kurz und knapp durch die Wendung narrabam fluminum amores auf den Punkt gebracht. Wenn mit fluminum amores auf den Titel der drei Bücher Amores Bezug genommen wird, so ist doch der Inhalt ein anderer: mit amores sind hier vom Kontext her eindeutig nicht mehr Liebesgedichte, sondern Liebesgeschichten gemeint, wie dies auch durch narrabam näherhin spezifiziert wird ${ }^{49}$, ganz in dem Sinn der Verwandlungsgeschichten, aus denen das Epos der Metamorphosen gebaut ist ${ }^{50}$.

Genauso zweischichtig wie der Ausdruck amores narrare - denn es sind ja schließlich Liebesgeschichten, die zwar nicht in ihrer katalogartigen Form und in ihrer epischnarrativen Ausgestaltung, wohl aber von ihrem Inhalt her zu Liebesgedichten passen - ist auch der Begriff demens doppeldeutig. Als "Narr" wird in der elegischen Dichtung der Liebende bezeichnet ${ }^{51}$, hier aber kann es sich auch auf den Dichter selbst beziehen, der sich in dieser Elegie eine der Gattung unangemessene Digression gestattet. So wird bei Properz einmal in eindeutig poetologischem Zusammenhang der Begriff demens auf den Dichter selbst bezogen, und noch dazu in genau dem entsprechenden Kontext: Apollon bezeichnet den Dichter als demens, da er es als Elegiker unternommen hatte, an die Abfassung eines epischen Gedichtes heranzugehen (carminis heroi

\footnotetext{
${ }^{46}$ In diese Richtung gehen Connors 1994: 20-22 (mit Verweis auf die bereits erwähnte Prosaschrift $\pi \varepsilon \rho i$

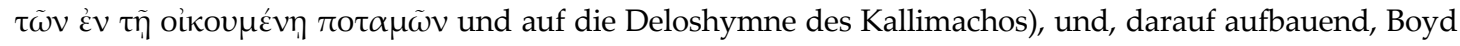
1997: $213 \mathrm{f}$.

${ }^{47}$ Dazu passend ist der mit „epischen Flußbeispielen“ überschüttete Sturzbach dann auch eher angeschwollen als „kallimacheisch-klein“ geworden; vgl. dagegen Barchiesi 1989: 63 und Boyd 1997: 216, mit Anm. 31, die aufgrund der Deutung des Kataloges als tendentiell „kallimachäisch“ eine gewisse Inkonsistenz in der Elegie erblicken.

${ }^{48}$ Typisch elegisches Vokabular bspw. pallidus in alqa (3.6.25), rapere (28), capere (33), flamma (41). Beispiele für Doppeldeutigkeiten in den Flußkatalogbeispielen vor der Iliageschichte liefert auch Eggers 1984: 184188 u. 233 f. S. dazu ebenfalls im folgenden die Ausführungen zum Ilia-Mythos.

${ }^{49}$ Das Verbum narrare steht in den Amores nie für das elegische Dichten, sondern für ein prosaisches „Erzählen“ bzw. „Mitteilen“, vgl. am. 1.13.35; 2.8.28; 2.11.49; 3.1.17 f; eine Aufforderung zum „epischen Erzählen" mit narrare bspw. bei Ov. met. 4.42. Genau in demselben Sinn wie in am. 3.6.101 geht es in met. 5.576 um amores narrare, also um eine Vermischung elegischer und epischer Gattungscharakteristika, denn im folgenden wird die Liebesgeschichte des Flusses Alpheios mit Arethusa, also ein "elegisches Thema“, in epischer Breite ausgeführt.

50 Ähnlich wie in den Metamorphosen ist auch das Spiel mit der Doppelnatur des Flusses, vgl. die Geschichte von Alpheios und Arethusa, met. $5.572 \mathrm{ff}$, besonders 636-638.

${ }^{51}$ Vgl. z.B. Prop. 2.30.1.
} 
tangere ... opus) ${ }^{52}$. Viel wichtiger als der Umstand, daß dadurch rückblickend das Unterfangen, epische Elemente in einen elegischen Kontext hineingetragen zu haben, für verrückt erklärt wird, ist der Umstand, daß in dieser Passage das Unterfangen selbst gerade auf poetologischer Ebene charakterisiert und - freilich augenzwinkernd - als ein Unding hingestellt wird ${ }^{53}$ : amores narrare, das ist für den Elegiker gewissermaßen eine contradictio in adiecto, aber genau das ist es, was ein zentrales poetologisches Merkmal von Amores 3.6 ins Auge faßt, und was man umschreiben könnte mit der Wendung „episierendes Elegisieren“. Was darunter näherhin zu verstehen ist, wird aus dem Folgenden noch deutlicher.

\section{Anio und Ilia: Kernstück des Innenteils}

\section{a) Der Ilia-Mythos}

Eingebettet in den Flußkatalog, aber eben diesen Rahmen wiederum sprengend, wird von Ovid ein Ausschnitt aus dem Mythos der Ilia behandelt. Name, Identität und Abstammung der Stammutter Roms waren schon im Altertum umstritten, und es existieren im Detail sowie im Ganzen stark variierende römische Gründungssagen ${ }^{54}$.

Schon der Name der Stammutter Roms wird in der Antike nicht einheitlich überliefert; je nach Tradition wird sie „Rhome“, „R(h)ea Silvia“ oder "Ilia“ genannt. Ovid selber benutzt sowohl die Namensform „Silvia“55 als auch die Form „Ilia“56.

Auch hinsichtlich ihrer Identität und Herkunft gibt es die unterschiedlichsten Überlieferungsstränge. So wird sie einmal als eine Trojanerin dargestellt, die durch das Anzünden der Flotte Aeneas zur Stadtgründung zwang, einmal ist sie die Frau des Aeneas selbst, in einer anderen Tradition wiederum die Frau des Ascanius, und nach einer dritten Version die Frau des Latinus. Nach anderen Darstellungen wird das Auftreten der Ilia in der Geschichte teilweise um Generationen später angesetzt, wenn sie etwa als Tochter des Aeneas oder gar als Tochter Numitors in Erscheinung tritt ${ }^{57}$; an diese letztgenannte Variante hält sich Ovid in Amores 3.6.

\footnotetext{
${ }^{52}$ Prop. 3.3.15 f.

${ }^{53}$ Bereits Lenz 1966: 223 sieht die Doppelbödigkeit von am. 3.6.102, in der scherzhaft das negiert wird, was dem Dichter im Gedicht das Wichtigste ist.

${ }^{54}$ Vgl. zum folgenden die Darlegung verschiedener Versionen bei Dionysius v. Halikarnassos $1.72 \mathrm{ff}$, bei Plutarch Rom. $1 \mathrm{ff}$ und bei Servius Verg. Aen. 1.273. Folgende Gewährsmänner kommen zeitlich gesehen mit Sicherheit als Quellen für Ovid in Betracht: Homer, Diokles v. Peparethos (Mitte 3. Jhdt. v.Chr.), Fabius Pictor (2. Hälfte 3. Jhdt. v.Chr.), Naevius (ca. 265 - ca. 195 v.Chr.), Ennius (239 - 169 v.Chr.), Vennonius (2. Hälfte 2. Jhdt. v.Chr.), Valerius Antias (1. Hälfte 1. Jhdt. v.Chr.), Vergil (70 - 19 v.Chr.), Horaz (65 - 8 v.Chr.), Tibull (ca. 50 - ca. 19 v.Chr.), Properz (ca. 47 - nach 16 v.Chr.), wobei die letzteren beiden nur bedingt Material liefern. Dionysius v. Halikarnassos und Livius sind Zeitgenossen Ovids (43 v.Chr. - ca. 17 n.Chr.), deren Kenntnis durch den Dichter zumindest nicht ausgeschlossen werden kann; erst nach Ovid schreiben Konon (Datierung unsicher, um die Zeitenwende), der anonyme Auctor De orig. gent. Rom. (beginnende Kaiserzeit), Plutarch (ca. 45 - ca. 125 n.Chr.), Pseudo-Acro (2. Jahrhundert n.Chr.?), Porphyrius (234 - ca. 303 n.Chr.) und Servius (um 400 n.Chr.).

${ }^{55}$ So u.a. fast. 2.383; 3.11. Zum Vergleich der verschiedenen Versionen des römischen Gründungsmythos bei Ovid am. 3.6 und am Anfang des dritten Buches der Fasti s. Boyd 1997: 211-219.

${ }^{56}$ Vgl. am. 3.6.47; fast. 2.598 u.a. Gegen Radke 1975: 1344 verwenden also die römischen Dichter nicht nur ausschließlich die Form „Ilia“.

${ }^{57}$ Vgl. dazu im einzelnen die Lexikonartikel „,Rea Silvia“ von Rosenberg 1914 und Lorentz 1909-1915.
} 
Nach der geläufigen Version des Mythos wird der rechtmäßige Albanerkönig Numitor von seinem jüngeren Bruder Amulius mit Gewalt vom Thron vertrieben ${ }^{58}$. Um sich vor eventuellen Racheakten der Nachkommen seines Bruders zu schützen, läßt Amulius Numitors Sohn umbringen ${ }^{59}$ und macht Ilia zur Vestalin, um sie so zur Keuschheit $\mathrm{zu}$ zwingen ${ }^{60}$. Sie wird jedoch von Mars vergewaltigt und bringt die Zwillinge Romulus und Remus zur Welt ${ }^{61}$. Daraufhin werden diese auf Befehl des Amulius im Tiber ausgesetz $t^{62}$ und Ilia selbst eingesperr ${ }^{63}$ oder in den Tiber gestürzt ${ }^{64}$. Daß Ilia sich selbst im Anio ertränkt, ist lediglich in der Elegie am. 3.6 bei Ovid zu finden ${ }^{65}$.

Die Stammutter Roms verdient freilich keineswegs einen so schändlichen Tod; die Ahnenverehrung und mythische Überhöhung machte es fast zwingend notwendig, daß Ilia als eine durch göttliches Eingreifen gerettete und numinos verklärte Gestalt in eine höhere Daseinsform übergeht und nach dem Tod weiterlebt. Genau dies ist in der traditionellen Ausbildung der römischen Gründungssage auch der Fall. Dabei gibt es zwei Überlieferungsstränge: einen, nach dem Ilia als die Gattin des Tiber, der zweite, nach dem sie als Gattin des Anio erscheint.

Bei Horaz carm. 1.2.13-20, wo eine Tiberüberschwemmung als Rache des Flusses für das der Ilia angetane Unrecht gedeutet wird, liegt es nahe, daß Ilia hier als Gattin des Tiber gedacht ist ${ }^{66}$. Dahin geht auch die Interpretation des Servius in seinem Vergilkommentar zu Aen. 1.273, der Horaz als Gewährsmann für diese Version anführt, während er sich für die Variante einer Ehe Ilias mit dem Fluß Anio auf den Hinweis ut quidam dicunt beschränkt.

Porphyrius verweist in seinem Kommentar zu Horaz carm. 1.2.17 in diesem Fall auf Ennius:

\footnotetext{
${ }^{58}$ Vgl. Diokles v. Peparethos und Fabius Pictor bei Plutarch Rom. 3, Dionysius v. Halikarnassos 1.71.4 f; 1.76.1, Livius 1.3.10 f, Ovid fast. 3.49 f; 4.53 f und Servius Verg. Aen. 1.273; 6.777. Die antiken Belege für den kurz dargestellten Teil der für Ovid relevanten Ilia-Erzählung werden hier und im folgenden jeweils in chronologischer Reihenfolge zitiert.

${ }^{59}$ Vgl. Dionysius v. Halikarnassos 1.76.1 f (bei ihm heißt der Sohn Aegestus), Livius 1.3.10 f (ohne Namensangabe) und Ovid fast. 4.55, wo der Sohn Lausus heißt.

${ }^{60}$ Vgl. Diokles v. Peparethos und Fabius Pictor bei Plutarch Rom. 3, Valerius Antias beim Auctor De Orig. gent. Rom. 19.4, Dionysius v. Halikarnassos 1.76.3, Livius 1.3.10 f und Servius Verg. Aen. 1.273; 6.777.

${ }^{61}$ Vgl. Fabius Pictor und Vennonius beim Auctor De orig. gent. Rom. $20.1 \mathrm{f}$, Vergil Aen. $1.273 \mathrm{f}$, Dionysius v. Halikarnassos 1.77,1 f; 1.78.4, Livius 1.4.1-3, Ovid am. 3.39 f; fast. 3.9 ff und Servius Verg. Aen. 1.273; 6.778. Nach anderen Versionen wird sie von einem nicht näher benannten Freier oder gar von Amulius selbst vergewaltigt, vgl. Dionysios v. Halikarnassos $1.77 .1 \mathrm{f}$ und Plutarch Rom. 4.

${ }^{62}$ Vgl. Diokles v. Peparethos und Fabius Pictor bei Plutarch Rom. 3, Fabius Pictor bei Dionysius v. Halikarnassos 1.79.4 ff, Cicero rep. 2.4 und Livius 1.4.1-3.

${ }^{63}$ Auf Bitte der Tochter des Amulius, Antho, die Ilia in tiefer Freundschaft verbunden ist - eine entsprechende Konstellation findet sich in Shakespeares As You Like It - , wird Ilia nur eingesperrt und erst nach dem Tod des Amulius befreit, vgl. Diokles v. Peparethos und Fabius Pictor bei Plutarch Rom. 3, Dionysius v. Halikarnassos 1.79.1-3, Livius 1.4.1-3, Konon FGrH 26 F1 48 und Plutarch Rom. 9.

${ }^{64}$ Vgl. Ennius bei Porphyrius Hor. carm. 1.2.17, Servius Verg. Aen. 1.273 und Dionysius v. Halikarnassos 1.78.5-1.79.3. Die Behauptung, es hätte in der Antike eine Tradition gegeben, nach der Ilia in den Anio gestürzt worden sei, und dies sei gar die geläufige Version des Mythos gewesen (so z.B. Niebuhr 1833: 221; Preller 1858: 699; Le Bonniec 1969: 130, Anm. 123 und Schubert 1992: 119), läßt sich anhand der überlieferten Texte nicht verifizieren und beruht zum Teil auf einer ungenauen Interpretation von Servius' Kommentar zu Vergil Aen. 1.273 (so bei Lorentz 1909-1915: 64), wo zwar von einer Ehe zwischen Ilia und Anio die Rede ist, nicht aber von einem Sturz Ilias in den Anio, geschweige denn von einem Selbstmord.

65 Vgl. Wilhelm 1933: 169.

${ }^{66}$ So deutet es bereits Pseudo-Acro in seinem Kommentar zu carm. 1.2.17. Vgl. auch Sidonius Apollinaris, Paneg. in Maior. 25-28. So auch Rutledge 1980: 303 und Connors 1994: 109, Anm. 30.
} 
Ilia auctore Ennio in amnem Tiberim iussu Amulii regis Albanorum praecipitata Antemnis ${ }^{67}$ Anieni matrimonio iuncta est.

„Nach Ennius wurde Ilia, auf Befehl des Albanerkönigs Amulius in den Fluß Tiber gestürzt, bei Antemnae dem Anio zur Frau gegeben."

Bei Antemnae mündet der Anio in den Tiber. Die sich hieraus ergebenden geographischen Umständlichkeiten sind im Mythos ohne Belang, sie liefern einer am Strukturalismus orientierten Mythenanalyse jedoch meistens Anhaltspunkte dafür, daß ursprünglich selbständige Überlieferungen nachträglich synthetisiert wurden. Vielleicht hat Ennius selbst versucht, zwei verschiedene ihm vorliegende Traditionsstränge durch diese künstliche Konstruktion miteinander zu verbinden und in Einklang zu bringen ${ }^{68}$.

Eine etwas ausführlichere Stellungnahme findet sich im Kommentar von PseudoAcro zu Horaz carm. 1.2.20:

Diuersae de Ilia poetarum positiones sunt. Nam Ilia mater Romuli fuit, quem ex Marte suscepit, quae mortua sepulta ad ripam Anienis fluuii dicitur, qui in Tiberim cadit, et, quia abundans aquis Anio cineres Iliae in Tiberim deduxit, dicta est Ilia Tiberi nupsisse, et ideo dixit 'uxorius amnis', qui se ad eius querelam iactaret ultorem. Alii dicunt, quod ista Ilia Anieni nupserit; nam multi hoc sentiunt poetae. Sed Horatius, ut Tiberi det causas irascendi, Tiberis magis dixit uxorem.

„Die Ansichten der Dichter, Ilia betreffend, sind verschieden. Ilia war nämlich die Mutter des Romulus, den sie von Mars empfangen hatte. Sie soll nach ihrem Tod am Ufer des Flusses Anio bestattet worden sein, der in den Tiber mündet. Weil die über die Ufer getretenen Wasser des Anio Asche der Ilia in den Tiber getragen haben, behauptete man von Ilia, sie habe den Tiber geheiratet, und deswegen hat er [sc. Horaz] ihn als uxorius amnis bezeichnet, der sich auf ihre Klage hin als Rächer gerierte. Andere behaupten, daß eben diese Ilia den Anio geheiratet habe; denn viele Dichter sind dieser Meinung. Aber Horaz bezeichnete sie eher als Frau des Tiber, um dem Tiber Grund für seinen Zorn zu geben."

Auch hier wird mithilfe einer noch komplizierteren und schon deshalb nicht unbedingt überzeugenderen Konstruktion der Versuch unternommen, die beiden Überlieferungen irgendwie miteinander zu verbinden. Wie Servius gibt Pseudo-Acro keinen näheren Hinweis darauf, wer denn nun zu den multi poetae gehört, die von einer Heirat Ilias mit dem Anio gesprochen haben sollen, und auch Ovid, der sich in Amores 3.6 an die Version hält, nach der Ilia von Anio geehelicht wird ${ }^{69}$, beruft sich dabei auf Gewährs-

\footnotetext{
${ }^{67}$ Die Konjektur Antemnis statt antea enim von Bücheler (bei Skutsch 1985: 75) ist überzeugend, denn warum sollte Ilia vor ihrem Sturz in den Tiber mit Anio verheiratet worden sein? Darüber hinaus ist die ersetzende „Verbesserung" eines nicht gut bekannten geographischen Eigennamens durch einen unkundigen Schreiber gut nachvollziehbar.

${ }^{68}$ Gegen Sabot 1976: 486 kann also Ennius wohl nicht als Gewährsmann für eine Ehe der Ilia mit dem Tiber angeführt werden. Rutledge 1980: 303, der antea enim anstatt von Antemnis beibehält, weist dementsprechend nicht Ennius, sondern Porphyrius den Versuch zu, zwei Traditionen vereinen zu wollen. Selbst wenn man aber der Konjektur von Bücheler nicht zustimmt, so bleibt doch die Aussage - daß das Schicksal der Ilia in irgendeiner Weise sowohl mit dem Anio als auch mit dem Tiber verbunden war - in ihrem Kern gleich. - Daß bei Ennius ann. fr. 1.26 (Skutsch) nicht Ilia, sondern Aeneas den Tiber anredet, dazu vgl. den Kommentar von Skutsch (1985: 184 f), und zum Traum der Ilia (fr. 1.34 ff), wo ihre Rettung durch den Fluß nur sehr vage andgedeutet wird, den Kommentar auf den Seiten 193 ff.

${ }^{69}$ Über den Grund, warum Ovid sich ausgerechnet für diese Variante des Mythos entschied, lassen sich nur Vermutungen anstellen. Nach Ansicht von Rutledge 1980: 303 f hat Ovid sich für die Version einer Ehe
} 
leute, ohne diese näher zu benennen (dicitur, 3.6.82). Die in den Quellen begegnende Vagheit in Bezug auf die Gewährsmänner für eine Ehe der Ilia mit Anio läßt zumindest vermuten, daß die Herkunft dieses Überlieferungsstrangs schon länger nicht mehr bekannt war und keiner der späteren Kommentatoren noch einen Originalbeleg hätte zitieren können. Nur bei Porphyrios findet sich noch ein konkreter Hinweis auf Ennius, ohne Zitat; vielleicht war Ennius also derjenige, der für diese Version des Mythos entweder selbst verantwortlich zeichnet, oder der selbst schon nur noch vage Andeutungen bezüglich seiner Quellen geben konnte.

Ovid hält sich also in Amores 3.6 an die Mythenversion des Ennius und der „vielen Dichter ${ }^{\prime 70}$, die ungenannt und uns unbekannt bleiben ${ }^{71}$, vielleicht auch schon den Lesern zu Ovids Zeiten unbekannt waren, weil die stärkere Rezeption der monumentalen ennianischen Annalen anderes in Vergessenheit geraten ließ. Bei Ennius ist uns die Erzählung der Ilia glücklicherweise in einem längeren Fragment erhalten ${ }^{72}$, in dem die Geschehnisse durch einen Traum der Ilia antizipiert werden. Sie berichtet nach dem Erwachen mitten in der Nacht - eine alte Dienerin muß eine Lampe bringen ihrer Schwester davon, wie es ihr schien, als ob ein "schöner Mann“ (homo pulcer, gemeint ist $\mathrm{Mars}^{73}$ ) sie an ein unbekanntes Flußufer verschleppte ${ }^{74}$. Die Vergewaltigung wird übergangen beziehungsweise durch das Verbum "verschleppen“ (raptare) allenfalls angedeutet; als nächstes berichtet Ilia davon, wie sie im Traum allein die fremde Gegend durchirrt und nach ihrer Schwester sucht ${ }^{75}$. Stattdessen hört sie die Stimme ihres Vaters, der ihr nach dem Überstehen kommender Drangsale ein neues Glück verheißt, das ihr "aus dem Fluß" erstehen werde ${ }^{76}$. Die feierliche, aber auch kryptische

zwischen Ilia und Anio aus Verehrung für Vergils Beschreibung des Tibers (Aen. 8.31 ff) entschieden. „Witty and shameless as he could sometimes be, Ovid was not (yet) so audacious as to make ridiculous a character which Vergil had endowed with an awesome, almost holy, aura" (ebd. 303).

${ }^{70}$ Ennius hat Ovid offenbar gelesen, was aus trist. $2.259 \mathrm{f}$ hervorgeht (sumpserit Annales - nihil est hirsutius illis - : / facta sit unde parens Ilia nempe leget).

${ }^{71}$ Fraglich ist, ob Ovid sich auch sonst an diese Mythenversion gehalten hat. Als umstritten und nicht auf Anhieb klar erweist sich in diesem Zusammenhang fast. $2.597 \mathrm{f}$, wo es heißt: dixerat; adnuerant nymphae Tiberinides omnes / quaeque colunt thalamos, Ilia diua, tuos. Sind die Nymphen, die Sorge tragen für das eheliche Schlafgemach der Ilia, Nymphen des Tiber, wie man zunächst annehmen könnte, oder sind hier nicht vielmehr Nymphen eines anderen Flusses gemeint? Die zitierten Verse scheinen aufs erste nahezulegen, daß hier die Nymphen des Tiber das Schlafgemach der Ilia hegen; so auch die Interpretation von fast. 2.598 bei Bömer 1958: 127, in der Fasti-Ausgabe von Gerlach 1960: 394 und ebenso noch Holzberg in der Fasti-Ausgabe von 1995: 309 zu fast. 2.598: „Rhea Silvia ... hier als Gattin des Flußgottes Tiber“ (mittlerweile in der 2. Auflage korrigiert). Daß Ovid innerhalb seines Werkes zwei einander widersprechende Versionen des IliaMythos zitiert, ist keineswegs abwegig. Die Intention des Distichons fast. $2.597 \mathrm{f}$, eine möglichst große und breite Zustimmung von allen Seiten zu signalisieren, und vor allem die Fortsetzung durch -que (bei quaeque) macht jedoch wahrscheinlich, daß hier die Nymphen eines weiteren Flusses in Latium den Tibernymphen hinzugefügt werden sollen, zumal da Vers 589 Jupiter alle Nymphen Latiums zusammenruft. Vers 598 dürfte also in Anlehnung an die von Ovid in am. 3.6.45 ff benutzte Mythenversion als Umschreibung für die Nymphen des Anio anzusehen sein. Vgl. dazu auch Le Bonniec 1969: 130 mit Anm. 123 und Courtney 1988: 20.

${ }^{72}$ Fr. XXIX, ann. 1.34-50 Skutsch.

${ }^{73}$ S. dazu Skutsch 1985: 197.

${ }^{74}$ nam me uisus homo pulcer per amoena salicta / et ripas raptare locosque nouos, $1.38 \mathrm{f}$.

75 ita sola / postilla, germana soror, errare uidebar / tardaque uestigare et quaerere te neque posse / corde capessere: semita nulla pedem stabilibat, 1.39-42. Auf diese Passage spielt aufgrund der Wortbezüge Ov. am. 3.6.50 vielleicht direkt an (errabat nudo per loca sola pede).

${ }^{76}$ exim compellare pater me uoce uidetur / his uerbis: „o gnata, tibi sunt ante gerendae / aerumnae, post ex fluuio fortuna resistet, 1.43-45. Zu resistet i.S.v. resurget s. Skutsch 1985: 200. 
Orakelsprache ${ }^{77}$ liefert uns keinen expliziten Hinweis auf die Identität des genannten Flusses bei Ennius; bei Ovid jedenfalls ist es Anio, durch den der Ilia Rettung zuteil wird.

Während in dem überlieferten Enniusfragment der Anfang der Geschichte in den Blick genommen wird, konzentriert sich Ovid bei seiner Adaption eher auf das Ende derselben. Im Traum der Annalen wird Ilia nach der Vergewaltigung durch Mars in der fernen Zukunft ein neues Glück verheißen; Schwangerschaft, Geburt und Bestrafung durch Amulius muß sie noch durchmachen, bevor ihr Rettung winkt. Ovid hingegen setzt Schwangerschaft, Geburt der Zwillinge und Verstoßung durch Amulius voraus und fokussiert die Begebenheit auf die Peripetie der Handlung, die zugleich das Ende ist: Ilias Suizidversuch führt zur Ehe mit dem Flußgott Anio $^{78}$. Wer Ilia hier Rettung verheißt, ist nicht ihr Vater, sondern der Retter selbst, und die Rettung liegt nicht in weiter Ferne, sondern sie steht unmittelbar bevor. Von daher entsteht zusätzlich der Eindruck einer Raffung der ennianischen Geschehensabläufe durch Ovid: die Vergewaltigung durch Mars und das nefas des Amulius wird nur rückblickhaft gestreift (v 49), die Handlung beginnt mit einer Rede, die eine Prophezeiung beinhaltet, die der Redende durch seinen Antrag sofort im Anschluß zur Erfüllung bringt.

Ovid beginnt mit einer Apostrophe an den Flußgott Anio, in der vor allem dessen lebensspendende Kraft gerühmt wird (vv 45-46). Die Spannung des Lesers wird dadurch erhöht, daß der Fluß namentlich erst in Vers 51 genannt wird ${ }^{79}$. Das nächste Distichon stellt eine elegante Überleitung zum erzählenden Teil dar. Während rein formal die Apostrophe an Anio fortgesetzt wird, befindet sich der Leser inhaltlich mit dem Hinweis auf die äußerlich schauderhaft zugerichtete Ilia schon mitten im Geschehen, das formal erst mit Vers 49 einsetzt. In Vers 49 erfährt der neugierig gewordene Leser nur kurz die Gründe für die Verzweiflung der Ilia. Ovid setzt voraus, daß sein Publikum mit den Andeutungen patruique nefas delictaque Martis um den Hintergrund und die Voraussetzungen der nun folgenden Handlung weiß. Wie aber die Rekonstruktion der geläufigen Versionen des Mythos vor Ovid gezeigt hat, wußten die Leser zwar, daß mit patrui nefas die schmähliche Vertreibung Numitors, die Tötung seines Sohnes, die der Ilia aufgezwungene Weihe zur Vestalin und die Aussetzung der Zwillinge durch Amulius gemeint sein konnte, und mit delicta Martis die Vergewaltigung der Ilia durch Mars, aber von einer deshalb ganz allein am Gestade des Anio verzweifelt umherirrenden Ilia hatte man noch nicht gehört, wurde doch nach der Tradition Ilia entweder eingesperrt oder auf Befehl des Amulius in den Tiber gestürzt ${ }^{80}$. Der Leser wird hier also in eine Erwartungshaltung versetzt: Wie wird Ovid den bekannten Mythos auf seine eigene Art formen? Oder, anders gefragt: Wie kommt Ilia am Ende dann doch noch in den Fluß, wenn sie nicht auf Befehl des Amulius dort hineingestürzt wurde ${ }^{81}$ ? Diese Fragestellung baut einen Spannungsbogen auf, der erst am Ende des Abschnitts seine Auflösung erfährt.

\footnotetext{
77 S. dazu Skutsch 1985: 200.

${ }^{78}$ Zur genaueren Rekonstruktion der von Ovid vorausgesetzten Geschehensabläufe des Mythos s. Punkt 5.b) „Adaption des Ilia-Mythos durch Ovid“.

${ }^{79}$ Ovid benutzt die ungebräuchlichere Form "Anien“.

${ }^{80}$ Vgl. Wilhelm 1933: 169: „Der Tradition entgegen erscheint Ilia bei Ovid als Ausgestoßene, die sich selbst in den Anio stürzt."

${ }^{81}$ Die Version mit der Gefangensetzung Ilias kommt durch ihr ungehindertes und einsames Umherirren kaum mehr in Frage.
} 
Ein weiterer Umstand steigert die Neugier des Lesers. Die Geschichte von Anio und Ilia steht am Ende eines Katalogs von Liebesgeschichten von Flüssen, d.h. der Leser erwartet im folgenden wiederum eine Liebesgeschichte. Nach den vorliegenden Zeugnissen war der Ilia-Mythos vor Ovid zum letzten Mal bei Ennius Gegenstand einer ausführlicheren Darstellung, also rund anderthalb Jahrhunderte früher. Die Details der Ilia-Erzählung bei Ennius sind leider kaum rekonstruierbar ${ }^{82}$. Es mag von der Verbindung Ilias mit Anio die Rede gewesen sein, aber speziell der Abschnitt des ersten Treffens der beiden wird kaum breit ausgemalt gewesen sein, jedenfalls sicher nicht in „elegischer" Manier. Indem er die Annäherung zwischen Ilia und Anio näher beschreibt, unternimmt Ovid es also - und ab Vers 49 zeichnet sich ab, daß die folgende Schilderung ausführlicher ausfallen wird -, ein für den Mythos nebensächliches und in der Literatur bisher kaum behandeltes Geschehen näher zu beschreiben, nämlich wie es überhaupt dazu kommt, daß Ilia im Fluß nicht umkommt, sondern daß der Flußgott sie zu seiner Frau macht. Das war neu, und man durfte gespannt sein, wie Ovid die Liebesgeschichte der Ilia und des Flußgotts ausmalen, und auf welche Weise er am Ende wieder an den traditionellen Mythos anknüpfen würde.

Der erzählende Teil gliedert sich in vier Abschnitte. Zunächst tritt Ilia auf, wobei die Voraussetzungen für ihr Auftreten und ihr Zustand kurz angedeutet werden (vv 49-50).

Im zweiten und ausführlichsten Teil (vv 51-66) erscheint Anio auf der Bildfläche, erblickt Ilia und wirbt in einer längeren Rede um ihre Gunst. Die Rede des Flußgottes läßt sich in zwei größere Abschnitte untergliedern. In den Versen 53-58 erkundigt er sich nach dem Grund für die offensichtliche Not Ilias. Zum zweiten Abschnitt leitet das „Schwellendistichon“ v 59 f über, wo der Flußgott - mehr zu sich selbst als zu Ilia gewandt - mit sich übereinkommt, die Frau zu trösten. Der Tröstungsversuch entpuppt sich dann im zweiten Abschnitt (vv 61-66) als ein Heiratsantrag ${ }^{83}$.

Der dritte Teil mit den Versen 67-78 zeigt die ablehnende Reaktion Ilias auf die Werbung des Flußgotts und ihre Verzweiflung, die in einen kürzeren Monolog mündet, worin sie den Klagen über ihr Schicksal Ausdruck verleiht. Im letzten Abschnitt (vv 79-82) wird beschrieben, wie Ilia sich verzweifelt in den Fluß stürzt, der sie dann $\mathrm{zu}$ seiner Frau macht. Bezeichnenderweise beruft sich Ovid erst bei dieser letzten Aussage (vv 81-82) auf nicht näher bezeichnete Gewährsleute (dicitur, v 82); ein weiteres Indiz dafür, daß die Ovid'sche Ausgestaltung des Mythos bis Vers 80 reicht, während das Distichon Vers $81 \mathrm{f}$ wieder mit der Tradition übereinstimmt.

\section{b) Adaption des Ilia-Mythos durch Ovid}

Mit der überraschenden Pointe ist Ovid da angekommen, wo er von Mythos' wegen ankommen mußte, und der anfangs aufgebaute Spannungsbogen wird aufgelöst: Durch ihren selbst verursachten Sturz in den Fluß wird Ilia die Gattin des Anio. Eine Frage

\footnotetext{
82 Vgl. dazu Skutsch 1985: 197 f, 202 u. 212 f. Das gilt noch mehr für die Behandlung des Stoffes bei Naevius (vgl. fr. III Ribbeck ${ }^{3}$ ).

${ }^{83}$ Mißverstanden wird die Passage bei Rimell 2006: 186 (,in Am. 3.6, for example, after being seduced by Anio, Ilia was so ashamed that she had broken her vows as a vestal virgin that she lifted up her dress and hurled herself suicidally into the river“); der Bruch der Gelübde als Vestalin geschah durch die Vereinigung mit Mars, nicht mit Anio.
} 
bleibt jedoch noch zu klären: Wie läßt sich die von Ovid gegebene Erzählung von Anio und Ilia in den bekannten Verlauf des Mythos einbetten? Denn ein ganz entscheidendes Detail der Ilia-Erzählung bleibt in dem hier ausgeführten Abschnitt ausgeklammert: Was passiert mit Romulus und Remus?

Abgesehen davon, daß Ovid eine Version des Mythos benutzt haben könnte, die uns nicht überliefert ist, gibt es drei näherhin in Frage kommende Möglichkeiten:

1. Das Schicksal der Kinder ist Ovid völlig unwichtig, da es ihm allein darauf ankommt, aus der in der Tradition kurz angedeuteten Tatsache, daß Ilia die Gemahlin des Anio wurde, eine in den Rahmen des Kataloges von Amores 3.6 passende Flußliebesgeschichte zu machen.

2. Ovid will mit seiner Version andeuten, daß Ilia sich gleich nach der Vergewaltigung durch Mars aus Verzweiflung über die Schande in den Fluß stürzt, und daß somit die Zwillinge im Fluß zur Welt kamen.

3. Ovid erwähnt patruique nefas delictaque Martis (v 49) in chronologisch umgekehrter Reihenfolge und meint mit delicta Martis zwar der Tradition gemäß die Vergewaltigung Ilias durch Mars, mit patrui nefas jedoch die Aussetzung und damit beabsichtigte Tötung der bereits geborenen Zwillinge und die Verstoßung der Ilia durch Amulius.

Die erste Möglichkeit wird von Lenz vertreten ${ }^{84}$. Es gibt aber m.E. einen Umstand, der es eher unwahrscheinlich macht, daß Ovid sich nicht um die Folgen seiner Darstellungsweise gekümmert hat. Dieser Umstand liegt darin begründet, daß es sich bei dem vorliegenden Mythos ja immerhin um den Gründungsmythos des römischen Volkes handelt, nicht um eine fast unbekannte und entlegene Sage aus dem griechischen Raum, die man leichter einmal im eigenen Sinn verändern konnte, ohne daß das mythologische Gebäude insgesamt ins Wanken kam. Die Frage, was denn nun mit Romulus und Remus passiert sei, ist nicht nebensächlich und war sicherlich jedem Römer präsent ${ }^{85}$.

\section{Ilia ist noch schwanger}

Will man sich also mit dieser ersten Möglichkeit nicht zufrieden geben, so muß man der Frage nachgehen, wie Ovid sich Anknüpfung und Fortgang seiner Erzählung gedacht hat. Die zweite Möglichkeit der Interpretation ${ }^{86}$ geht dahin, daß Ilia sofort nach der Vergewaltigung durch Mars in ihrer Verzweiflung über die ihr angetane Schmach davonläuft und ziellos umherirrt. Angesichts des Flusses entschließt die Schwangere sich zum Freitod und stürzt sich in die Fluten, der Flußgott rettet sie und macht sie in seinem Reich zu seiner Frau. Dort bringt Ilia unter dem Schutz des Anio Romulus und Remus zur Welt.

\footnotetext{
${ }^{84}$ Vgl. Lenz 1965: 223: „Daß Ilia von Mars die Zwillinge empfangen hat und daher im Fluß nicht eigentlich verschwinden kann, interessiert den von der Tradition unbeschwerten Dichter hier gar nicht. Ihm ist es nur um die Gestalt des Mädchens zu tun."

${ }^{85}$ Noch für Augustinus (civ. 3.5) war der Mythos so geläufig, daß er die „Mutter des Romulus“ nicht einmal namentlich nennt und ihr Schicksal nur streift. Vgl. auch Schubert 1992: 117: „Daß Ovid einfach unbekümmert über die Tatsache hinwegging, daß Ilia später die Mutter der Zwillinge wurde, ist ziemlich unwahrscheinlich."

${ }^{86}$ Spekulativ erwägt diese Möglichkeit ansatzweise Schubert 1992: 119, Anm. 310.
} 
Für diese Interpretation spricht, daß die von Ovid gezeichnete Verfassung der Ilia und ihr Monolog psychologisch gesehen nicht nur dem Zustand einer eben verstoßenen, sondern auch der Verfassung einer vor kurzem erst vergewaltigten Frau gut entsprechen würde: die Verzweiflung über die Schande, das Alleinsein-Wollen, das planlose Umherirren. Des weiteren würde dieser erschlossene Verlauf des Mythos eine ziemlich plausible Erklärung dafür liefern, warum die Zwillinge dem aufmerksamen Haß des Amulius entronnen sind: Amulius hätte von der Vergewaltigung durch Mars nichts bemerkt, und mit Ilias Selbstmord wäre für ihn die Gefahr, daß ihm aus dem Geschlecht des Numitor ein Rächer erwachsen könnte, ohnehin gebannt. Sicher vor Amulius hätten deshalb die Kinder der Ilia im Reich des Flußgottes zur Welt gebracht werden können; eine Erklärung, die in mythischer Diktion mindestens ebenso plausibel klingt, wie die Errettung der Knaben durch Wölfin und Specht ${ }^{87}$. Als Vorbild für diese Version könnte Kallimachos gedient haben, der in der vierten Hymne (vv 68 ff) die mit Apollon und Diana schwangere Leto auf der Suche nach einem Ort, der sie gebären lassen würde, den Fluß Peneios inständig bitten läßt, sein Wasser für die Geburt der Zwillinge bereitzustellen.

Problematisch an dieser Interpretation ist allerdings der Umstand, daß eine solche Version des Mythos sonst nirgends belegt ist. Konnte der Leser sich ohne einen näheren Anhaltspunkt erschließen, daß Ovid sich den Ablauf so und nicht anders vorgestellt hat? Dazu muß man zunächst einräumen, daß Veränderung und Neugestaltung eines Mythos durch den Dichter nicht selten waren. Die Metamorphosen sind voll von Beispielen, die zeigen, daß Ovid zwar auf die mythische Tradition zurückgreift, diese aber ganz eigenständig behandelt. Dazu spricht noch ein kontextuelles Argument für die zweite Interpretation. Es ist dies das dem Abschnitt von Anio und Ilia direkt vorausgehende Distichon v $43 \mathrm{f}$. Zunächst fällt auf, daß mit dem Tyro-Mythos ein enger Bezug zum folgenden hergestellt wird durch die starke Ähnlichkeit des Sagenverlaufs, was hier sicherlich kein Zufall ist ${ }^{88}$ : Tyro ( Ilia) wird von Poseidon ( Mars) in Gestalt des Flußgottes Enipeus ( Anio) vergewaltigt und bringt die Zwillinge Pelias und Neleus ( $\sim$ Romulus und Remus) zur Welt ${ }^{89}$. Des weiteren ist auffällig, daß Ovid bereits bei diesem relativ bekannten Mythos verändernd eingreift, indem er statt Poseidon den Flußgott Enipeus mit Tyro zusammenbringt ${ }^{90}$. Es könnte sein, daß Ovid in Anlehnung an den Tyro-Mythos ebenfalls bei der Erzählung von Anio und Ilia das Schicksal der Zwillinge mit einem Flußgott verbunden wissen will, und die vorgeschaltete TyroSage wäre dann ein Hinweis darauf, daß der Dichter mit seiner Version der Ilia-Sage dem Flußgott Anio die rettende Funktion zuschreiben will, die der Tradition nach die Wölfin und der Specht innehatten ${ }^{91}$.

\footnotetext{
${ }^{87}$ Vgl. etwa Plutarch Rom. 3-4.

${ }^{88} \mathrm{Vgl}$. auch die formal ganz ähnlich gestalteten Verse 44 und 48.

${ }^{89} \mathrm{Vgl}$. Homer Od. $11.235 \mathrm{ff}$.

${ }^{90}$ Ausgehend von diesem Austausch der Götter könnte man spekulieren, ob Ovid mit seiner Ilia-Erzählung vielleicht andeuten wollte, daß es zumindest unsicher ist, ob Romulus und Remus nun von Mars und nicht vielmehr von Anio gezeugt wurden, um sich - was er offen nicht hätte wagen können - damit lustig zu machen über die Herleitung des römischen Volkes von dem großen Kriegsgott Mars. Allerdings würde eine solche Interpretation mythischem Denken wohl kaum entsprechen, welches ganz selbstverständlich davon ausgeht, daß die „Umarmung“ eines Gottes zu Nachwuchs führt. So heißt es schon bei Homer $O d$.

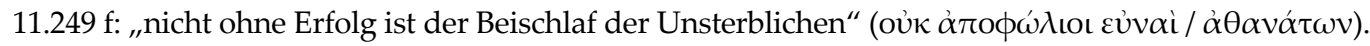

${ }^{91}$ Als psychologisches Argument führt des weiteren Schubert 1992: 119 mit Anm. 309 an, daß es eher wahrscheinlich sei, daß eine Schwangere ins Wasser geht als eine Mutter (dort auch Literatur dazu). Es liegt je-
} 


\section{Romulus und Remus sind bereits geboren}

Für die dritte Möglichkeit entscheidet sich Brandt'92; er interpretiert in seiner Amores-

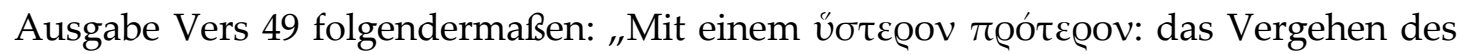
Mars, nämlich sie, die Vestalin, zur Mutter gemacht zu haben ..., geht dem nefas patrui voraus; patruus ist Amulius, sein nefas die Ausstossung der Ilia ... und der grausame Befehl, die Zwillinge im Flusse umkommen zu lassen. ${ }^{\prime 93}$ Nach Brandt wäre also Ilia erst mit den Zwillingen niedergekommen, dann hätte Amulius die Kinder zu töten versucht und sie verstoßen, so daß sie daraufhin verzweifelt umherirrend an das Ufer des Anio gelangte. Gegen diese Interpretation steht zunächst die Tatsache, daß auch diese Version des Mythos sonst nirgend belegt ist. Selbst Dionysios von Halikarnassos und Plutarch, die ja eine erstaunliche Akribie an den Tag legen, was das Aufzählen von Varianten der Gründungssage Roms angeht, erwähnen nicht, daß Ilia von Amulius nur verstoßen worden sein könnte ${ }^{94}$. Wie bereits oben ausgeführt, spricht dies aber nicht gegen die Möglichkeit einer eigenständigen Bearbeitung durch Ovid.

Ein weiteres Problem dieser Interpretation liegt darin, daß nach der herkömmlichen Überlieferung jeder Leser unter nefas patrui - zeitlich ganz richtig vor delicta Martis - zunächst die Vertreibung Numitors, die Tötung von dessen Sohn und die Zwangsweihe der Ilia durch Amulius verstand. Es ist also zumindest problematisch, davon auszugehen, daß Ovid, ohne einen weiteren Anhaltspunkt zu geben als die Auslassung des Schicksals der Zwillinge, von seinen Lesern erwartete, daß sie unter nefas patrui - in zeitlicher Verkehrung vor delicta Martis - nun plötzlich die Verstoßung der Ilia durch Amulius verstehen sollten. Die Frage ist nun, ob sich in der Überlieferung Anhaltspunkte finden lassen, die dem damaligen Leser ohne nähere Erklärung

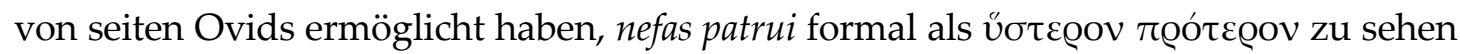
und inhaltlich darunter die Aussetzung der Zwillinge und die Verstoßung der Ilia zu verstehen.

Hier fällt auf, daß die Quellen in der Regel davon ausgehen, daß die Bestrafung der Ilia nicht sofort im Anschluß an die Vergewaltigung, sondern erst nach der Geburt der Zwillinge, also ein dreiviertel Jahr später, stattfindet ${ }^{95}$. Man läßt sich also irreleiten, wenn man davon ausgeht, daß Ilia selbstverständlich gleich nach der Verletzung ihrer Keuschheit durch Mars zur Rechenschaft gezogen wurde. So wie Callisto in den Metamorphosen erst dann aus dem Gefolge der Diana verstoßen wird, als ihre "Schande" - nämlich von Jupiter vergewaltigt schwanger zu sein - nach neun Monaten beim Baden offenbar wird ${ }^{96}$, so wird auch Ilias „Schande“ erst mit der Geburt der Zwillinge offenbar und geahndet. modo Vestalis (v 75) heißt somit nicht, wie man es interpretieren müßte, wenn man von dem zweiten Lösungsvorschlag ausgeht, daß die Verstoßung Ilias nach der Vergewaltigung durch Mars, sondern daß ihre Verstoßung nach der Geburt der Zwillinge nur kurze Zeit zurückliegt. Von der konkreten Art der Bestrafung läßt

doch nahe, daß es Ovid bei seiner Version nicht um psychologische Wahrscheinlichkeiten, sondern vor allem um die witzige Pointe ging.

${ }^{92}$ Dieser Interpretation schließt sich außerdem Latta 1963: 11 an.

${ }^{93}$ Brandt 1911: $159 \mathrm{f}$.

${ }_{94}^{4}$ Die übliche Strafe für unkeusche Vestapriesterinnen war vielmehr das lebendige Begraben (vgl. bei Ovid selbst fast. 6.457-460).

${ }^{95}$ Vgl. Fabius Pictor bei Auctor De orig. gent. Rom. 20.2, Livius 1.4.2-3, Servius Comm. in Verg. Aen. 1.273.

${ }^{96} \mathrm{Vgl}$. Ov. met. $2.409 \mathrm{ff}$, besonders 453 und 462-465. 
sich relativ einfach abstrahieren; wenn also Ovid Ilia hier gegen die Tradition als Ausgestoßene und nicht als Gefangene oder Getötete vorstellt, so war doch trotz der zeitlichen Umkehrung von patruique nefas delictaque Martis dem Leser der Ablauf des My-

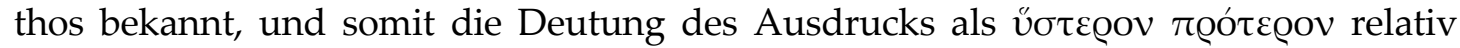
naheliegend. Mit Hilfe der zeitlichen Umkehrung wird stilistisch von Ovid überdies erreicht, daß unter nefas patrui sowohl das vor der Vergewaltigung als auch das danach der Ilia angetane Unrecht durch Amulius verstanden werden kann.

Daß Ovid sich den Hergang des Mythos mit großer Wahrscheinlichkeit so vorgestellt hat, ergibt sich zuletzt auch aus einem werkimmanenten Vergleich. Fasti $3.9 \mathrm{ff}$ beschreibt der Dichter, wie Ilia von Mars im Schlaf vergewaltigt wird, ohne daß diese es bemerkt ${ }^{97}$. Aus fast. 3.45-48 geht hervor, daß Ilia bei der Geburt der Zwillinge offensichtlich noch im Dienst der Vesta steht; erst nach der Geburt erfährt Amulius davon und schreitet ein ${ }^{98}$. Am ehesten ist also wohl dieser dritten Lösungsmöglichkeit zuzustimmen, nach der sich die Szene zwischen Anio und Ilia erst nach der Geburt der Zwillinge Romulus und Remus abgespielt hat ${ }^{99}$.

\section{c) Ovid'sche Polysemie und Psychologie: Über lüsterne Flüsse}

In den folgenden zwei Kapiteln soll es darum gehen, wie Ovid mit dem tradierten Mythos umgeht. Es wird sich zeigen, daß er den Stoff in dreierlei Hinsicht bearbeitet und dadurch regelrecht "verfremdet", und zwar durch a) subtile Erotisierung, b) Psychologisierung und c) eine feine Ironisierung der Vorlage.

Der erreichte Effekt ist dadurch um so stärker, als diese drei Elemente dem Mythos ursprünglich gänzlich fremd sind. Wenn es um die Vereinigung von Menschen und Göttern geht, sind Mythen nicht erotisch, sondern genealogisch oder aitiologisch interessiert; das Faktum der Vereinigung ist entscheidend, nicht das Wie. Ebenso ginge man völlig an einem adäquaten Verständnis des Ilia-Mythos vorbei, wenn man annähme, es ginge in ihm um eine psychologisch einfühlsame Schilderung des bei einer vergewaltigten Frau beobachtbaren Opfersyndroms. Wichtig sind hier soziale Regeln und Tabus, die zu einer exemplarischen Erzählung verdichtet werden, nicht Opferpsychologie. Und natürlich ist der Gründungsmythos des römischen Volkes nicht eine Erzählung, die darauf angelegt ist, daß man sie mit einem leichten Augenzwinkern und einem zweideutigen Lächeln in den Mundwinkeln liest, sondern es handelt sich im Grunde natürlich um eine zutiefst ernste und identitätsstiftende Angelegenheit.

Ovid trägt diese fremden Elemente in den Mythos hinein, und er ist hierin ein Meister. Die Erzählung gerät bei ihm weder zu einer platten Sexgeschichte, noch zu einer reinen psychologischen Studie und auch nicht zum bloßen Klaumauk. Er verfremdet, aber er verzerrt nicht und wird nie einseitig. Das mag neben seinem literarischen Talent auch noch einen anderen Grund haben: Vorsicht; denn ein solch freierer Umgang mit dem römischen Gründungsmythos sorgte sicher nicht in allen Kreisen für

\footnotetext{
${ }^{97}$ et sua diuina furta fefellit ope, Ov. fast. 3.22. Der Umstand, daß Mars Ilia im Schlaf vergewaltigt, ist wiederum eine Version Ovids, die in der traditionellen Überlieferung nicht erwähnt wird.

98 Ov. fast. 3.49-51.

${ }_{99}$ Vgl. dazu auch Connors 1994: 109; Boyd 1997: 215 (die selbstverständlich für Ilia von einer „condemnation to drowning" ausgeht, die aber antik nirgends belegt ist).
} 
Begeisterung, und bei Bedarf konnte Ovid unschuldig mit der Schulter zucken und behaupten, er habe alles doch eigentlich ganz ernst gemeint.

Zunächst zur Erotisierung des Mythos, die untrennbar mit dessen Psychologisierung verknüpft ist. Bereits Altheim schreibt in seiner Römischen Religionsgeschichte treffend ${ }^{100}$ :

„Unter Ovids Händen ergreift ein Prozeß der Erotisierung alles, dessen er habhaft wird. [...] Unter seiner Berührung erblüht, was zuchtvoll und verhalten war, in üppiger Fülle. Es geht ins Farbige, Schillernde, Weibliche, Verführerische ..."

Dieser „Prozeß der Erotisierung“ findet auch hier statt. Die im Flußkatalog vor der Erzählung von Anio und Ilia angeführten Beispiele sind zum Teil so entlegen, daß man über die dahinterstehenden Mythen nichts weiß ${ }^{101}$. Die bekannteren Beispiele führen nicht zwangsläufig auf eine erotische Situation hin; so endet beispielsweise der Kampf des Achelous mit Herakles um Deïanira lediglich mit einer Niederlage des Flußgottes $^{102}$. Andere wiederum münden in eine erotische Situation, wie der unmittelbar vor dem Abschnitt über Anio und Ilia angeführte Mythos von Enipeus und Tyro. Allen Beispielen aber ist unabhängig vom Ausgang gemeinsam, daß sie von einer heftigen Liebe des jeweils männlichen Parts zeugen, die von Seiten der Geliebten nicht unbedingt erwidert wird. Die Grundsituation der römischen Liebeselegie wird von Ovid auf die Liebesgeschichten von Flüssen übertragen: glühende Verehrer und Liebhaber auf der einen Seite, widerstrebende Frauen auf der anderen. Den Mythos interessiert ursprünglich nicht die Art und Weise der gegenseitigen Zuneigung, sondern das Faktum und besonders das Ergebnis einer solchen Verbindung. Allein schon durch die Einbettung der Mythen in ein Liebesgedicht, aber auch durch die elegische Diktion bewirkt Ovid eine Akzentverschiebung103: aus göttlichen Urvätern und Stammgründern, aus den Gipfelpunkten alter Ahnenreihen werden lüsterne elegische Liebhaber ${ }^{104}$.

Besonders deutlich wird dies bei dem länger ausgeführten Beispiel von Anio und Ilia. Liest man den Abschnitt mit den Augen eines Lesers, der das Gedicht bereits kennt und der um den Ausgang der Erzählung - Ilia landet im torus des Anio - schon weiß, so wird von Anfang an deutlich, daß Ovid hier eine erotische Spannung aufbaut ${ }^{105}$. Schon die Darstellung des Anio in den Versen 45-46 ist bewußt doppeldeutig formuliert. Natur- und Landschaftsschilderungen werden bei Ovid in der Regel gezielt eingesetzt und haben oft die Funktion, menschliche Zustände und Befindlichkeiten widerzuspiegeln. So betritt etwa die jungfräuliche Callisto einen Hain, den noch niemals Äxte berührten, in dem sie dann von Jupiter vergewaltigt wird ${ }^{106}$; die Schilderung der

\footnotetext{
${ }^{100}$ Altheim 1953: 257.

${ }^{101}$ Vgl. zu den einzelnen Stellen die kurzen Kommentare bei Brandt 1911: 157-159 und Lenz 1965: $221 \mathrm{f}$.

${ }^{102}$ Ov. am. 3.6.35-38. Ovid beschreibt ausführlich und nicht ohne Elemente der Komik diesen Ringkampf später in met. $9.1 \mathrm{ff}$.

${ }^{103} \mathrm{Vgl}$. beispielsweise pallidus in alqa (3.6.25), vultus rapere (3.6.28), capere alqm (3.6.33), flamma (3.6.41). Zu Doppeldeutigkeiten im Flüssekatalog vgl. auch Eggers 1984: 184-188 und 233 f.

${ }^{104}$ Dabei geht es immer um die Erotik zwischen Mann und Frau; auf diesem Hintergrund ist die Deutung von Rimell 2006: 200 zu am. 3.6 als homoerotisches Geschehen zwischen dem Sprecher und dem Fluß abwegig (,the poem becomes homoerotic, even masturbatory“).

105 Vgl. dazu auch Schubert 1992: 118, wo die Erotik schon daran festgemacht wird, daß Ovid auf das ungepflegte Äußere der Ilia hinweist, was dann den Flußgott auf den Plan ruft. Vgl. auch De Caro 2003: 175: „Il mito di Ilia forma un archetipo della mitologia ovidiana, colorato in senso erotico ..."

106 Ov. met. $2.409 \mathrm{ff}$, besonders v 418.
} 
zum Lustwandeln einladenden Umgebung eines Sees entspricht der sinnlichen Natur der dort wohnenden Nymphe Salmacis, die Hermaphroditus zu vergewaltigen versucht ${ }^{107}$. Gleiches gilt für die Beschreibung des Anio in Amores 3.6. Auch wenn das Epitheton pomifer für Anio möglicherweise lediglich der literarischen Tradition verpflichtet ist ${ }^{108}$, stellt die Schilderung der Natur bereits eine Andeutung der Sinnlichkeit des Flußgottes dar. Wie der Fluß reißend dahinfließt (v 51 und v 80: rapidis ... ab undis und in rapidas ... aquas), so ist der Gott selbst hitzig und leidenschaftlich (animosus v 51). Es gibt ferner Belege dafür, daß arvum übertragen für das Geschlechtsorgan der Frau verwendet werden kann ${ }^{109}$, so daß möglicherweise auch der Ausdruck arva rigas (v 46) für das Publikum einen erotischen Unterton hatte ${ }^{110}$.

In dem Partizip volutans (v 45) und in dem Adjektiv raucus (v 52) zeigt sich besonders deutlich die Absicht Ovids, zu bewußt doppeldeutigen Formulierungen zu greifen, da man beide Ausdrücke sowohl in erotischem Sinn auf die Person des Flußgottes als auch gewissermaßen ",neutral“ auf die Natur des Wassers beziehen kann ${ }^{111}$. So läßt sich mit dem Partizip uolutans nicht nur das Sich-Fortwälzen des Wassers, sondern auch das lustvolle Sich-hin-und-Herwälzen im Bett beschreiben. Das geht aus einer Stelle bei Properz hervor, wo die Geliebte dem eifersüchtig kontrollierenden Liebhaber ihre Unschuld und Treue beteuert ${ }^{112}$ :

apparent non ulla toro uestigia presso, signa uolutantis nec iacuisse duos.

„Du siehst hier keinerlei Spuren auf zerdrücktem Bett, Zeichen eines Sich-Wälzens, und nicht haben hier zwei gelegen.“

Mit rauca uoce kann sowohl das dumpfe Rauschen der Wellen als auch die vor sexueller Erregung heisere Stimme gemeint sein ${ }^{113}$. Eine solche doppeldeutige Verwendung des Adjektivs raucus begegnet bei Ovid selbst in den Metamorphosen, wo Alpheus die scheinbar harmlose Frage quo properas? an die badende Arethusa richtet, wobei allein der lüstern-rauhe Ton (rauco ore) ihr sofort klarwerden läßt, was sie erwartet, und sie zu panischer Flucht veranlaßt $\mathrm{t}^{114}$.

Wenn des weiteren Ovid in der Anrede an Anio Ilia mit der Bemerkung einführt, sie habe dem Flußgott „gefallen“ (Ilia cui placuit, v 47), so konnte der gebildete Leser sich an eine Stelle erinnert fühlen, in der Tibull von Ilia bereits ganz ähnlich gesprochen

\footnotetext{
${ }^{107}$ Ov. met. 4.285 ff, besonders vv 298-301 u. v 314. Die Beispiele ließen sich vermehren; vgl. dazu v.a. die Studie von Segal 1969, oder die Hinweise auf Ov. am. 1.5 und 3.1 bei Hunter 2006: 29, mit Anm. 69 (s. ebd. 29: „Ovid typically leaves nothing to chance.“).

108 Vgl. etwa bei Properz 4.7.81.

${ }^{109}$ Vgl. etwa Lucr. 4.1107: atque in eost Venus ut muliebra conserat arva; Anth. Lat. 712.17: Arentque sulcos molles aruo Venerio, und - freilich spät - in einem Hymnus auf die mentula bei Maximian 5.119: haec si gemma micans rutilum non conserat aruum, / alternum fallax mortiferumque genus.

${ }^{110} \mathrm{Vgl}$. Adams 1982: 24: „The Latin sexual language is full of images which may be called 'agricultural' or 'rustic' ... in particular various words for the cunnus and culus: ager, agellus, saltus, arvum, sulcus ..."

111 Vgl. Cicero De orat. 1.259 und Verg. Aen. 6.327.

112 Prop. 2.29.35 f.

${ }^{113}$ Wenn Eggers 1984: 134 mit Anm. 300, rauca ora als Synekdoche versteht, dann erhebt Anio seiner Ansicht nach nicht nur das Haupt aus dem Wasser, sondern erscheint in seiner vollen Gestalt; diese Annahme ist jedoch nicht zwingend.

${ }^{114}$ Ov. met. 5.600: „quo properas?” iterum rauco mihi dixerat ore. $\mathrm{Zu}$ animosus und raucus vgl. auch Donini 1969: 218.
} 
hat. Bei Tibull ist es freilich nicht Anio, sondern Mars, dem zu "gefallen“ Ilia bestimmt ist:

te quoque iam uideo, Marti placitura sacerdos

Ilia, Vestales deseruisse focos;

"Auch dich sehe ich schon, Priesterin, der es bestimmt ist, Mars zu gefallen,

Ilia, wie du den Herd der Vesta verlassen hast;"

und wie es bei Mars nicht nur bei dem "gefallen" geblieben ist, so wird auch hier am Ende Ilia dem Anio nicht nur "gefallen“, sondern ihm auch im prägnanten Sinn „gefällig sein ${ }^{\prime 115}$.

Auch der zunächst harmlos wirkende Ausdruck hanc Anien ... uidit (v 51) zielt auf ein Sehen ab, in dem zugleich das Begehren und die Bereitschaft zum Handeln liegt. Die Vergewaltigung der Ilia durch Mars beschreibt Ovid später kurz und bündig so ${ }^{116}$ :

Mars uidet hanc uisamque cupit potiturque cupita.

„Mars erblickt sie; die Erblickte begehrt er und der Begehrten bemächtigt er sich."

Es ist das gleiche Schema, nur daß Mars seine Zeit nicht wie Anio mit Reden vergeudet, sondern gleich über die Schlafende herfällt. Ganz parallel in der Formulierung zu Amores 3.6.50 f sind des weiteren zwei Verse im 6. Buch der Fasti, wo Ovid den Raub der Proserpina erzählt:

errabat nudo per sua prata pede

„mit nacktem Fuß irrte sie über ihre Wiesen“

heißt es zunächst von Proserpina (fast. 6.426; vgl. am. 3.6.50: errabat nudo per loca sola pede); und dann (fast. 6.445):

hanc uidet et uisam patruus uelociter aufert ...

"diese erblickt der Onkel und die Erblickte raubt er im $\mathrm{Nu}$..."

Wieder sind Sehen und die In-Besitznahme der begehrten Frau zusammengeschweißt zu einer einzigen Handlungssequenz.

Ilia gefällt in Amores 3.6 trotz oder gerade wegen ihres äußerlich unordentlichen Zustandes. Auch das ist ein elegischer Topos ${ }^{117}$; der Leser der Amores ist bei der Elegie 3.6 schon längst mit diesem Phänomen vertraut gemacht. So beschreibt Ovid in Elegie 1.7, wie er seiner puella die Haare zerrauft ${ }^{118}$ und die Wangen zerkratzt hat ${ }^{119}$ und wie schön sie ihm gerade mit ihren zerrauften Haaren erscheint ${ }^{120}$. Eben in dieser Elegie liegt noch ein weiterer Bezug zu Amores 3.6, wenn Ovid schreibt, er habe sich hinreißen

\footnotetext{
115 Tibull 2.5.51 f. Ovid selbst schreibt fast. 4.55 ebenfalls placet Ilia Marti. In den Metamorphosen eine ähnliche Formulierung in der Daphne-Geschichte: cui placeas, inquire tamen ... (met. 1.512).

116 Ov. fast. 3.21.

117 Vgl. dazu auch Cunnighan 1958. Schon in der Antike ist Ovids Neigung für kleine Schönheitsfehler aufgefallen, vgl. Sen. contr. 2.2.12.

118 Ov. am. 1.7.11: ... digestos potui laniare capillos, vgl. am. 3.6.48.

${ }^{119}$ Ov. am. 1.7.49 f: ... sustinui ... ferreus ingenuas ungue notare genas; vgl. die wörtlichen Anklänge in am. 3.6.48: ungue notata genas.

${ }^{120}$ Ov. am. 1.7.11-13.
} 
lassen „wie ein Gebirgsbach“ (tumidi ritu torrentis agebar) ${ }^{121}$; wieder der Griff zur Naturschilderung, um menschliche Verhaltensweisen zu charakterisieren. In Fasti 3.9 ff, wo Ovid die Vergewaltigung der Ilia durch Mars beschreibt, spielt ebenfalls die Verlockung eine wichtige Rolle, die von der zerzausten und lässig bekleideten Frau ausgeht ${ }^{122}$ :

\section{fessa resedit humo uentosque accepit aperto} pectore turbatas restituitque comas.

„Erschöpft hat sie sich auf den Boden gesetzt und die Winde empfangen mit offener Brust und die zerzausten Haare wieder in Ordnung gebracht."

Auch Trauer und Furcht können der puella einen besonderen Reiz verleihen. Eine Parallele zu Ilia, die weinend zu Boden blickt ( $\mathrm{v} 67 \mathrm{f})^{123}$

dixerat; illa oculos in humum deiecta modestos

spargebat tepido flebilis imbre sinus,

„Sprachs. Jene, zu Boden die sittsamen Augen gesenkt,

Netzte mit warmen Tränen weinend die Brust, "

bietet Amores 2.5.43 f:

Spectabat terram: terram spectare decebat.

Maesta erat in uultu: maesta decenter erat.

„Sie blickte zur Erde: das Blicken zur Erde stand ihr gut.

Traurig war ihr Gesicht: in ihrer Trauer war sie anziehend."

Noch wörtlicher ist der Anklang in Amores 2.4, der "Registerarie "124 unter den Elegien, wo Ovid vorgibt, sich für alle Frauen begeistern zu können; Vers $11 \mathrm{f}$ schreibt er:

Siue aliqua est oculos in me deiecta modestos,

uror ...

„Seis, daß eine auf mich die sittsamen Augen gesenkt hat, ich brenne ..."

Wichtig ist zum Vergleich hier auch ars 1.126, wo nach Ovid vielen Sabinerinnen beim Raub selbst die Furcht recht gut steht, und ars 1.534, wo die auf Naxos von Theseus zurückgelassene Ariadne gerade in ihrer Verzweiflung Bacchus' Gefallen findet. Besonders in letzterem Beispiel liegen zum Teil wörtliche Parallelen zur Schilderung der Ilia in Amores 3.6 vor.

Vor diesem Hintergrund der subtilen Erotisierung muß man auch die Rede des Anio lesen, die dieser an Ilia richtet. Ovid versucht, sich in die Situation der verstoßenen Frau hineinzuversetzen: Nichts mehr sehen und hören wollen, fliehen, egal wohin, allein sein, ganz Beschämung und Schmerz (vv 47-50; 53-58) ${ }^{125}$. In diesem Zustand der Verzweiflung erblickt Anio Ilia (v 51), und er versucht, sich ihr zu nähern, indem er

\footnotetext{
${ }^{121}$ Ov. am. 1.7.43.

${ }^{122}$ Ov. fast. $3.15 \mathrm{f}$.

${ }^{123}$ Mehr aus Gründen der Kuriosität sei hier vermerkt, daß Donini 1969: 220, dieses Distichon zu den besten zählt, die Ovid je geschrieben hat.

124 Vgl. Woytek 1995: 428 f, Anm. 54; Schmitzer 2001: 36 mit Anm. 34.

${ }^{125} \mathrm{Zu}$ den Gebärden des Schmerzes v 48 vgl. auch Tibull 1.1.68.
} 
zunächst die Rolle des liebevoll Tröstenden spielt. Man könnte das, was Anio hier betreibt, als eine „psychologische Vergewaltigung“ bezeichnen. Der Täter greift sein Opfer nicht mit brutaler Gewalt an und macht es nicht kraft seiner körperlichen Überlegenheit zum Objekt seines Willens, sondern er nützt geschickt die Not seines Opfers aus, indem er abwartet, bis die Verzweiflung ihm, der allein sich dem Opfer in seinem Unglück noch zuwendet, dieses von selbst in die Arme treibt ${ }^{126}$. Daß die Rolle des Tröstenden eine gute Ausgangsbasis ist, um eine unglückliche Frau für sich zu gewinnen, zeigt auch der Mythos von Dionysos und Ariadne, der für die Ovid'sche Neukonstruktion des Ilia-Mythos als Vorbild gedient haben könnte. Dionysos nimmt sich der auf Dia von Theseus verlassenen Frau an und heiratet sie ${ }^{127}$.

Scheinbar besorgt erkundigt sich Anio nach dem Grund des ängstlichen Umherirrens $^{128}$. Dabei verwendet er jedoch einen Ausdruck, der auch in sexuellem Kontext gebraucht werden kann und damit der Frage einen schwülen Unterton verleiht (3.6.53): quid nostras ... teris anxia ripas?, wörtlich: „Was reibst du ängstlich unsere Ufer ...?“ Bei Properz werden einmal die sexuellen Ausschweifungen der Kleopatra gegeißelt und sie selbst in diesem Zusammenhang als eine "zwischen ihren Dienern 'geriebene' Frau" (famulos inter femina trita suos) bezeichnet ${ }^{129}$, und ein weiterer Beleg für diese Verwendungsweise von terere findet sich bei Petron ${ }^{130}$.

Nachdem vier Fragen, auf die später noch einzugehen sein wird, unbeantwortet geblieben sind, bricht Anio in eine Sentenz des Mitleids aus (v $59 \mathrm{f}$ ) ${ }^{131}$. Beachtenswert ist der kleine, aber psychologisch bedeutsame Umstand, daß Anio diese Worte mehr an sich selbst als an die umherirrende Ilia richtet. Er führt quasi ein kurzes Selbstgespräch bzw. richtet den Appell an sich, daß man solch einem Unglück abhelfen müsse, und legitimiert dadurch vor sich selbst seinen Annäherungsversuch als einen geradezu notwendigen Akt der Tröstung. In diesem Sinne fährt Anio mit Beschwichtigungen und Versprechungen fort, die seiner Ansicht nach Ilia über das ihr geschehene Übel hinweghelfen können (vv 61-66). Formal wird die beschwichtigende Art des Flußgottes durch Wiederholungen unterstrichen: Ilia, pone metus ... Ilia, pone metus (v $61 \mathrm{f})^{132}$. Die Struktur - Aufruf durch den Gott, die Furcht abzulegen, darauf folgender „Heiratsantrag" und Aussicht auf eine „leitende Stellung“ und Geschenke - kehrt genauso in ars 1.556-558 bei Dionysos und Ariadne wieder:

pone metum: Bacchi, Cnosias, uxor eris.

munus habe caelum: caelo spectabere sidus.

saepe reges dubiam Cressa Corona ratem.

\footnotetext{
${ }^{126}$ Vgl. Bretzigheimer 2001: 179: „Anio entspricht einem elegischen Liebhaber, der Ilias Ausweglosigkeit als Chance für eine Werbung nutzt ..."

${ }^{127}$ Vgl. Ov. met. 8.176 f: desertae et multa querenti / amplexus et opem Liber tulit ...

${ }^{128}$ Der Umstand, daß Anio anfangs Ilia namentlich und ihre Abstammung bezeichnend anspricht (v 54), mußte nach Donini 1969: 219 dazu führen, daß Ilia sich geschmeichelt fühlte. Es ist jedoch fraglich, ob die Verzweifelte das so zu schätzen wußte. Hier handelt es sich wohl eher um ein Einschmeicheln als um ein Schmeicheln.

${ }^{129}$ Prop. 3.11.30.

${ }^{130}$ Petron 87.8: Utcumque igitur inter anhelitus sudoresque tritus quod uoluerat accepit, rursusque in somnum decidi gaudio lassus.

${ }^{131}$ Ein Gemeinplatz in der Literatur (so schon Homer Od. 23.103), vgl. auch Tibull 1.1.63 f. Bei Ovid in den Amores bereits in Buch 1.11.9; des weiteren met. 9.614 und 7.33, wo er in lustiger Übertreibung die üblichen silices durch scopuli ersetzt. Vgl. Wilhelm 1933: 170.

${ }^{132} \mathrm{Vgl}$. auch die Wiederholung tu centum aut plures ... nam centum aut plures (v $\left.63 \mathrm{f}\right)$. S. dazu den Kommentar zu am. 3.6.62 f von Marg \& Harder 1962: 222.
} 
„Laß deine Furcht: die Gattin des Bacchus, Frau aus Knossos, wirst du sein.

Als Geschenk nimm den Himmel: am Himmel wird man dich als Gestirn erblicken.

Oft wirst du als kretischer Kranz das unsichere Schiff lenken."

Um, wie Anio glaubt, seiner Werbung eine noch größere Wirkung zu verleihen, streicht er dabei noch seine Größe und seinen Reichtum heraus: Sein Königspalast steht Ilia zur Verfügung (v 61), über hundert und sogar noch mehr Nymphen herrscht er (v 64) und Ilia wird noch reichere Gaben erhalten, als er ihr jetzt verspricht ( $v 66)^{133}$. Aber auch hier verrät sich im Unterton wieder das, worauf eigentlich Anio es abgesehen hat. Schon der Hinweis auf die über hundert Nymphen, die flumina nostra tenent, ist etwas doppeldeutig, kann er doch einerseits zwar ganz harmlos die Tatsache meinen, daß über hundert Nymphen im Fluß des Gottes wohnen, andererseits aber auch andeuten, daß Anio über diese Nymphen wie über einen Harem verfügt. So gebraucht Tibull 1.5.39 und 2.6.52 tenere im Sinn von "eine Geliebte in Armen halten“. Bei Ovid selber heißt es direkt in der folgenden Impotenz-Elegie in Bezug auf die puella ${ }^{134}$ :

hanc tamen in nullos tenui male languidus usus.

„Und doch habe ich diese schlaff im Arm gehalten, ohne Nutzen davon zu haben."

Eine weitere versteckte Doppeldeutigkeit bietet der Schluß der Rede des Anio (v 66). Entscheidend ist bei der Interpretation dieser Passage, daß man Elegie 2.14.13 f zum Vergleich heranzieht, wo es heißt: Quis Priami fregisset opes, si numen aquarum
iusta recusasset pondera ferre Thetis?

„Wer hätte je die Macht des Priamos gebrochen, wenn die Meeresgöttin

Thetis sich geweigert hätte, die Lasten vollständig auszutragen?“

pondera ferre, die Umschreibung für das Schwangersein der Thetis mit Achill, ist parallel zu lesen mit der Wendung munera ... feres in Amores 3.6.66, wodurch die Aussage, daß Ilia noch reichere Geschenke als versprochen "tragen“ wird, ihre unschuldige Allgemeinheit verliert ${ }^{135}$. Daß diese beiden Passagen aufeinander bezogen werden konnten, wird noch durch den Umstand bekräftigt, daß der Dichter in Amores 2.14 direkt im Anschluß an das Distichon, das von Thetis handelt, das Beispiel der Ilia anführt ${ }^{136}$. Dabei ist der Name Ilia nur durch ein Wort von pondera ferre im vorigen Vers getrennt; ein Umstand, der beim Leser die assoziative Verbindung von 3.6.66 und 2.14.14 erleichtert und begünstigt. Zusätzlich wird mit munera ... uberiora feres inhaltlich ein Bogen zu pomifer arua rigas (v 46), der anfänglichen Charakterisierung des Flusses, geschlagen ${ }^{137}$.

${ }^{133}$ Vgl. dazu etwa auch das Prahlen Apollos, während er Daphne verfolgt, Ov. met. 1.515 ff. Dazu ebenfalls der Kommentar zu Ov. am. 3.6.63 f von Marg \& Harder 1962: 222. In diesen Zusammenhang gehört auch die Doppeldeutigkeit des Ausdrucks ne me sperne, precor, tantum (v 65), den man auch als Prahlerei des Anio auffassen kann, vgl. dazu unten Anm. 183.

134 Ov. am. 3.7.3.

${ }^{135}$ Zur Verwendung von ferre bei Schwangeren vgl. Corpus Tibullianum 3.4.90 und Ovid met. 3.268 f; 8.133; 9.287; 10.470 .

136 Ov. am. 2.14.15: Ilia si tumido geminos in ventre necasset ...

${ }^{137}$ Auch munus mit sexueller Konnotation ist anderweitig belegbar, so etwa bei Petron 87.8: et non plane iam molestum erat munus. Vgl. auch Stroh 1979: 350 mit Anm. 103. 
Die Reaktion der Ilia ist Trauer und Angst. Stumm in ihrem Schmerz versunken, scheint sie nicht viel von dem mitbekommen zu haben, was Anio sprach. Nur ein dumpfes Gefühl erneuter Bedrohung steigt in ihr auf, ihr Instinkt drängt sie zur Flucht, aber benommen, vor Angst wie gelähmt, bleibt sie stehen ${ }^{138}$. Dreimal will sie fliehen, aber die Angst lähmt (v 69: ter molita fugam ter ad altas restitit undas); wieder findet diese Stelle eine Parallele im Ariadne-Mythos, ars 1.552, wo es heißt:

terque fugam petiit, terque retenta metu est.

„Dreimal wollte sie fliehen, dreimal wurde sie von der Furcht daran gehindert.“139

Die Antwort der Verängstigten zeigt, daß sie zwar die Bewerbung des Anio irgendwie zur Kenntnis genommen hat, aber diese Erkenntnis kommt ihr kaum voll zu Bewußtsein oder wird zumindest von dem Schmerz über das ihr vor kurzem geschehene Übel gleichsam in den Hintergrund gedrängt. Formal wird dies von Ovid zum einen dadurch hervorgehoben, daß im Gegensatz zu Anio, der Ilia mehrmals anspricht (vgl. vv $54.61 \mathrm{f}$ ), Ilia den Flußgott kein einziges Mal anredet, zum anderen dadurch, daß er die Verse, in denen Ilia kurz auf den Antrag Anios Bezug nimmt (v 75 f), gleichsam eingezwängt zwischen den beiden Distichen stehen läßt, die ihrer Verzweiflung Ausdruck verleihen (v $73 \mathrm{f}$ und v $77 \mathrm{f}$ ). Wiederum findet sich später bei Ovid, diesmal in den Fasti, eine parallele Struktur bei der Klage der Ariadne über den untreuen Dionysos ${ }^{140:}$

o utinam mea sors, qua primum coeperat, isset, iamque ego praesenti tempore nulla forem!141

„Wenn mein Schicksal sich doch nur so gestaltet hätte, wie es anfangs begonnen hatte, und ich zu diesem Zeitpunkt doch nur schon tot wäre!“

Aus psychologischer Sicht bemerkenswert ist der Umstand, daß Ovid hier an Ilia mit erstaunlichem Einfühlungsvermögen das Phänomen des Opfersyndroms schildert: Obwohl sie der Vergewaltigung und der daraus resultierenden Verstoßung völlig wehrlos ausgesetzt war, fühlt sie sich doch schuldig (vv 75-78) $)^{142}$.

Es kommt schließlich zur Kurzschlußhandlung. Die verzweifelte Frau sieht keinen Ausweg mehr und stürzt sich in den Fluß, um ihr Leben zu enden, und damit in die Arme des Flußgottes (vv 79-82) ${ }^{143}$. Anio wird sogleich "handgreiflich“ (v 81): supposuisse manus ad pectora hat eine deutlich erotische Konnotation ${ }^{144}$. Donini führt hier als

\footnotetext{
${ }^{138}$ Formal von Ovid eindrucksvoll unterstrichen durch die langen Silben in der ersten Pentameterhälfte von Vers 70: cūrrēndī uīrēs.

${ }^{139}$ Vgl. auch die parallele Gestaltung von am. 1.7.61 f. Vergebliche Versuche finden seit Homer regelmäßig dreimal statt, vgl. Od. $11.206 \mathrm{f}$.

${ }^{140}$ Auf Parallelen im Verhalten Ilias mit dem der Lucretia in den Fasti weist Connors 1994: 110 (mit Anm. 31) hin.

141 Ov. fast. $3.477 \mathrm{f}$.

${ }^{142} \mathrm{Vgl}$. auch die Schilderung des Opfersyndroms bei der von Jupiter vergewaltigten Callisto, Ov. met. $2.447 \mathrm{ff}$.

${ }^{143}$ Der Sturz wird formal durch das Stilmittel der Synaloiphe unterstrichen: atque ita se in rapidas perdita misit aquas (v 80). Zumindest verwiesen sei hier auf die Untersuchungen von Zwierlein 1999, der diesen Vers gerade auch aufgrund der ungewöhnlichen Synaloiphen für „doppelt anstößig“ hält und in am. 3.6 nicht nur die gesamte Erzählung von Ilia und Anio, sondern auch weitere Verse aus dem Flüssekatalog und vom Ende der Elegie für spätere Interpolationen (aus tiberischer Zeit) hält, s. ebd. 422, Anm. 4.

${ }^{144}$ So auch Weinlich 1999: 216, die paraphrasierend übersetzt ",nach ihren Brüsten greifend“, und sogar so weit geht zu behaupten, daß Ovid ,die Begebenheit unter rein erotischen Aspekten betrachtet“.
} 
Vergleichsstelle met. 4.359 an, wo die liebestolle Salmacis im See Hermaphroditus an die Brust faßt $\mathrm{t}^{145}$. Noch deutlicher erhellt dies aus der direkt auf 3.6 folgenden Elegie, wo dasselbe Verb im Zusammenhang mit den Bemühungen der puella gebraucht wird, den impotenten Dichter zum Geschlechtsverkehr anzuregen:

... lasciuum femori supposuitque femur. ${ }^{146}$

„... und wollüstig hat sie ihren Schenkel unter den meinen geschoben."

Weiterhin wird der Fluß als lubricus bezeichnet (v 81), was neben „schlüpfrig“ auch die Bedeutung „verführerisch“147 oder „betrügerisch“148 haben kann; die Polysemie des Adjektivs zeigt abschließend und die Natur des Wassers sowie des Flußgottes zugleich beschreibend den Charakter des Anio ${ }^{149}$.

Daß Ilia im Bett des Anio landet, steht pointiert am Schluß des ganzen Abschnitts. Auf ganz ähnliche Weise endet der Ariadne-Mythos ars 1.564:

sic coeunt sacro nupta deusque toro.

"So vereinen sich auf heiligem Bett die Vermählte und der Gott.“

Hier wird durch coire das Geschlechtliche noch unverblümter ausgedrückt als in Amores 3.6.82. Zwei Verse weiter (ars 1.566), wo es um die Verführung einer Frau auf dem torus geht, ist der Anklang an Amores 3.6.82 noch deutlicher, auch durch die Wortstellung:

... atque erit in socii femina parte tori ...

,... und eine Frau teilhaben wird am gemeinsamen Bett ...."150

Es ist die erstaunliche Fähigkeit Ovids, sich in die psychische Verfassung einer vergewaltigten und verstoßenen Frau hineinzuversetzen, die bei dieser Erzählung auffälltt151. Hier ist Ilia nicht die hehre Stammutter Roms, die regina sacerdos, die glorreiche Mutter des Marssohnes und Romgründers Romulus wie bei Vergil ${ }^{152}$, oder die ein heimliches Liebesstelldichein mit Mars verbringende Vestalin wie bei Tibull ${ }^{153}$, sondern eine Ver-

\footnotetext{
${ }^{145}$ Ov. met. 4.359: subiectatque manus inuitaque pectora tangit. Vgl. Donini 1969: $220 \mathrm{f}$.

146 Ov. am. 3.7.10.

147 Vgl. Hor. carm. 1.19.8.

148 Vgl. Verg. Aen. 11.716.

${ }^{149}$ Vergleichbar doppelbödig wie die Werbung des Anio ist die Selbstvorstellung des Sprechers in Amores 1.3, der unter einem Blickwinkel als Musterknabe, unter einem anderen aber als Casanova erscheint, vgl. dazu Woytek 1995, v.a. 430 ff. Woytek kommt zu dem Fazit: „Es gibt m. E. hinlänglich sichere Anhaltspunkte für die Feststellung, der Autor habe in diesem Amoresgedicht gleichsam einen doppelten Boden eingezogen, um die prima facie so herzergreifende Wohlanständigkeit des Sprechers in grellem und deshalb so komischem Kontrast durch Lüsternheit zu konterkarieren, was sich bei Auflösung der Doppeldeutigkeit seiner Worte erschließt" (ebd. 435).

150 Ähnlichkeit hat weiterhin der Mythos der Anna, vgl. fast. $3.647 \mathrm{f}$ : corniger hanc cupidis rapuisse Numicius undis / creditur et stagnis occuluisse suis. Vgl. des weiteren Ov. met. 3.342-344 und $8.590 \mathrm{ff}$.

${ }^{151}$ Vgl. Fränkel 1970: 23: „Ovid ... ist imstande, alles mit den Augen der Frau zu sehen ...“ Zu Ovids „erotischer Psychologie“ vgl. auch Holzberg 1998: 77. Die Fähigkeit Ovids, das Phänomen „Liebe“ psychologisch auch und gerade mit den Augen einer Frau zu durchdringen, zeigt in aller Deutlichkeit die Schilderung der sich in ihren Bruder verliebenden Byblis, met. $9.454 \mathrm{ff}$.

${ }^{152}$ Vgl. Verg. Aen. $1.273 \mathrm{f}$ und $6.777 \mathrm{f}$.

${ }^{153}$ Vgl. Tib. 2.5.51-54.
} 
stoßene im Zustand äußerster Verzweiflung ${ }^{154}$. Aber Ovid bleibt nicht dabei stehen, er ist nicht der Mahner in der Wüste, der mit der Schilderung der schrecklichen Folgen einer Vergewaltigung die Sünder zur Umkehr rufen will, sondern er treibt auch mit dem Ernst sein Spiel ${ }^{155}$. Neben der Psychologisierung des Mythos ist es vor allem die unterschwellige Erotisierung, die der ganzen Passage ihr unverwechselbares Gepräge gibt. Psychologisierung und Erotisierung machen aus einem heroisch-epischen Exempel ein elegisches, oder, um genauer zu sein: elegische und episch-heroische Elemente fließen zu einer neuen Einheit zusammen, zu einem neuen Ganzen, in dem sich die einzelnen Merkmale und Eigenheiten der Gattungen nicht mehr leicht voneinander trennen lassen. Freilich ist das Mittelstück von Ilia und Anio eine Liebesgeschichte und damit gehört sie zur Elegie und zum Thema der Amores. Aber zugleich ist ein so breit ausgeführtes mythisches Exempel auch wieder "episch“, und die Handelnden sind eben nicht eine Hetäre und ein Römer im süßen Müßiggang, sondern ein Flußgott und die Stammutter Roms in höchster Not und Verzweiflung - freilich wiederum in einer erotisch-humoristisch gebrochenen Not und Verzweiflung. Zum ersten Mal nach dem Eröffnungsgedicht 3.1 wird im dritten Amores-Buch genau hier mit 3.6 der eigentliche Boden der Liebeselegie verlassen (poeta und puella und ihre Verflechtungen: 3.2-3.5) und ein von poetologischer Reflexion begleitetes Aufbrechen der Gattung vollzogen ${ }^{156}$.

\section{d) Ovid'sche Ironie: Ein Flußbett wird zum Ehebett}

Die Frage, ob Ovid die Erzählung von Anio und Ilia seinem Publikum eher mit einem lästerlich-spöttischen Unterton präsentiert, oder ob er ohne Spitze, lediglich in lockertendenzlosem Plauderton unterhalten will, wurde in der Forschung konträr beantwortet. So schreibt Brandt in der Einführung zu seiner kommentierten Amores-Ausgabe ${ }^{157}$ :

„Ein weiteres Prachtstück ironischer Persiflage ist auch die rührende Ansprache der Ilia. Man sieht förmlich den Spötter Ovid vor Behagen grunzend sich auf seinem Lectulus streckend, als ihm diese Pseudo-Lucretia-Stimmung zu schildern gelungen war."

\footnotetext{
${ }^{154}$ Vgl. Davis 2006: 79: „Observe how the narrator emphasises not only her physical appareance but also the rape's devastating psychological effects."

${ }^{155}$ Allgemein bezeichnet Glatt 1991: 168, den Umgang Ovids mit dem Thema „Liebe” in den Amores als „,artistisches Spiel”. Auch für Reitzenstein 1968: 211 ist die bei Ovid geschilderte Liebe keine ernste Leidenschaft, sondern ein „reizvolles Spiel”. Vgl. auch Heinze 1919: 10 f; Otis 1966: 16. Davis 2006: 80, schließt sich dieser Meinung im großen und ganzen an, interpretiert aber gerade die Darstellung des Ilia-Mythos in am. 3.6 als eine im Tonfall ernste Kritik (!) an der staatlich-offiziellen Darstellung von Roms Gründungsgeschichte: „For the most part, Ovid treats the Julian version of Rome's origins as a source of humour or as an object of mockery, but in Amores 3.6 the poet exposes what the Augustan version of the myth omits, the individual injustice and suffering involved in the story of Rome's foundation."

156 So auch Marg \& Harder 1962: 220 (,sprengt den Bereich der Amores“ ... "gibt in der Behandlung einer Sagensituation eine Art Vorblick auf Heroides, Metamorphosen, Fasten“). Anders hingegen Lenz 1966: 222: „Ihn [sc. den Dichter] reizte die Aufgabe, die Seelenqual des Mädchens [sc. Ilia] darzustellen, ohne die durch den Charakter der erotischen Elegie gezogenen Grenzen zu überschreiten."

${ }^{157}$ Brandt 1911: 34. Suter 1989: 19 vertritt die Auffassung, daß die ganze Passage am. 3.6.45-82 in einem "mock-heroic style” gehalten sei. Allgemein zu "the parodic wit, the ironical self-deception and sophisticated entertainment of the 'impersonal' Amores“ vgl. Martyn 1981: $2436 \mathrm{f}$ (Zitat 2437); Frécaut 1972: 180 („,le poète a toute liberté de disposer le décor à sa guise et de se divertir à jouer la comédie, en improvisant avec virtuosité sur des arguments empruntés au répertoire, en pastichant et en parodiant les chefs-d'œuvre de ses prédécesseurs“); dezidiert De Caro 2003: 88 („La poesia tende esclusivamente al diletto ...“).
} 
Für Wilhelm dagegen ist in Amores 3.6.45 ff von Ironie und Spott nichts zu spüren ${ }^{158}$. Anio ist für ihn der

"gefühlvolle Wassermann, der sich in ein Menschenkind verliebt und ihm Hand und Herrschaft in seinem kristallinen Reiche anbietet";

seine Ansprache an Ilia sei ehrerbietig, teilnehmend und ernst gemeint ${ }^{159}$.

„Wie in der Ariadnefabel, so ist es auch hier ein Gott, der eine Hintergangene und Verlassene ... durch Erhebung zur eigenen göttlichen Gemahlin von allem widerfahrenen Leid erlöst." ${ }^{\prime 160}$

Wie die beiden Pole zeigen, ist die Frage nach Ironie oder Ernst nicht einfach zu beantworten. Der Umstand, daß in der Forschung die Meinungen in dieser Hinsicht geteilt sind, ist nicht unbedingt ein Zeichen dafür, daß man lediglich der "richtigen“ Interpretation noch nicht auf die Spur gekommen ist, sondern ein Hinweis auf die Kunst Ovids, die eben gerade darin besteht, doppelbödig und vielgesichtig zu schreiben ${ }^{161}$. Zentral ist die Freude dieses Dichters

„am geistreichen Spiel, am geschliffenen Paradoxon, sein Ausnutzen ambivalenter Worte und Wesen; Ovid jongliert gleichermaßen mit schillerndem Ausdrucksmaterial wie mit Akteuren, die in der Hand des gestaltenden Künstlers in Form und Fühlen wandelbar sind. "162

Freilich sieht es zunächst so aus, als ob Anio in dieser Erzählung Ilia ein unglaublich großherziges und edles Angebot machte; ist sie doch von allen geächtet und kann aufgrund ihrer Unkeuschheit nicht mehr damit rechnen, daß sich noch jemand ihrer annehmen, geschweige denn ihr die Ehe anbieten wird. Auf diese erste Verständnisebene des Textes konnte sich Ovid bei Bedarf auch immer zurückziehen, wenn ihm etwa zum Vorwurf gemacht worden wäre, er schreibe zu frivol und unehrerbietig. Dennoch lassen sich aufgrund der oben durchgeführten Aufschlüsselung polysemer Worte, die die hintergründige Erotik der Szene zutage gefördert hat, durch werkimmanente Vergleiche und eine nähere Analyse der Struktur des Abschnitts Aussagen treffen, die die unterschwellige Ironie der Szene zutage fördern und erkennen lassen, daß Ovid die mythische Vorlage vom "gefühlvollen Wassermann“ und von einer „Erlösung vom Leid“ subtil untergräbt.

\footnotetext{
158 Vgl. Wilhelm 1933: 173. Allgemein auch Luck 1961: 198: „Ovid selbst ist keineswegs der frivole Lüstling, als der er sich gelegentlich aufspielt“; Ovid sei „auf seine Art ein Moralist“.

159 Wilhelm 1933: 171.

${ }^{160}$ Wilhelm 1933: 172; ähnlich aufgenommen von Schubert 1992: 120; vgl. auch Gärtner 2005: 285 f (,,... ist der Akt des Flußgottes keine bloße lüsterne Erfüllung eines eigenen erotischen Wunsches, sondern vor allem ein Akt der Hilfeleistung für eine verzweifelte Frau“, mit Verweis auf Enn. ann. fr. $1.44 \mathrm{f}$ Skutsch). Anders Morgan 1977: 90, Anm. 8: „Although she [sc. Ilia] eventually surrenders herself to the river, we are never told that she improved her lot by this act ..."

${ }^{161}$ Vgl. die treffende Äußerung von Albrecht 2000: 175: „Reiche Ernte verspricht auch die Mehrdeutigkeit der Worte, das ambiguum, obwohl vom Interpreten hier viel Takt verlangt wird - nur ein Schritt zu weit und wir verlassen das Feld des Künstlerischen. Einer exakten Beschreibung entzieht sich Ovids subtile Verwendung von Witz, Humor und Ironie.“ Ähnlich Boyd 2002: 116, zum Autor der Amores: „Even in his earliest literary incarnation, Ovid manages to elude our most earnest attempts to make him fit easy definition."

162 Eggers 1984: 188.
} 
Daß Ovid grundsätzlich Witz und Ironie gegenüber aufgeschlossen war, auch und gerade in Liebes- bzw. „Vergewaltigungsgeschichten“, zeigen mit Sicherheit die Metamorphosen, wenn etwa der lüsterne Apollon, der die panisch fliehende Daphne verfolgt, sie bittet, doch langsamer zu rennen, damit sie sich nicht an den Dornen die Schenkel blutig reiße; er würde sie dann auch langsamer verfolgen ${ }^{163}$. Eine ähnlich etwas unpassend wirkende Besorgnis legt Anio in den Fragen zutage, die er anfangs an Ilia richtet (vv 53-58). So ist es menschlich und verständlich, eine Verzweifelte danach zu fragen, weshalb ihre Angst sie hergetrieben hat (quid nostras ... teris anxia ripas, v 53), weshalb sie allein und verlassen ist (quid sola uagaris, v 55), und weswegen sie weint (quid fles, v 57). Etwas fehl am Platz aber wirkt - in einer solchen Situation! der Hinweis darauf, daß sie sich durch das Weinen die Augen verdirbt (v 57) ${ }^{164}$. Eine deutliche Parallele, die inhaltlich fast schon an Zynismus grenzt, findet sich beim Raub der Sabinerinnen, wo Ovid einen der Räuber zum „Trost“ zu einer Geraubten sagen läßt ${ }^{165}$ :

atque ita: "quid teneros lacrimis corrumpis ocellos? quod matri pater est, hoc tibi“, dixit, "ero".

„Und er sprach: ‘Was verdirbst du mit Tränen die zarten Augen?

Was für die Mutter der Vater ist, das“, so sprach er, „,will ich für dich sein.“

Wie Anio (vv 61-66), so meint in den Metamorphosen auch Apollo durch das Herausstreichen seiner eigenen Größe und Bedeutung die Fliehende sich geneigt machen zu können; als ob es dieser in diesem Moment nicht egal wäre, ob es nun der berühmte Sohn Jupiters oder ein schmutziger Hirt ist, der sie vergewaltigen will166. Natürlich war es prinzipiell in der Antike ein großer Unterschied, ob ein Gott oder ein Sterblicher bei einer Vergewaltigung als Urheber des Nachwuchses angesehen wurde. Aber Ovid versteht es, den Blickwinkel des Mythos, der vor allem an der Herrschaftslegitimation bestimmter Familien und Geschlechter interessiert war, oder, wie bei Apollon und Daphne, die Funktion eines Aitions erfüllt ${ }^{167}$, in den Blickwinkel der verfolgten und bedrängten Frau zu verwandeln, und insgesamt den Mythos zu „verelegisieren“, Hehres herunterzutransformieren auf die Ebene des Bodenständig-Alltäglichen. Die konsequente Vermenschlichung der Götter tut ein übriges, so daß am Ende tatsächlich eine eher lächerliche Figur bleibt, der die Frau gegen ihren Willen ausgeliefert ist ${ }^{168}$. In diesem Sinne wirkt auch die etwas versteckt formulierte Aussicht für Ilia, die erste Dame im Nymphenharem zu sein (v 63 f) ${ }^{169}$, nicht eben unkomisch.

\footnotetext{
${ }^{163}$ Ov. met. 1.508-511. Vgl. dazu Bretzigheimer 1994: 518-523, v.a. 518 mit Anm. 49. Bretzigheimer weist darauf hin, daß das angekündigte Verhalten Apollons der Empfehlung entspreche, die Ovid dem amator in der ars amatoria erteilt, nämlich das Tun der puella nachzuahmen. Es liegt aber auf der Hand, daß die Situationen grundverschieden sind, und die Verfasserin räumt selbst ein, daß man an der Aufrichtigkeit des göttlichen Angebots seine Zweifel hegen könne (ebd. 522 mit Anm. 63). Das Komödienhafte in den Amores betont Holzberg 2001: 116-119.

${ }^{164}$ Nach Axelson 1945: 43 wurde ocellum wohl nicht mehr als Deminutivum empfunden.

165 Ov. ars $1.129 \mathrm{f}$.

166 Vgl. Ov. met. $1.512 \mathrm{ff}$.

${ }^{167}$ Vgl. dazu Burkert 1993: $18 \mathrm{f}$.

${ }^{168}$ Wollte Ovid daran festhalten, daß die Vergewaltigung für die Frau etwas durchaus Positives darstellt, wenn es sich bei dem Täter um einen Gott handelt, so müßte er z.B. Daphne nach der Selbstoffenbarung des Apoll Halt machen lassen, was diese aber keineswegs tut.

${ }^{169}$ Vgl. zur Stelle das oben bereits Ausgeführte.
} 
Freilich besteht ein Unterschied zwischen der Daphne-Apollon-Episode und der Ilia-Anio-Erzählung darin, daß Apollon trotz all der göttlichen Macht, die er bereit ist, gänzlich in den Dienst seiner Liebe zu stellen ${ }^{170}$, für sich und Daphne keine glückliche Zukunft erwirken kann, während zu Anios Gunsten spricht, daß er seinen Antrag im Bewußtsein vortragen kann, ein gutes Schicksal für Ilia (und für sich) zur Erfüllung zu bringen, wie dies bei Ennius der Ilia durch ihren Vater geweissagt worden war ${ }^{171}$. Auffällig (und parallel zur Daphne-Erzählung) ist in der Ovid'schen Darstellung des Iliamythos aber doch die Diskrepanz zwischen dem eifrig-lüsternen Anio und der verzweifelten Ilia, der bis zuletzt auch nicht ein Hauch von Begeisterung über ihre nun nahe bevorstehende „Rettung“ und ihr künftiges Eheglück anzumerken ist.

Die originellste Pointe gelingt Ovid zweifellos mit seiner ungewöhnlichen Auflösung des Abschnitts und dem Anschluß an den tradierten Mythos ${ }^{172}$. Gelangt die Handlung mit der Rede der Ilia (vv 73-78) zu einem dramatischen Höhepunkt, der an die Monologe der Helden kurz vor ihrem schrecklichen Ende in Tragödie und Epos erinnert $^{173}$ - wobei jedoch der Hinweis, daß Ilias Augen vom Weinen geschwollen waren (tumidis, v 79), die tragische und erhabene Wirkung bereits etwas stört ${ }^{174}$-, so endet die Verzweiflungstat der Ilia in einem Witz: Sie wählt sich für ihren Selbstmord den Fluß, und wirft sich damit gerade dem Beischlaf in die Arme, dem sie durch den Tod zu entrinnen versuchte ${ }^{175}$. Wie schon bei der Mehrzahl der Elegien der Amores, so wird auch im kleinen der Ilia-Abschnitt mit einem Distichon (v $81 \mathrm{f}$ ) beendet, das nach Art eines Aprosdoketons eine überraschende Wendung bringt $t^{176}$.

Ovid spielt hier mit der Doppelnatur des Anio: einerseits Fluß, andererseits Gott. Ein ähnliches Spiel findet sich met. 5.572 ff: Arethusa badet im Fluß Alpheus, Alpheus erblickt sie und verfolgt die Fliehende über weite Strecken. Letztendlich wird Arethusa in eine Quelle verwandelt, aber auch das hilft ihr nichts: Alpheus wandelt sich ebenfalls wieder in seine Wassernatur zurück, und erlangt auf diese Weise die ersehnte Vereinigung ${ }^{177}$.

Es wird zwar nicht berichtet, wie Ilia letztlich auf die körperliche Annäherung Anios reagiert hat, aber ihre kurz zuvor klar geäußerte Abscheu vor jeglichem Antrag (cur ... taedas inuitor ad ullas / turpis, v $75 \mathrm{f}$ ) hinterläßt beim Leser nicht eben die Erwartung eines happy end - und doch konnte Ovid bei einem eventuellen Tadel, er sei in seinem unehrerbietigen Umgang mit dem Mythos zu weit gegangen, das open end als Schutzschild benutzen und Anios Ausnutzung der Hilflosigkeit Ilias zur Befriedigung der eigenen Wünsche als hehre Rettungstat hinstellen. Selbst der in erotischem Kontext be-

\footnotetext{
170 Vgl. Gärtner 2008: 24.

${ }^{171}$ Enn. ann. fr. $1.44 \mathrm{f}$ (Skutsch), v.a. 45: post ex fluuio fortuna resistet.

172 Dies scheinen andeutungsweise bisher nur Lenz 1965: 223 (Komm. zu am. 3.6.76) und Connors 1994: 110 gesehen zu haben.

173 Vgl. Wilhelm 1933: 172 f; Sabot 1976: 486 und 489.

174 Vgl. Latta 1963: 12.

175 Vgl. Connors 1994: 110: „from Ilia's point of view it is suicide - apparently Ovid's invention; from Anio's point of view it is marriage - as was told in Ennius. [...] This passage thus offers an unusually precise interaction between the tragic and comic elements so often juxtaposed by Ovid." Hutchinson 2008: 189 schreibt zum Verhalten des Anio: „The crudity and cunning of desire shows through his action ..."

${ }^{176}$ S. zur häufigen Verwendung dieses Stilmittels in den Amores De Caro 2003: 84.

177 In fast. $5.661 \mathrm{f}$ sind die beiden Naturen zur gleichen Zeit in den Blick genommen, wenn die Fluten des Tiber anhalten, um den Flußgott Tiber in seine Grotte gelangen zu lassen: hactenus, et subiit uiuo rorantia saxo lantra; leves cursum sustinuistis aquae.
} 
legte Ausdruck supposuisse manus ad pectora (v 81, s. dazu oben) ist nicht so eindeutig frivol, daß Ovid nicht auch hätte behaupten können, er bezeichne damit nichts anderes als die Rettungstat eines fürsorglichen „Bademeisters“ gegenüber einer Ertrinkenden.

Umstritten ist in der Forschung, wie weit Ovid sich in den Augen seiner Zeit mit seiner Ironie vorgewagt hat. So bemerkt Brandt zu Amores 3.4.37-40:

„Aber höchst frivol ist es, wenn er [sc. Ovid] die korrupten Zustände Roms auf die Unkeuschheit der Rhea Silvia zurückführt, weil er hierdurch Dinge angreift, die sicherlich vielen seiner Zeitgenossen noch unantastbares Heiligtum waren" 178,

während Stroh zur selben Stelle schreibt: „Das ist kühn, aber doch auch wieder nicht überkühn", und darauf hinweist, daß Ovid immerhin nicht auf den Ehebruch der Venus anspiele, durch den Aeneas auf die Welt kam $^{179}$. Inwieweit also analog die auf den lüsternen Anio hereinfallende Ilia in Amores 3.6 Anstoß erregt haben mag, ist schwer zu sagen ${ }^{180}$. Daß man zu Ovids Zeiten auch anderweitig nicht allzu großen Respekt vor den $\mu \tilde{v} \theta$ ot hatte, belegt jedenfalls Livius, wenn er spöttisch bemerkt, daß Ilia nach der Niederkunft Mars als Vater ihrer zweifelhaften Nachkommenschaft angegeben hätte, „,sei es, daß sie wirklich daran glaubte, sei es, weil es ehrenvoller war, einem Gott die Schuld zu geben“ (seu ita rata, seu quia deus auctor culpae honestior erat, Martem incertae stirpis patrem nuncupat $)^{181}$.

Neben der Erotisierung und Psychologisierung ist jedenfalls ein drittes, die Ilia-Erzählung bestimmendes Charakteristikum festzuhalten: die Ironisierung. Der Stoff, den Ovid für sein exemplum wählt, ist heroisch-mythisch par excellence, handelt es sich doch um einen Ausschnitt aus dem Gründungsmythos des römischen Volkes. Auch die breite Ausmalung einer solchen mythischen Erzählung ist eher etwas für das Epos Typisches. Doch das stellenweise sogar tragödienhafte Pathos wird konterkariert durch die zum Zweck der Erotisierung verwendete elegische Terminologie, durch die Vermenschlichung der Akteure und durch den hintergründigen Witz. Elegisches und Episches fließt auf diese Weise in der Ilia-Erzählung zu einer neuen, unauflösbaren Einheit zusammen.

\section{e) Amores 3.6.45-82: Übersetzung mit Anmerkungen}

Nicht will ich dich übergehn, der durch Felsenklüfte sich wälzend

Tibur, der griechischen Stadt, obstbringend wässert die Flur.

Ilia hat dir gefallen, obgleich von schaurigem Aussehn ${ }^{182}$ :

\footnotetext{
${ }^{178}$ Brandt 1911: 34 f; ähnlich De Caro 2003: 175, zum Ilia-Mythos in am. 3.6 („non convenzionale rispetto all'ideologia nazionale“). Vgl. allgemein Otis 1966: 14: „The whole three books of the Amores constitute in fact an extremely clever burlesque not only of elegiac convention but also of Augustan society and literature", und Davis 1981: 2462.

179 Stroh 1979: 341.

180 Schubert 1992: 120 hält dies eher für unwahrscheinlich; Courtney 1988: 20 sieht in der Geschichte von Anio und Ilia „, an irreverent adaptation of Ennius", geht aber nicht auf die Frage ein, inwieweit dies dem Dichter Mißgunst eingebracht haben könnte.

${ }^{181}$ Livius 1.4.2.

${ }^{182}$ cultus und colere bezeichnen bei Ovid in den Amores mehrfach das auf äußerliche Schönheit bedachte Sich-Herrichten der Frau oder den durch diese „Toilette” erreichten Zustand, vgl. am. 1.8.26; 2.10.5; ausführlich ars $3.101 \mathrm{ff}$ (zu cultus); zu colere: am. 2.4.37; 2.5.45; 3.7.1. Otis 1968: 251 bezeichnet die in den Amores zutage tretende Auffassung Ovids von der Liebe regelrecht als eine „Philosophie des cultus” (vgl. dazu v.a.
} 
Nagelzerfurcht das Haar, Wangen vom Nagel zerfurcht.

Seufzend über des Oheims Frevel und Marsens Vergehen

Irrte mit nacktem Fuß sie durch die Fluren allein ${ }^{183}$.

Diese sah Anien, voll Drang ${ }^{184}$, aus reißenden Wogen,

Und seine Stimme erklang rauh aus der Mitte des Grunds.

„Was“, so sprach er, „streifst voll Angst du unsere Ufer,

Ilia, troischen Bluts, König Laomedons Kind?

Und wie siehst du nur aus? ${ }^{185}$ Was schweifst umher du alleine?

Und kein weißes Band hält dir umwunden das Haar?

Was nur weinst und verdirbst du mit Tränen die triefnassen Augen,

Schlägst die entblößte Brust wahnsinnig dir mit der Hand?

Der hat in seiner Brust lebendiges Eisen und Kiesel,

Der im zarten Gesicht gleichgültig Tränen erblickt.

Ilia, laß deine Furcht: Unser Königspalast steht dir offen,

Ströme ehren dich dann. Ilia, laß deine Furcht!

Du wirst herrschen, ja du! Unter hundert Nymphen und mehr noch;

Hundert nämlich und mehr bergen die Wasser, die mein.

Bitte, verschmäh mich nur nicht ${ }^{186}$, du Tochter aus troischem Stamme ${ }^{187}$ :

auch Ovid selbst, ars 3.121-128). Vgl. dazu auch den Aufsatz von Watson 1982. Im Deutschen ist es kaum möglich, einen adäquaten Ausdruck zu finden.

${ }^{183}$ Andere Übersetzungsmöglichkeit: „,... sie durch die einsame Flur.” Diese Übersetzung legt sich nahe aufgrund der engen Wortstellung per loca sola; die oben gewählte Übersetzung berücksichtigt den Stichwortbezug zu Zeile 55, wo Anio sola auf Ilia bezogen in der Frage quid sola uagaris? wieder aufnimmt und durch seine eigene Anwesenheit deutlich macht, daß die loca eben nicht sola sind. Außerdem spricht das Vorbild von Ennius für diese Deutung, denn auch bei Ennius irrt Ilia allein am Flußufer entlang (hier liegt wahrscheinlich sogar ein direkt beabsichtigter intertextueller Bezug vor, vgl. Enn. ann. fr. 1.39 f Skutsch: ... ita sola / postilla, germana soror, errare uidebar, mit Ov. am. 3.6.50: errabat nudo per loca sola pede).

184 "Hochgemut" oder "beherzt" gibt hier als Übersetzung von animosus nicht viel her; nach Ausweis des Thesaurus kommt als griechisches Äquivalent für animosus u.a. $\theta v \mu$ icós, „leidenschaftlich, hitzig, ungestüm" in Frage, was hier wohl eher den Sinn der Stelle treffen dürfte. Bei Ovid wird animosus in diesem Sinn gebraucht met. 2,84 und trist. 4.6.3 (von Pferden) und met. 12.469 (von einem Kentauren).

${ }^{185}$ Die Frage nach den $c u l t \bar{u}$ s der Ilia bezieht sich hier wohl ganz allgemein auf das Aussehen (vgl. am. 2.10.5; fast. 2.318; met. 6.454; 8.854), könnte aber auch speziell auf den Verlust des Ornats und der Insignien des Priesterinnenamtes abzielen.

${ }^{186}$ Andere Übersetzungsmöglichkeit: „Bitte, mich großen verschmäh’ nicht ...”. Der lateinische Text läßt offen, ob tantum als Adverb oder als auf me bezogenes Adjektiv aufzufassen ist. Ein freilich nicht zwingendes Argument für die Übersetzung als Adjektiv ist zum einen die Wendung nomina tanta in derselben Elegie (v 102), die sich auf die Flüsse des Katalogs und damit auf Anio rückbezieht, zum anderen der inhaltliche Zusammenhang der Stelle, da Anio schon in den Versen direkt vorher sich brüstet (vv 61-64). Für die Deutung als Adverb spricht die Mehrzahl der Stellen, in denen ne mit tantum verbunden eindeutig im Sinn von „nur nicht” übersetzt werden muß, vgl. am. 2.15.18; 3.8.59; Pont. 2.10.8; met. 8.54 und andere.

${ }^{187}$ Die Herausgeber haben sich hier für die Lesart Troiana entschieden, obwohl die meisten (und auch die wichtigsten) Textzeugen Romana überliefern. Den Anachronismus, Ilia als „Römerin“ zu bezeichnen, leistet sich Ovid allerdings noch einmal, und zwar in den Fasti, wo er ein zweites Mal ausführlich auf den IliaMythos eingeht, an derselben Stelle im Vers (fast. $3.9 \mathrm{f}$, angeredet ist Mars: tum quoque inermis eras, cum te Romana sacerdos / cepit, ut huic urbi semina magna dares), obwohl er keine 13 Verse später davon spricht, daß die schwangere Ilia den "Gründer Roms“ in sich trägt (fast. 3.23 f: somnus abit, iacet ipsa grauis; iam scilicet intra / uiscera Romanae conditor urbis erat). Es war somit nicht problematisch, Ilia als „Römerin“ zu bezeichnen (vgl. auch Hor. carm. 3.9.8), obwohl der Gründer Roms noch erst geboren werden soll, da das römische Geschlecht im damaligen Verständnis nicht erst bei Romulus, sondern bereits bei Venus und Anchises seinen Ausgangspunkt nimmt (vgl. Ov. fast. 1.39 f; 3.425 f; 4.119-124; 6.257). Allerdings redet in am. 3.6 Anio selbst Ilia anfangs mit ab Idaeo Laomedonte genus (v 54) an und beschließt seine Rede mit der korres- 
Gaben erhältst du noch mehr, als ich bereits dir versprach."

Sprachs. Doch jene, sittsam, die Augen zu Boden gerichtet,

Netzte mit Tränenfluß weinend die liebliche Brust.

Dreimal plante sie Flucht, hielt dreimal an ragenden Wogen;

Kräfte für den Lauf nahm und entriß ihr die Angst.

Spät gleichwohl mit feindlichem Daumen die Haare zerraufend

Sprach sie, die dies nicht verdient ${ }^{188}$, folgendes, zitternden Munds:

„Wären gesammelt doch längst und längst in der Vätergruft meine

Knochen geborgen, solang keusch man sie einsammeln konnt'!

Jüngst noch Vestalin - warum überhaupt lädt mich man zur Hochzeit,

Schandvoll, vom ilischen Herd wert doch verleugnet zu sein?

Auf denn, was laß ich vom Finger des Volks mich als unkeusch bezeichnen?

Weg mit dem Antlitz, das Schmach, allseits bekannt, mir nun färbt!“

Sprachs und zog ihr Kleid dann vor die geschwollenen Augen,

Warf verzweifelt sich so tief in die reißende Flut.

Unten gelegt an die Brust hat der schlüpfrige Strom ihr die Hände,

heißt es, und hat ihr gewährt Rechte des ehlichen Betts.

\section{Flußmetaphorik und poetologische Aussageebene in der Elegie}

\section{a) Dichtung und Wasser}

Galt das Hauptaugenmerk bislang den „epischen“ Flüssen im Flußkatalog und darin vor allem dem Fluß Anio, soll in einem letzten Teil die Aufmerksamkeit auf den namenlosen Fluß gelenkt werden, der in der Rahmenhandlung der Elegie den Sprecher an seiner Weiterreise hindert. Es gibt einen tieferen Grund dafür, daß Ovid als unüberwindliches Hindernis für den Liebhaber ausgerechnet einen Fluß gewählt hat. Das Element des Wassers in seinen verschiedenen Erscheinungsformen war nämlich als bedeutungsgeladene Metapher für verschiedene Arten literarischer Erzeugnisse vor allem im Bereich der Dichtung von einiger Wichtigkeit ${ }^{189}$. Darauf greift Ovid hier zurück.

Als traditionsprägend in dieser Hinsicht ist Kallimachos anzusehen. Dichtung, die

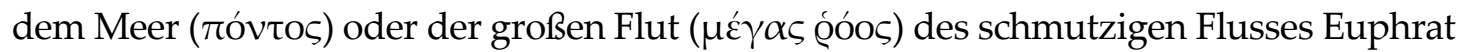
gleicht, wird von Kallimachos abgelehnt und einer Dichtung gegenübergestellt, die dem unvermischten, reinen und kleinen Tropfen aus einer Quelle ähnelt ${ }^{190}$. In diesen Zusammenhang gehören weitere Aussagen des Dichters, mit denen er ein Großepos,

pondierenden Anrede in dem Distichon 3.6.65 f; liest man Romana, wäre eine solche Diskrepanz aus dem Mund ein und derselben sprechenden Figur in der Tat anstößig und jedenfalls härter, als wenn Ovid als auktorialer Erzähler Ilia einmal als Romana sacerdos anredet wie in fast. 3.9.

$188 \mathrm{Zu}$ indignus i.S.v. „unverdient, schuldlos” vgl. am. 3.9.3, ars 1.532, met. 1.508.

${ }^{189}$ Vgl. dazu u.a. Clauss 1989, der dies mit zahlreichen Belegen anhand der Episode von den lykischen Bauern in Ovids Metamorphosen länger ausführt.

${ }^{190}$ Kall. h. 2.105-112; ein Passus, den nach Hunter 2006: 36 „Roman poets at least took as programmatic for Callimachus' poetry", und auf den Ovid selbst wahrscheinlich in am. 1.15.35 f anspielt (s. ebd. 38). Bezüge auf Kallimachos in am. 3.6 werden in Hunters Buch nicht behandelt. 


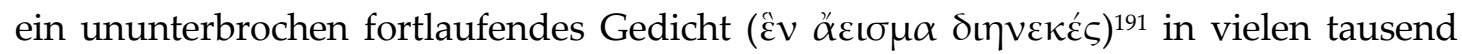
Versen entschieden ablehnt und sich für das Feine, Zarte und Kurze ausspricht ${ }^{192}$.

In der römischen Literatur werden diese Bilder aufgegriffen und weiter gepflegt ${ }^{193}$. So kontrastiert etwa Properz das stürmische Meer ${ }^{194}$, das aequor uastum ${ }^{195}$, den Fluß Permessos ${ }^{196}$ und die fontes magni des Helikon, aus denen die Epiker wie Ennius schöpften $^{197}$, mit dem Flüßchen des Elegikers, das so klein ist, daß das eine Ruder das Wasser, das andere aber den Ufersand berührt ${ }^{198}$. Als der Dichter davon träumt, sich auch einmal daran zu versuchen, die großen Taten der Könige zu besingen ${ }^{199}$, wird er von Apollon getadelt ${ }^{200}$ :

quid tibi cum tali, demens, est flumine? quis te

carminis heroi tangere iussit opus?

„Was hast du, Narr, mit einem solchen Fluß zu schaffen? Wer hat dich geheißen, an das Werk eines heroischen Gedichtes heranzugehen?"

Im neunten Gedicht des dritten Buches, wo Properz das an ihn herangetragene Ansinnen, ein Epos zu schreiben, in Form einer recusatio zurückweist, wird im Zusammenhang mit dem „,kleinen Fluß“ explizit auf Kallimachos verwiesen (vv $35 \mathrm{f}$ und 43):

$$
\begin{aligned}
& \text { non ego uelifera tumidum mare findo carina: } \\
& \text { tota sub exiguo flumine nostra mora est ... } \\
& \text { inter Callimachi sat erit placuisse libellos ... }
\end{aligned}
$$

„Nicht zerteile ich das wallende Meer mit segeltragendem Kiel:

die ganze Zeit verweile ich auf einem winzigen Fluß ...201

neben den Büchlein des Kallimachos Gefallen gefunden zu haben, wird mir genügen ..."

b) Der torrens als „epischer" Fluß

Auf diesem Hintergrund wird deutlich, daß hinter den Beschreibungen des angeschwollenen torrens bei Ovid in Amores 3.6 mehr steht als die bloße Schilderung einer

\footnotetext{
${ }^{191}$ Kall. fr. 1.3 (Pfeiffer).

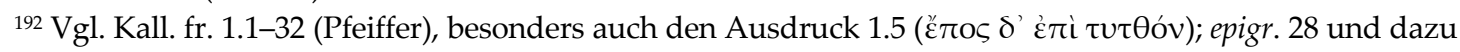
die Einleitung von Howald \& Staiger 1955: $22 \mathrm{f}$ und 30 sowie Otis 1966: 5: „Callimachus advocated the 'short epic' and the 'Hesiodic epic' as well as more variety of form and novelty of theme. By the 'short epic' ( he meant either didactic ... or a very loosely knit collection of short, self-contained episodes and stories (such as his own Aitia or Causes)."

${ }^{193} \mathrm{Vgl}$. Hutchinson 2008: 187: "Metapoetically, rivers of course have epic connotations.”

${ }^{194}$ Prop. 3.3.24.

195 Prop. 3.9.3.

196 Prop. 2.10.25 f.

197 Prop. 3.3.5 f.

198 Prop. 3.3.23.

199 Prop. 3.3.1 ff.

200 Prop. 3.3.15 f.

${ }^{201} \mathrm{Zu}$ dieser Übersetzung von sub vgl. den Hinweis im textkritischen Apparat von Fedeli sowie monte sub aërio bei Verg. Aen. 6.234.
} 
Naturerscheinung 202. Die Bezugnahmen auf die gebräuchlichen poetologischen Reizworte und die Anspielungen auf Kallimachos sind zu zahlreich, als daß man sie übersehen könnte ${ }^{203}$. In 3.6.88 redet der Dichter den torrens mit rustice an, weil er das Treffen der Liebenden verhindert ${ }^{204}$; so fiel bereits in 3.1 in Bezug auf eine Liebe, die sich nicht der Elegie bedienen kann und deshalb erfolglos bleiben muß, das Stichwort rusticus $^{205}$. Die crassae aquae ${ }^{206}$, die der Fluß turpi gurgite mit sich wälzt (v 8), sind geradezu das Gegenstück zur programmatischen Wendung der Moṽ $\sigma \alpha \lambda \varepsilon \pi \tau \alpha \lambda \varepsilon ́ \eta$ bei Kallima$\operatorname{chos}^{207}$, die über die Ufer getretenen Wassermassen (v 19 u. 85 f) erinnern an den $\mu \varepsilon \dot{\gamma} \alpha \varsigma$ @óos des Euphrat ${ }^{208}$, die limosae ripae (v 1) und das Adjektiv lutulentus (v 95) nehmen $\tau \dot{\alpha} \pi \mathrm{O} \lambda \lambda \dot{\alpha} \lambda \hat{u} \mu \alpha \tau \alpha \gamma \tilde{\eta} \varsigma$ auf ${ }^{209}$, und die Anrede des torrens mit riuis collecte caducis (v 91) und non candide (v 105) bildet das Gegenstück zum kallimachäischen „reinen und un-

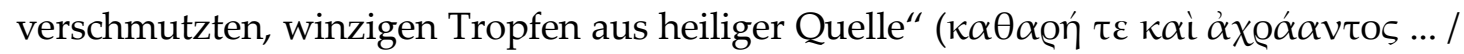

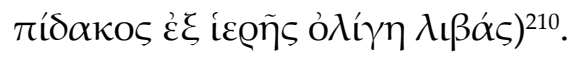

Diese intertextuellen Bezüge zum großen griechischen Vorbild untermauern die bisherigen Argumente dafür, daß hinter der ersten Verständnisebene des Gedichtes eine zweite, poetologische Aussageebene liegt. Ovid bzw. das elegische Ich tritt in diesem Gedicht besonders stark als Doppelnatur, als amator einerseits, andererseits aber auch als poeta auf. Auf dem Hintergrund der kallimachäischen Bezüge sind die Äußerungen über den torrens als doppeldeutig anzusehen; sie beziehen sich nicht nur auf

\footnotetext{
${ }^{202}$ Schon ohne die Vereinnahmung durch poetologische Reflexion wird der "Sturzbach“ in der Literatur von Homer an als Vergleich oder Bild benutzt, um etwas Großes, Pompöses, Gewaltsames bildlich zu erfassen, vgl. Hom. Il. 4.452-456: die aufeinanderprallenden Troer und Achaier werden verglichen mit vom Winter angeschwollenen Sturzbächen ( $\chi \varepsilon \dot{\mu} \mu \alpha \varrho \varrho o \iota)$, die mit mächtigem Tosen den Gebirgen entstürzen; Seneca etwa verwendet das Bild vom torrens zur Bezeichnung von allzu weitschweifigen und aufgeblasenen Rednern (epist. 4.40.8).

${ }^{203}$ Vgl. dazu Suter 1989: 15 ff; anders Weinlich 1999: 214, Anm. 98, die eine solche Interpretation für „nicht angemessen" hält, und in der langen Suasorie des Sprechers nur einen Ausdruck der Verzweiflung des Sprechers erblickt.

${ }^{204}$ Ov. am. 3.6.87 f: quid mecum, furiose, tibi? quid mutua differs / gaudia, quid coeptum, rustice, rumpis iter? $\mathrm{Ob}$ Ovid hier mit dem Ausdruck coitus interruptus spielt, ist nach Suter 1989: 19 mit Anm. 9 nicht zu entscheiden, da diese Wendung erst spät belegt ist.

${ }^{205}$ Vgl. Ov. am. 3.1.43-46. Davis 1989: 29 hebt diesen Aspekt stark hervor („,uneducated river“), ohne auf weitere poetologische Konnotationen einzugehen.

${ }^{206}$ crassus heißt nicht nur „dick“ (hier also gebraucht i. S. v. „,verdickt, schlammig“), sondern auch „roh, ungebildet“; daß Ovid dieses Adjektiv mit aqua kombiniert, ist ungewöhnlich und ein weiterer Hinweis darauf, daß hinter der Beschreibung der Naturerscheinung v. a. eine poetologische Aussage gemacht werden soll.

${ }^{207}$ Kall. fr. 1.24 (Pfeiffer).

${ }^{208}$ Kall. h. 2.108. Ich kann gegen Albert 1988: 228, Anm. 690, keinen unlösbaren Widerspruch in der Tatsache erkennen, daß zweimal, nämlich $a m$. 3.6.19 f und 85 f, vom Übertreten des Ufers durch den Fluß die Rede ist, da dieser sich sowieso ständig in Veränderung befindet und somit nicht nur ein festes und bestimmtes Ufer hat; zum Zeitpunkt von v $85 \mathrm{f}$ ist der torrens eben über die Uferhöhe hinaus gestiegen, die er in $\mathrm{v} 19 \mathrm{f}$ erreicht hatte.

${ }^{209}$ Kall. h. $2.108 \mathrm{f}$.

${ }^{210}$ Kall. h. 2.111 f. Vgl. auch Suter 1989: 18 und Barchiesi 1989: 63: „Il fiume è descritto in termini sostanzialmente 'anticallimachei'”. Barchiesi weist überdies darauf hin, daß diese Beschreibung des Flusses gut korrespondiert mit seiner Funktion als Liebeshindernis (ebd.). Suter 1989: 18 mit Anm. 7 und 8 bemerkt, daß auch die Länge von am. 3.6, mit 106 Versen nach am. 1.8 das zweitlängste Gedicht in den Amores, an den „big river” bei Kallimachos erinnert. Vgl. auch Connors 1994: 109 („As the elegiac narrator becomes more like an epic narrator, the river becomes more anti-Callimachean, that is, more flooded."), und die Wiederaufnahme dieser Gedanken bei Boyd 1997: 212 f.
} 
die erste Handlungsebene ${ }^{211}$, sondern auch auf eine hinter ihr liegende Deutebene. Als amator steht das elegische Ich vor einem stark angeschwollenen Gebirgsbach, der ihn daran hindert, zu seiner Geliebten zu gelangen; auf einer übertragenen Ebene wird der poeta in seiner Arbeit behindert und aufgehalten durch etwas, was er im Bild als stark angeschwollenen, schlammigen und reißenden Fluß bezeichnet, und dies kann nach den oben angeführten Intertexten nichts anderes sein als die Beschäftigung mit epischer Dichtung ${ }^{212}$. Es stellt sich aber die epische Dichtung nicht nur als Hindernis in den Weg, sondern sie drängt sich sogar in die Elegie, in den Prozeß des elegischen Dichtens hinein ${ }^{213}$. Einerseits bezeichnet Ovid dieses Unterfangen als schändlichen Zeitverlust und als dementia ${ }^{214}$. Andererseits scheint er aber unbestreitbar einen gewissen Gefallen an dieser Art des Dichtens, am „episierenden Elegisieren“ gefunden zu haben, sonst würde er nicht soviel Mühe darauf verwenden.

\section{c) Vorübung für die Metamorphosen}

Der Fluß, der sich Ovid in den Weg stellt, ist freilich weder der Euphrat, noch der Permessos, sondern ein namenloser torrens, dessen Größe stark von den jeweiligen Witterungsverhältnissen abhängt und der von mehreren kleinen Bächen gespeist wird (vv 91-96). Poetologisch gedeutet hilft diese Beobachtung, die Interpretation von Elegie 3.6 noch etwas zu verfeinern. Von der Vermischung der beiden Gattungen Elegie und Epos war bereits ausführlich die Rede. Es sind allerdings in der Forschung noch weitere Gattungselemente ausfindig gemacht worden, die Ovid in Elegie 3.6 einfließen läßt²15. Scivoletto sieht in dem Gedicht Elemente der "subjektiven“ sowie der „objektiven" Elegie und des Epigrammes, Fluchformeln und Parallelen zur dramatischen Dichtung ${ }^{216}$. Nach Courtney wirken die Beispiele im Flüssekatalog wie die exempla einer suasoria ${ }^{217}$. Suter bemerkt, daß der Anfang des Gedichts in groben Zügen dem Aufbau einer antiken oratio entspricht und sieht in der Geschichte von Anio und Ilia eine Parodie auf epischen Stil218; nach Verger ist der Beginn des Gedichts eine Gebetsparo$\mathrm{die}^{219}$. Wie der torrens sich aus verschiedenen Bächen speist (riuis collecte caducis, v 91), so lebt das Gedicht selbst aus dem reizvollen Ineinanderfließen mehrerer Gattungsele-

\footnotetext{
${ }^{211}$ So Lenz 1966: 223: „Die Häufung der Beschimpfungen soll komisch wirken.“

212 Vgl. Hutchinson 2008: 187: „Poem 6 includes a narrative on Ilia ... within the narrator's monologue to the river: love-elegy encloses the epic and tragic.“ Im Gegensatz zu Suter wird hier der "große Fluß" nicht als „schlechtes Gedicht“ interpretiert, sondern als Bild für das epische Dichten (Suter 1989: 19: der „big river" als „bad poem“ verhindere, daß Ovid zur Geliebten gelangt, während seine kurzen und damit "guten" Gedichte ihm immer Zutritt zur Geliebten verschafft und andere Arten von Wundern vollbracht hätten, mit Verweis auf am. 2.1.22-28.33 f).

${ }^{213}$ Und damit gelangt die Elegie als „werbende Dichtung“ (vgl. Stroh 1971) nicht mehr zum Ziel, denn es ist nicht mehr vorrangig die puella, die angesprochen wird, sondern die lectores docti; entsprechend kann auch auf der äußeren Handlungsebene der Sprecher von 3.6 seine Geliebte nicht mehr erreichen. Zur „Kreuzung der Gattungen“ als typisches Merkmal für die hellenistische Dichtung und zu deren Einfluß auf die römische Poesie s. Kroll 1924: 202-224.

${ }^{214}$ Ov. am. 3.6.101 f.

${ }^{215}$ Vgl. Scivoletto 1976: 25 (,mescolanza di generi”).

216 Vgl. Scivoletto 1976: 25 mit Anm. 26.

217 Vgl. Courtney 1988: 23.

218 Vgl. Suter 1989: 19.

${ }^{219}$ Vgl. Verger 1992: 141-143.
} 
mente $^{220}$. Und gerade dadurch wird hier von Ovid eine Technik vorweggenommen, die in seinem eigenen Epos, den Metamorphosen, ständig zur Anwendung kommen wird. So wie der torrens aus verschiedenen Bächen gespeist wird, so ist auch das geplante Großepos des Dichters kein Epos in reiner und unvermischter Form, sondern ein Werk, das schillernd in sich Elemente verschiedenster Gattungen vereint ${ }^{221}$.

In erster Linie ist der torrens in Amores 3.6 ein Bild für die epische Dichtung allgemein; durch seine besonderen Eigenarten und Merkmale, die ihn von anderen großen, „epischen“ Flüssen deutlich unterscheiden, ist er aber auch ein Bild, das vorausverweist auf die spezielle Art und Weise der späteren epischen Technik Ovids ${ }^{222}$. Sieht man in dieser Elegie eine Art Vorübung für die Metamorphosen, bildlich verdichtet in der Beschreibung des torrens, lassen sich noch mehr Bezüge herstellen. Das von Ovid geplante Werk ${ }^{223}$ ist zwar in einer gewissen Hinsicht ein Epos zu nennen, in anderer Hinsicht aber ist es aufgrund der Vermischung der Gattungs- und Stilelemente ein Werk, das es in dieser Form vor Ovid nicht gegeben hat und das somit ein literarisches Novum darstellt ${ }^{224}$. Es ist kaum anzunehmen, daß der Dichter sich dessen nicht bewußt war; im Gegenteil: in noua fert animus ... läßt Ovid die Metamorphosen beginnen, und auch ohne die Fortsetzung erhalten diese Worte bereits einen eigenen Sinn ${ }^{225}$. Diese Merkmale der Neuheit und Unbekanntheit finden nun im Bild des torrens von Amores 3.6 eine genaue Entsprechung; fast alle Aussagen lassen sich neben der vordergründigen Ebene auch übertragen auf der poetologischen Ebene verstehen und sinnvoll zu einem Ganzen verbinden. Dieses neue literarische Werk, das dem Dichter vor Augen schwebt und sich ihm in den Weg stellt, ist nicht "legitimiert", es hat keine vornehme Abkunft und keinen Ruhm (vv 89 f):

$$
\begin{aligned}
& \text { quid? si legitimum flueres, si nobile flumen, } \\
& \text { si tibi per terras maxima fama foret - }
\end{aligned}
$$

\footnotetext{
${ }^{220}$ Vgl. Suter 1989: 19.

${ }^{221}$ Vgl. Farrell 1992, der die mélange der Gattungen in den Metamorphosen exemplarisch anhand der Polyphem-Episode im 13. Buch aufzeigt, und Bernbeck 1967: 129; dort weitere Verweise auf die einschlägige Literatur. Neben der Speisung durch mehrere Bäche gibt es noch ein anderes Bild, mit dem der Dichter in raffinierter Manier auf die Metamorphosen anspielen könnte, und das ist die saisonbedingte Veränderung der Gestalt des Flusses. Jetzt ist er mächtig angeschwollen ( $\mathrm{v} 7 \mathrm{f}$ etc.), doch vordem war er noch ein kleines Rinnsal (paruus eras, v 5); im Winter nimmt er schlammig seinen Lauf, im Sommer ist er offensichtlich ausgetrocknet (vv 95 f). Auch wenn damit keine Metamorphose im strengen Sinn vorliegt, ist im Rahmen dessen, was im Bild möglich ist, eventuell ein Vorausverweis auf die Metamorphosen gemacht. Dem witzigen Paradoxon eines ausgetrockneten Flusses bzw. Flußgottes hat Eggers 1984: 137-139 die gebührende Aufmerksamkeit zukommen lassen.

${ }^{222}$ Daß das sechste Gedicht des dritten Amoresbuches den Charakter einer literarischen Vorübung besitzt, die vor allem auf die Metamorphosen vorausverweist, ist in der Forschung bereits mehrfach behauptet worden, vgl. dazu Luck 1969: 158 („,a sort of preview of the Metamorphoses“); Sabot 1976: 489; Verger 1992: 141 mit Anm. 1 und Holzberg 1998: 72. Als Ausgangspunkt für diese Behauptung diente allerdings nicht die poetologische Deutung des torrens, sondern die Beobachtung, daß ein Flüssekatalog mit einem länger ausgeführten Beispiel innerhalb eines elegischen Liebesgedichtes einen Fremdkörper epischer Provenienz darstellt. Beide Zugangsweisen führen zum gleichen Ergebnis und verstärken es.

${ }^{223} \mathrm{Daß}$ Ovid mit den Vorarbeiten zu den Metamorphosen schon früh begonnen hat, ist wahrscheinlich, vgl. Luck 1961: 171.

${ }^{224}$ Vgl. Bernbeck 1967: 127 ff. Nach Bernbeck sind die Metamorphosen „ein Gedicht, welches das Epos umspielt und daher mit diesem in enger Verbindung steht, selbst aber eigentlich keiner der bekannten poetischen Gattungen zuzuordnen ist", ebd. 129.

225 Zum Proöm der Metamorphosen s. zuletzt Kenney 2006; zum oben genannten Gedanken der „Neuigkeit“ ebd. 266.
} 
„Es wäre etwas anderes, wenn ${ }^{226}$ du rechtmäßig fließen würdest, wenn du ein vornehmer Fluß wärest, wenn du in den Ländern umher größte Berühmtheit besäßest -“

Die neue Mischform hat keinen Namen, sie kommt nirgends her, hat keinen Vertreter, man weiß nicht, wo man sie anzusiedeln hat; sie ist im letzten Ovids ureigene Schöpfung (vv $91 \mathrm{f})$ :

nomen habes nullum, riuis collecte caducis, nec tibi sunt fontes nec tibi certa domus.

„Du hast keinen Namen, bist ein Sammelsurium aus herabstürzenden Bächen, weder besitzt du Quellen noch ein sicheres Zuhause."

Amores 3.6 als kleine „epische Vorübung“ des Elegikers ${ }^{227}$, die Eigenarten des torrens als Vorausverweis auf die Charakteristika von Ovids epischer Metamorphosendichtung - selbst wenn man der Interpretation so weit nicht folgen möchte, so bleibt doch die Beobachtung bestehen, daß die Rahmenhandlung der Elegie auf poetologischer Ebene das Verhältnis von elegischer und epischer Dichtung zum Thema macht.

\section{d) Das Amphibolische an der Vermählung von Anio und Ilia}

Diese poetologische Tiefendimension des Rahmenteiles spiegelt sich nun aber auch im Innenteil der Elegie, näherhin in dem ausgeführten mythischen exemplum von Ilia und Anio. Will man den Fluß Anio auf einer poetologischen „Skala“ einordnen, so läßt er sich aufgrund seiner Epitheta (per caua saxa uolutans, v 45; animosus, v 51; lubricus, v 81) und der Beschreibung seiner Fruchtbarkeit und Größe ${ }^{228}$ eindeutig als „epischer Fluß" charakterisieren. Wie in der Rahmenhandlung des Gedichts also der elegische Dichter vor dem "epischen“ torrens steht, so steht in der mythischen Erzählung des Innenteils Ilia vor dem „epischen“ Anio, und beiden erscheint ihr Zustand „ausweglos". Wenn in der Rahmenhandlung der Sturzbach für das Epos, der Reisende für den Elegiker steht, dann liegt es nahe, im Innenteil Ilia als „elegisches Pendant“ zum „epischen“ Anio zu interpretieren. Daß Ilia eine solche poetologische Bildfunktion durchaus zugewiesen werden kann, läßt sich durch mehrere werkinterne Anspielungen und wörtliche Anklänge plausibel machen.

In der eindeutig poetologischen und von daher 3.6 besonders nahestehenden Programmelegie Amores 3.1 entwirft Ovid das Bild vom Dichter als Schiedsrichter in einem Schönheitswettbewerb ${ }^{229}$ : die Tragödie, ein dem Epos vergleichbares literarisches „Großprojekt ${ }^{\prime 230}$, streitet mit der Elegie um die Gunst des Dichters, der sich dann dazu entschließt, für kurze Zeit sich noch weiterhin der Elegie zu widmen. Bei näherer Betrachtung lassen sich auffallende Parallelen in Redeweise und Charakterisierung feststellen

\footnotetext{
${ }^{226}$ Zur Übersetzung von quid si s. Fränkel 1970: 193, Anm. 56.

${ }_{227}$ In diese Richtung geht auch Boyd 1997: 14, in Hinblick auf die Amores insgesamt: „I shall argue ... that the Amores should be understood as having a central position on the continuum of Ovid's interest in the boundaries of genre ... In other words, I shall suggest that we read the Amores as forerunners of Ovid's later work in the best possible sense, rather than as forgettable juvenilia."

${ }^{228}$ Vgl. Ov. am. 3.6.46.61-64. In die Nähe zum torrens der Rahmenhandlung rücken den Anio auch seine rapidae aquae, vgl. $\mathrm{v} 51$ und $\mathrm{v} 80$.

${ }^{229} \mathrm{Vgl}$. dazu ausführlich Zgoll 2010 (erscheint in Kürze).

${ }^{230}$ Vgl. Ov. am. 3.1.70: a tergo grandius urguet opus; vgl. auch 3.1.11-14.23 f.64.68.
} 
zwischen der personifizierten Tragödie in Amores 3.1 und dem "epischen“ Anio in 3.6, und zwischen dem Dichter bzw. der Elegie in 3.1 und der Person der Ilia in 3.6. Ist die Elegie, die in 3.1 den Sieg davonträgt, noch schön gekämmt, parfumiert und reizvoll gekleidet, so ist Ilia bzw. die Elegie in 3.6 bereits im Stadium der Auflösung begriffen $^{231}$. In 3.1.19 wird berichtet, daß auf den elegischen Dichter oft verächtlich mit dem Finger gezeigt wird:

saepe aliquis digito uatem designat euntem ;

genauso heißt es 3.6.77 von Ilia, daß sie dies nicht weiter ertragen könne:

quid moror et digitis designor adultera uulgi?

Während der elegische Dichter in 3.1.21 f sich nichts daraus zu machen scheint, daß man sich über ihn in ganz Rom den Mund zerreißt:

fabula, nec sentis, tota iactaris in urbe, dum tua praeterito facta pudore refers,

will Ilia dieser Schande nun endgültig entgehen (3.6.78):

desint famosus quae notet ora pudor!

Wie der „epische“ Anio in 3.6 ergreift in 3.1 die Tragödie als erste das Wort. Die Struktur, Frage und Anrede des Gegenübers, ist auffallend parallel:

am. 3.1.15 f:

Et prior 'ecquis erit,' dixit, 'tibi finis amandi,

O argumenti lente poeta tui?

am. 3.6.53 f:

atque ita 'quid nostras' dixit 'teris anxia ripas, Ilia, ab Idaeo Laumedonte genus?

Wie bei der Tragödie, so ist auch der Wohnsitz des Epos (bzw. des Anio) mit einer regia zu vergleichen ${ }^{232}$, und beide, Tragödie wie Anio, werden mit dem Adjektiv animosus bedacht $^{233}$.

In Amores 3.9 wird der Tod Tibulls betrauert. Wie 3.1 und 3.6 unterscheidet sich Elegie 3.9 deutlich von den übrigen Elegien, die um das Verhältnis von amator und geliebter puella kreisen. Und wiederum ergeben sich deutliche Parallelen zwischen der Schilderung der trauernden Elegie bzw. des trauernden Amor und der trauernden Ilia in 3.6. Wie die personifizierte Elegie, so ist auch Ilia flebilis ${ }^{234}$; wie Amor schlägt sie sich die Brust ${ }^{235}$ und vergießt Tränen ${ }^{236}$; bei beiden handelt es sich um unverdienten und unwürdigen Schmerz ${ }^{237}$.

\footnotetext{
${ }^{231}$ Vgl. Ov. am. 3.1.7-10 mit am. 3.6.47-50; beide Male wird auf Haare, Gesicht und Füße eingegangen.

${ }^{232}$ Ov. am. 3.1.40: obruit exiguas regia uestra fores. am. 3.6.61: Ilia, pone metus: tibi regia nostra patebit.

${ }^{233}$ Ov. am. 3.1.35: animosa Tragoedia. am. 3.6.51: Anien ... animosus.

${ }^{234}$ Ov. am. 3.9.3: flebilis ... Elegeia. am. 3.6.68: spargebat ... flebilis ... sinus.

235 Ov. am. 3.9.10: pectoraque infesta tundat aperta manu. am. 3.6.58: pectoraque insana plangis aperta manu.

${ }^{236}$ Ov. am. 3.9.11: excipiunt lacrimas sparsi per colla capilli. am. 3.6.68: spargebat tepido flebilis imbre sinus.

${ }^{237}$ Ov. am. 3.9.3: indignos ... solve capillos. am. 3.6.72: edidit indignos ... sonos.
} 


\section{e) "Episierendes Elegisieren”}

Wenn man diese Parallelen in Wortwahl, Syntax und Inhalt nicht als Zufall ansehen will, so wäre in der Erzählung von Anio und Ilia die poetologische Aussage der Rahmenerzählung in raffinierter Weise gespiegelt und vertieft. Im Rahmen wie im Innenteil geht es vornehmlich um das gewaltsame Eindringen epischer Elemente in die elegische Dichtung und um das daraus sich ergebende unauflösbare Nebeneinander und Ineinander der beiden Gattungen, um ein „episierendes Elegisieren“ - so wie es sich später in den Metamorphosen umgekehrt, aber ganz vergleichbar um ein „elegisierendes Episieren" handeln wird ${ }^{238}$.

Im Rahmen wird die genuin elegische Paraklausithyron-Szenerie, die Verhinderung eines Zusammenkommens der Liebenden, dadurch „episch“ verfremdet, daß die Tür durch einen Fluß ersetzt wird. Diese Umstellung zieht die Folge nach sich, daß der Liebhaber seine Rede nicht mehr wie in Amores 1.6 mit banalen Schmeicheleien und rüden Drohungen anfüllt (Ebene der elegischen Welt), sondern sie mit der Erzählung von Flußliebesgeschichten geradezu schmückt und erhöht (Ebene des epischen Erzählens).

Im Innenteil wird dies veranschaulicht anhand der Erzählung von Anio und Ilia. Die Elegie (= Ilia) stürzt sich in das Epos (= Anio), und das Epos vermählt sich daraufhin mit der Elegie - eine wahrhaft amphibolische Vermählung. Und dazu ein glücklicher Einfall, ein mit Raffinesse gewähltes, treffendes poetisches Bild für die bereits praktizierte neue Art des episierend-elegisierenden Dichtens und für das geplante neue und große Werk des Dichters, gehen doch die Abweichungen vom epischen Stil in den Metamorphosen vielfach auf das Gebiet der Ovid so vertrauten und von ihm bevorzugten elegischen Dichtung ${ }^{239}$, so daß das Bild einer Heirat von Epos und Elegie auch ein zentrales Wesensmerkmal der Metamorphosen vorwegnimmt.

Gewiß kann man fragen, wie es zur Vorstellung eines innovativen Dichtungsprojekts paßt, daß die ein solches Vorhaben symbolisierende Verbindung zwischen Ilia und Anio so amphibolisch und nicht rundweg positiv dargestellt wird, warum der auf das Eindringen epischer Elemente in das elegische Dichten hindeutende Sturzbach am Ende der Elegie beschimpft und verflucht wird. Unsicherheit und Ärger Ovids über seine sich verselbständigenden Talente, bevor es an der Zeit ist? Das wäre sehr weit hergeholt. Man kann bei zwei unterschiedlichen, sich überlagernden und parallel laufenden Deutebenen eines Gedichtes nicht auf beiden Ebenen gleiche Stringenz und Kohärenz bis ins letzte Detail erwarten. Ovid muß bei allen poetologischen „Reizwörtern" und Andeutungen doch auch in der „elegischen Welt" und „im Bild“ bleiben, die vordergründige story der Elegie muß „funktionieren“. Der Bereich der Elegie würde vollends überschritten, hätte man das Gedicht positiv ausgehen lassen, denn ein auf

\footnotetext{
${ }^{238} \mathrm{Zu}$ einer anderen Deutung des Verhältnisses zwischen Binnenerzählung und Rahmen der Elegie 3.6 (ohne poetologische Interpretation) gelangt Gärtner 2005, in einem Aufsatz über die Exempelkataloge in den Amores, bei denen seinen Untersuchungen zufolge das jeweils letzte Exempel „eine den formalen Anschluß des Gleichnisses transzendierende, das Verständnis vertiefende Sinndimension“ (ebd. 277) aufweist. Gemäß seiner Auffassung von Anio als „göttlichem Retter“ kommt er zu dem Ergebnis, daß Anio „,als Musterbild eines gütigen Flusses dem ungnädigen Gießbach entgegengestellt“ werde; wiederum sei, "wie schon mehrfach zuvor beobachtet, das letzte Exempel innerlich am subtilsten auf die erotische Konstellation des Gesamtgedichts abgestimmt, wobei die Abstimmung in diesem Fall auf einen kontrastiven Gegensatz hinausläuft" (ebd. 286).

${ }^{239}$ Vgl. Bernbeck 1967: 134.
} 
eine Suasorie eingehender und deshalb abschwellender Fluß gehört gänzlich in den Bereich des Mythos, und damit hätte man auch den Topos vom erfolglosen amator und das Paraklausithyron-Motiv fallen lassen müssen. Außerdem wäre es zugleich auf der poetologischen Ebene zu einer Inkonsistenz gekommen, denn der Sturzbach hätte damit auch seine „epischen“ und auf die Metamorphosen vorausweisenden Charakteristika verloren. Jede Innovation erschreckt und fasziniert, zieht an und stößt zugleich ab; wenn man so will, spiegelt der anfangs gelobte, am Ende geschmähte Sturzbach und die mit Untertönen versehene Vereinigung Anios mit Ilia diese Ambivalenz wider.

Wie in Amores 3.1 geht es auch in 3.6 meines Erachtens lediglich dem Anschein nach um einen „Abschied“ von der Elegie ${ }^{240}$. In 3.1 haben die Elegie und ihr Dichter von der personifizierten Tragödie nur noch einen winzigen Aufschub bekommen (exiguum tempus, 3.1.67), doch mittlerweile sind schon einige Elegien geschrieben worden, ohne daß der Eindruck entstand, daß Ovid diese knappe Zeitvorgabe allzu ernst nehmen würde. In 3.6 irrt die Elegie am Ende ihrer Kräfte, kurz vor ihrem „Tod“, verzweifelt umher, wird aber buchstäblich in letzter Sekunde vom Epos aufgefangen und einverleibt, so $\mathrm{daß} \mathrm{ihr}$ - freilich in veränderter Form - ein Weiterleben sicher ist. Die Elegie ist tot - es lebe die Elegie!

Dr. Christian Zgoll

Seminar für Klassische Philologie, Georg-August-Universität Göttingen

E-mail:Christian.Zgoll@phil.uni-goettingen.de

${ }^{240}$ Zum dritten Amoresbuch als ernst gemeinter „Abschied auf die Liebeselegie“ vgl. Holzberg 1998: 73 und 2001: 134; Weinlich 1999: 12 und 266. Zur Position, daß dieser Abschied nur ein scheinbarer ist, vgl. Zgoll 2010 (erscheint in Kürze). 


\section{Literaturverzeichnis}

Adams, J. N. (1982) The Latin Sexual Vocabulary. London: Duckworth.

Albert, W. (1988) Das mimetische Gedicht in der Antike: Geschichte und Typologie von den Anfüngen bis in die augusteische Zeit. (Beiträge zur klassischen Philologie; 190.) Frankfurt a. M.: Athenäum.

Albrecht, M. v. (2000) ,Ovids Amores und sein Gesamtwerk.' - Wiener Studien 113, 167-180.

Altheim, F. (1953) Römische Religionsgeschichte. Bd. 2. Baden-Baden: Verlag für Kunst und Wissenschaft.

Axelson, B. (1945) Unpoetische Wörter. Lund: Gleerup.

Barchiesi, A. (1989) ,Voci e istanze narrative nelle Metamorfosi di Ovidio.' - Materiali e discussioni per l'analisi dei testi classici 23, 55-97.

Bernbeck, E. J. (1967) Beobachtungen zur Darstellungsart in Ovids Metamorphosen. (Zetemata; 43.) München: Beck.

Bernhardt, U. (1986) Die Funktion der Kataloge in Ovids Exilpoesie. (Altertumswissenschaftliche Texte und Studien; 15.) Hildesheim; Zürich; New York: Olms-Weidmann.

Bömer, F. (1957/1958) Publius Ovidius Naso, Die Fasten, hg., übers. u. komm., Bd. I (1957): Einl., Text u. Übers., Bd. II (1958): Kommentar. Heidelberg: Winter.

Boyd, B. W. (1997) Ovid's Literary Loves: Influence and Innovation in the Amores. Ann Arbor: University of Michigan Press.

Boyd, B. W. (2002) ,The Amores: The Invention of Ovid.' - Boyd, B. W. (ed.), Brill's Companion to Ovid. Leiden; Boston; Köln: Brill, 91-116.

Brandt, P. (1911) P. Ovidi Nasonis amorum libri tres, erklärt von P. Brandt. 1. Abt.: Text und Kommentar. Leipzig: Dieterich.

Bretzigheimer, G. (1994) ,Diana in Ovids ,Metamorphosen'.' - Gymnasium 101, 506-546.

Bretzigheimer, G. (2001) Ovids Amores: Poetik in der Erotik. (Classica Monacensia; 22.) Tübingen: Narr.

Burkert, W. (1993) ,Mythos - Begriff, Struktur, Funktionen.' - Graf, F. (Hg.), Mythos in mythenloser Gesellschaft: Das Paradigma Roms. (Colloquium Rauricum; 3.) Stuttgart; Leipzig: Teubner, 9-24.

Clauss, J. J. (1989) ,The Episode of the Lycian Farmers in Ovid's Metamorphoses.' - Harvard Studies in Classical Philology 92, 297-314.

Connors, C. (1994) ,Ennius, Ovid, and Representations of Ilia.' - Materiali e discussioni per l'analisi dei testi classici 32, 99-112.

Copley, F. O. (1956) Exclusus Amator: A Study in Latin Love Poetry. (Philological Monographs; 17.) New York: American Philological Association.

Courtney, E. (1988) ,Some Literary Jokes in Ovid's Amores.' - Horsfall, N. (ed.), Vir bonus discendi peritus: Studies in Celebration of Otto Skutsch's Eightieth Birthday. (Bulletin of the Institute of Classical Studies of the University of London: Supplement; 51.) London: University of London, Institute of Classical Studies, 18-23.

Cunnighan, M. P. (1958) ,Ovids poetica.' - Classical Journal 53, 253-259.

Davis, J. T. (1980) ,Exempla and Anti-Exempla in the Amores of Ovid.' - Latomus 39.1, $412-417$. 
Davis, J. T. (1981) ,Risit Amor: Aspects of Literary Burlesque in Ovid's Amores.' - Aufstieg und Niedergang der Römischen Welt II.31.4. Berlin; New York: de Gruyter, 24602506.

Davis, J. T. (1989) Fictus Adulter: Poet as Actor in the Amores. Amsterdam: Gieben.

Davis, P. J. (2006) Ovid and Augustus. A political reading of Ovid's erotic poems. London: Duckworth.

De Caro, A. (2003) Si qua fides: Gli Amores di Ovidio e la persuasione elegiaca. (Letteratura Classica; 25.) Palermo: Palumbo.

Donini, V. (1969) ,In Ovidi Amor. III 6 adnotationes.' - Latinitas 17.3, 210-222.

Eggers, T. (1984) Die Darstellung von Naturgottheiten bei Ovid und früheren Dichtern. (Studien zur Geschichte und Kultur des Altertums, N. F., 1. Reihe; 1.) Paderborn: Schöningh.

Farrell, J. (1992) ,Dialogue of Genres in Ovid's 'Lovesong of Polyphemus' (Metamorphoses 13.719-897).' - American Journal of Philology 113, 235-268.

Fränkel, H. (1970) Ovid: Ein Dichter zwischen zwei Welten. Darmstadt: Wissenschaftliche Buchgesellschaft. [Engl. Originaltitel: Fränkel, H. (1945) Ovid: A Poet between Two Worlds. (Sather Classical Lectures; 18.) Berkeley: University of California Press; Los Angeles: Cambridge University Press.]

Frécaut, J.-M. (1972) L'esprit et l'humour chez Ovide. Grenoble: Presses universitaires de Grenoble.

Gärtner, T. (2005) ,Zu einer Besonderheit der mythologischen Exempelkataloge in den ovidischen Amores.' - Maia 57, 277-290.

Gärtner, T. (2008) ,Die hellenistische Katalogdichtung des Phanokles über homosexuelle Liebesbeziehungen. Untersuchungen zur tendenziellen Gestaltung und zum literarischen Nachleben.' - Mnemosyne 61, 18-44.

Gauly, B. M. (1990) Liebeserfahrungen. Zur Rolle des elegischen Ich in Ovids Amores. (Studien zur klassischen Philologie; 48.) Frankfurt am Main etc: Lang.

Gerlach, W. (1960) Ovid: Fasti - Festkalender Roms. Lateinisch und Deutsch. München: Heimeran.

Glatt, M. (1991) Die "andere Welt“ der römischen Elegiker. (Studien zur klassischen Philologie; 54.) Frankfurt am Main etc: Lang.

Heinze, R. (1919) Ovids elegische Erzählung. (Berichte über die Verhandlungen der Sächsischen Akademie der Wissenschaften zu Leipzig, Philologisch-historische Klasse; Bd. 71, Heft 7.) Leipzig: Teubner.

Hinds, S. (2006) ,Generalizing About Ovid.' - Knox, P. E. (ed.), Oxford Readings in Ovid. Oxford: Oxford University Press, 15-50.

Holzberg, N. (1995) Publius Ovidius Naso, Fasti - Festkalender Roms, lat.-dt., auf der Grundlage der Ausgabe von W. Gerlach neu übers. und hg. von N. Holzberg. München; Zürich: Artemis.

Holzberg, N. (1998) Ovid: Dichter und Werk. 2. verbesserte Aufl. München: Beck.

Holzberg, N. (2001) Die römische Liebeselegie. Eine Einführung. 2. völlig überarb. Aufl. Darmstadt: Wissenschaftliche Buchgesellschaft.

Howald, E.; Staiger, E. (1955) Callimachi poemata, graece et germanice, transtulerunt praefati interpretati sunt E. Howald \& E. Staiger. Zürich: Artemis.

Hunter, R. (2006) The Shadow of Callimachus. Studies in the reception of Hellenistic poetry at Rome. (Roman Literature and Its Contexts.) Cambridge: Cambridge University Press.

Hutchinson, G. O. (2008) Talking Books. Readings in Hellenistic an Roman Books of Poetry. Oxford: Oxford University Press. 
Katz, P. (2009) ,Teaching the Elegiac Lover in Ovid's Amores.' - Classical World 102.2, $163-167$.

Kenney, E. J. (2006) ,Ovidius Prooemians.' - Knox, P. E. (ed.), Oxford Readings in Ovid. Oxford: Oxford University Press, 265-273.

Kroll, W. (1924) Studien zum Verständnis der römischen Literatur. Stuttgart: Metzler. (Ndr. 1964.)

Latta, B. (1963) Die Stellung der Doppelbriefe (Heroides 16-21) im Gesamtwerk Ovids. Marburg: Görich.

Le Bonniec, H. (1969) Ovide, Les Fastes, hg. von H. Le Bonniec. Bd. 1. Bologna: Pàtron.

Lenz, F. W. (1965) Ovid, Die Liebeselegien, lat.-dt., hg. u. übers. von F. W. Lenz. (Schriften und Quellen der Alten Welt; 15.) Berlin: Akademie-Verlag. (2., durchgesehene Aufl. 1966.)

Lörcher, G. (1975) Der Aufbau der drei Bücher von Ovids Amores. (Heuremata; 3.) Amsterdam: Grüner.

Lorentz, A. K. (1909-1915) ,Rea Silvia.' - Roscher, W. H. (Hrsg.), Ausführliches Lexikon der griechischen und römischen Mythologie. Leipzig: Teubner. Bd. IV, 63-64.

Luck, G. (1961) Die römische Liebeselegie. Heidelberg: Winter. (Übersetzte und überarb. Neuaufl. des engl. Orig.: Luck, G. (1959) The Latin Love Elegy. London: Methuen.)

Luck, G. (21969) The Latin Love Elegy. London: Methuen.

Marg, W.; Harder, R. (21962) Publius Ovidius Naso: Amores - Liebesgedichte, hg. und übers. von W. Marg \& R. Harder, lat.-dt. München; Zürich: Heimeran. (Ndr. 1992.)

Martyn, J. R. C. (1981) ,Naso - Desultor amoris (Amores I-III).' - Aufstieg und Niedergang der Römischen Welt II.31.4. Berlin; New York: de Gruyter, 2436-2458.

Morgan, K. (1977) Ovid's art of imitation. Propertius in the Amores. (Mnemosyne, Suppl.; 47.) Leiden: Brill.

Niebuhr, B. (1833) Römische Geschichte. Bd. 1 (4. unv. Aufl.). Berlin: Reimer.

Olstein, K. A. (1973) Motif Analysis of Ovid's Amores. Diss. Columbia.

Otis, B. (1966) Ovid as an Epic Poet. Cambridge: Cambridge University Press. (2. Aufl. 1970.)

Otis, B. (1968) ,Ovids Liebesdichtungen und die Augusteische Zeit.' - Albrecht, M. von; Zinn, E. (Hg.), Ovid. (Wege der Forschung; 92.) Darmstadt: Wissenschaftliche Buchgesellschaft, 233-254.

Preller, J. (1858) Römische Mythologie. Berlin: Weidmann.

Radke, G. (1975) ,Rea.' - Ziegler, K.; Sontheimer, W. (Hg.), Der Kleine Pauly. Lexikon der Antike. Bd. 4, 1344-1345.

Reitzenstein, E. (1968) ,Das neue Kunstwollen in den Amores Ovids.' - Albrecht, M. von; Zinn, E. (Hg.), Ovid. (Wege der Forschung; 92.) Darmstadt: Wissenschaftliche Buchgesellschaft, 206-232 (= Rheinisches Museum 84, 1935, 62-88).

Rimell, V. (2006) Ovid's Lovers. Desire, Difference, and the Poetic Imagination. Cambridge: Cambridge University Press.

Rosenberg, A. (1914) ,Rea Silvia.' - Kroll, W.; Witte, K. (Hg.), Paulys Real-Encyklopädie der classischen Altertumswissenschaft, 2. Reihe, Bd. I.1. Stuttgart: Metzler, 341-345.

Rutledge, E. S. (1980) ,Vergil and Ovid on the Tiber.' - Classical Journal 75, 301-304.

Sabot, A.-F. (1976) Ovide, poète de l'amour dans ses ceuvres de jeunesse: Amores, Héroïdes, Ars Amatoria, Remedia Amoris, De Medicamine Faciei Femineae. Paris: Ophrys.

Schmitzer, U. (2001) Ovid. (Olms Studienbücher Antike; 7.) Hildesheim etc: Olms. 
Schubert, W. (1992) Die Mythologie in den nichtmythologischen Dichtungen Ovids. (Studien zur klassischen Philologie; 66.) Frankfurt am Main etc: Lang.

Scivoletto, N. (1976) Musa Iocosa. Studio sulla poesia giovanile di Ovidio. Roma: ELIA.

Segal, Ch. P. (1969) Landscape in Ovid's Metamorphoses. A study in the transformations of a literary symbol. (Hermes Einzelschriften; 23.) Wiesbaden: Steiner.

Skutsch, O. (1985) Ennius: The Annals of Q. Ennius, ed. with introduction and commentary by O. Skutsch. Oxford: Clarendon.

Stroh, W. (1971) Die römische Liebeselegie als werbende Dichtung. Amsterdam: Hakkert.

Stroh, W. (1979) ,Ovids Liebeskunst und die Ehegesetze des Augustus.' - Gymnasium $86,323-352$.

Suter, A. (1989) ,Ovid, from Image to Narrative: Amores 1.8 and 3.6.' - Classical World 83, 15-20.

Verger, R. de (1992) ,Elucidations on Ovid, Amores 3.6. 1-22.' - Liverpool Classical Monthly 17, 141-143.

Watson, P. (1982) ,Ovid and cultus.' - Transactions and Proceedings of the American Philological Association 112, 237-244.

Weinlich, B. (1999) Ovids Amores: Gedichtfolge und Handlungsablauf. (Beiträge zur Altertumskunde; 128.) Stuttgart; Leipzig: Teubner.

Wilhelm, F. (1933) ,Mitteilungen. Zu Ovid Am. III 6.' - Philologische Wochenschrift Nr. 5, 141-144 und Nr. 6, 169-173.

Woytek, E. (1995) ,Die unlauteren Absichten eines Ehrenmannes (Zur Doppelbödigkeit von Ovid, Amores 1,3).' - Wiener Studien 108, 417-438.

Zgoll, Chr. (2010) ,Crossroads Narrative or Beauty Contest? Role-Play in Ovid, Amores 3.1.' (erscheint in Kürze).

Zwierlein, O. (1999) Die Ovid- und Vergil-Revision in tiberischer Zeit. Bd. I: Prolegomena. (Untersuchungen zur antiken Literatur und Geschichte; 57.) Berlin; New York: de Gruyter. 


\title{
Anhang: Textkritische Bemerkung zu Vers 3.6.31
}

\author{
te quoque promissam Xantho, Penee, Creusam
}

Die Handschriften haben statt Xutho (Konjektur von Heinsius) einheitlich Xantho. Xantho kann man natürlich als Verschreibung bzw. Doppelung von Vers 28 werten, wo dasselbe Wort auch noch an etwa gleicher Stelle im Vers kommt (cum rapuit vultus, Xanthe, Neaera tuos). Der Abwechslung halber würde man hier also einen neuen Namen vermuten, weshalb Heinsius wohl Xutho konjeziert hat.

Xuthos ist kein Flußgott, sondern ein in Thessalien angesiedelter Ahnherr des Stammes der Ionier, der mit Kreusa, der Tochter des athenischen Königs Erechtheus, Ion, Achaios und Diomede zeugt ${ }^{241}$. Xuthos ist also denkbar und auch mit einer Kreusa assoziiert. Nach der geläufigen Version des Mythos vermählt sich Xuthos mit Kreusa, während sie ihm hier bei Ovid von Peneios weggenommen wird; außerdem bekommt Xuthos Kreusa erst in Attika, nachdem er aus Thessalien entweder weggeschickt oder vertrieben wurde.

Dies könnte sich freilich auch noch nach dem Raub der Kreusa durch Peneios zugetragen haben, liefe aber auf eine relativ komplizierte Erzählstruktur hinaus: Peneios raubt Kreusa, die Xuthos versprochen war, muß sich zu diesem Raub aber als in Thessalien angesiedelter Flußgott nach Attika aufmachen - was an sich schon eine für den Mythos ganz merkwürdige Konstruktion wäre -, Kreusa aus Athen rauben, nach Thessalien zurückkehren und sie dort vor Xuthos verbergen; Xuthos, ursprünglich Thessalier, mittlerweile aber Athener, würde dann nach Thessalien zurückgehen, die Geraubte aufspüren und sie wieder nach Attika als Braut heimführen, wo er dann mit Kreusa seine drei Kinder zeugt. Es spielt kaum eine Rolle, in welchem zeitlichen Verhältnis die Beziehung der Kreusa mit Peneios zu derjenigen mit Xuthos steht; viel problematischer ist die geographische Schwierigkeit der Vereinigung einer athenischen Königstochter mit einem thessalischen Flußgott.

Unbefriedigend ist bei dieser Lösung zudem, daß ganz entgegen den so zahlreichen anderen Entführungsmythen Kreusa von Peneios keine Kinder empfängt. Das widerspricht auch der "mythischen Logik", nach der die Umarmung eines Gottes nie folgenlos bleibt ${ }^{242}$; ein solchermaßen konstruiertes Eingreifen eines Gottes wird in den meisten Fällen ja gerade für die Legitimation einer göttlichen Abstammung bestimmter Dynastien bemüht.

Xanthos hießen mehrere Flüsse, nicht nur der troische Skamandros. Insofern kann hier ein anderer Xanthos gemeint sein als in Vers 28, z.B. das gleichnamige Flüßchen in Epirus. Das würde gut zu Peneios passen, der ebenfalls in Epirus entspringt. Wenn die beiden Rivalen waren und als solche in einem Mythos auftraten, dann sollten sie sich auch geographisch nahe liegen. Der Peneios ist der Hauptfluß Thessaliens, und neben der attischen Kreusa ist auch eine thessalische Nymphe namens Kreusa bezeugt, eine Tochter der Ge, die dem Flußgott Peneios im Pindusgebirge den Lapithenkönig Hypseus gebiert ${ }^{243}$. Denkbar wäre also durchaus, daß ein Mythos exisitert hat, nach dem

\footnotetext{
${ }^{241}$ Vgl. zum Mythos von Xuthos Hes. cat. 10a.20-24; Konon FGrH 26 F 1.27; Strab. 8.7.1; Paus. 7.1.2 f.

${ }^{242}$ So heißt es schon bei Homer Od. 11.249 f: „nicht ohne Erfolg ist der Beischlaf der Unsterblichen“ (oùk

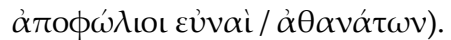

${ }^{243}$ Vgl. Pind. P. 9.15 f (mit Scholien) und Diod. 4.69.
} 
die beiden Flußgötter Peneios und Xanthos Rivalen waren, Peneios aber dem (kleineren und unbedeutenderen) Xanthos die Nymphe Kreusa raubt und mit ihr Nachkommenschaft zeugt ${ }^{244}$.

Eine solche Version würde zu den anderen Mythen des Ovid'schen Flußkataloges gut passen, und es wäre kein Gegenargument, darauf zu verweisen, daß alle anderen Flußgötter ja gerade besonders prominente Gestalten sind, denn in dem Distichon 3.6.31 f geht es eindeutig um den prominenten Peneios, während Xanthos (oder $\mathrm{Xu}$ thos) eine weniger wichtige Nebenrolle spielen kann - eben weil das Distichon schon mit einem prominenten Flußgott „belegt“ ist. Geographische Umständlichkeiten wie bei einem angenommenen Verhältnis zwischen Xuthos und Kreusa wären hier nicht störend, und es ergibt sich ganz analog zu anderen Mythen der Ablauf, daß ein stärkerer Rivale beim Frauenraub erfolgreich ist und natürlich mit der Geraubten auch Nachkommenschaft zeugt. Darüber hinaus erinnert diese Version vom Brautraub an den Kampf zwischen Lapithen und Kentauren und würde insofern als „Vorläufermythos", noch dazu im selben geographischen Raum angesiedelt, gut passen.

Sowohl das Zeugnis der Handschriften als auch die lectio difficilior eines zwar weniger bekannten und nicht mit dem Skamandros identischen, aber immerhin durchaus belegbaren und geographisch naheliegenden Flusses sprechen m.E. mehr für die Lesart Xantho als für Heinsius' nur auf den ersten Blick zufriedenstellende Konjektur, auch wenn hier natürlich aufgrund lückenhafter Mythenüberlieferung keine letzte Sicherheit zu gewinnen ist.

${ }^{244}$ So auch Ilberg s.v. „Kreusa“ in Roscher, Bd. II, 1890-97, 1425. 